\title{
WINNING WHEN THE ODDS ARE AGAINST YOU: A NARRATIVE INQUIRY OF AFRICAN AMERICAN FEMALE PERSISTENCE AT A PREDOMINANTLY WHITE UNIVERSITY
}

A Dissertation
Presented to
the Faculty of the Graduate School
at the University of Missouri-Columbia
In Partial Fulfillment
of the Requirements for the Degree
Doctor of Education
CHRISTINE M. WOODS
Dr. Tyon Douglas, Dissertation Supervisor

May 2021 
(C) Copyright by Christine Woods, 2021

All Rights Reserved 
The undersigned, appointed by the dean of the Graduate School, have examined the dissertation entitled

WINNING WHEN THE ODDS ARE AGAINST YOU: A NARRATIVE INQUIRY OF AFRICAN AMERICAN FEMALE PERSISTENCE AT A PREDOMINANTLY WHITE

\section{UNIVERSITY}

presented by Christine M. Woods, a candidate for the degree of doctor of education, and hereby certify that, in their opinion, is worthy of acceptance.

Dr. Ty-Ron Douglas

Dr. Jennifer Fellabaum-Toston

Dr. Casandra Harper Morris

Dr. Michael Williams 


\section{DEDICATION}

I dedicate this dissertation to my mother, Verdis "Bonnie" Fleming. You encouraged me to do better, to be better. If you were here I would say, "Ma, I did it!" 


\section{ACKNOWLEDGMENTS}

I have been blessed beyond measure with such a supportive group of academic mentors and colleagues. I am grateful for the guidance and push of my mentor and dissertation chair, Dr. Ty-Ron Douglas. I am also grateful for my committee members for believing in this project.

I dare not acknowledge the love and support of my family. To my husband Lester and my daughters, Lesli and Kiyah, I am forever grateful for you sharing me with the writing process of this dissertation. I still hear your voices saying, "you got this." I also want to acknowledge my village. I am beyond appreciative of my family and friends who encouraged and prayed for me during this journey. I also want to thank two phenomenal young ladies, Cayla and Ashley, who have been down with me since day one. Thank you for being the best moral support and "Tech Team" in the world!

Saving the best for last, I thank God for finishing this "good work." For I am a witness of Philippians 1:6: "Being confident of this very thing, that He who hath begun a good work in you will perform it until the day of Jesus Christ." 


\section{TABLE OF CONTENTS}

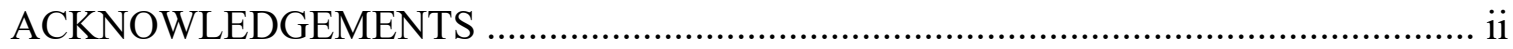

LIST OF TABLES ………………………………...........................................

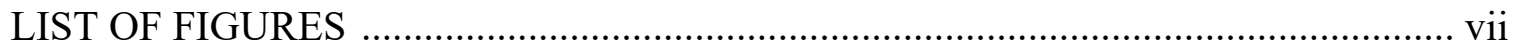

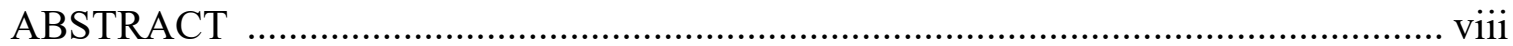

SECTION ONE: INTRODUCTION TO THE DISSERTATION-IN-PRACTICE.............1

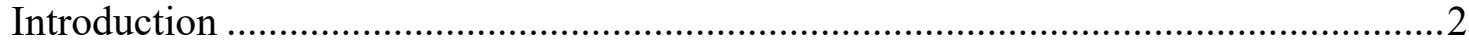

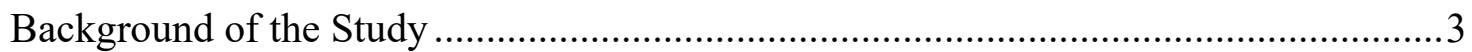

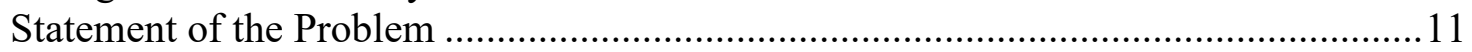

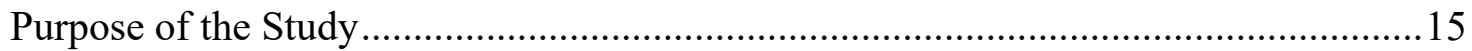

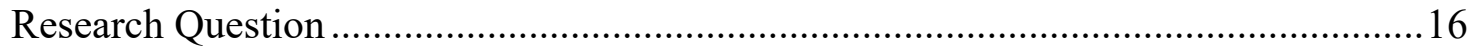

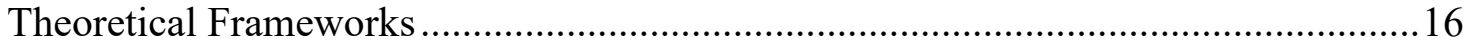

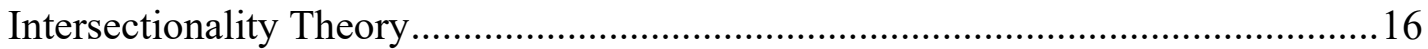

Ecological Systems Theory .............................................................................. 17

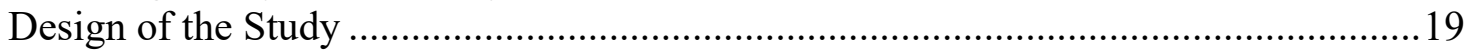

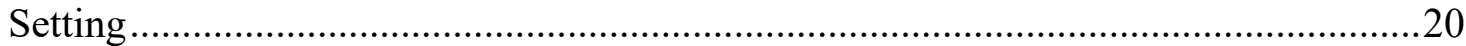

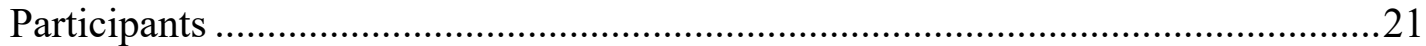

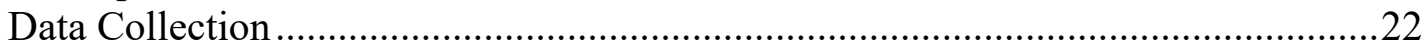

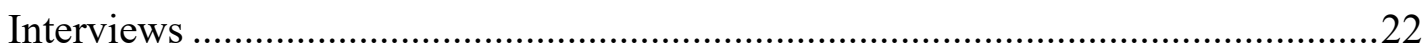

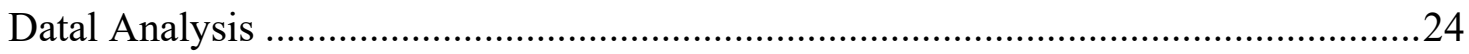

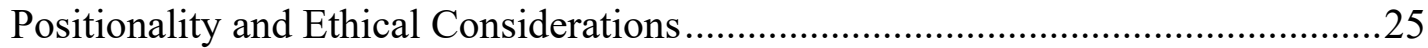

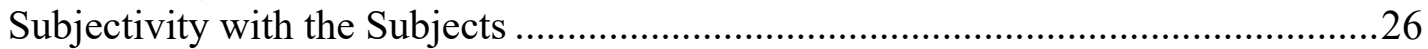

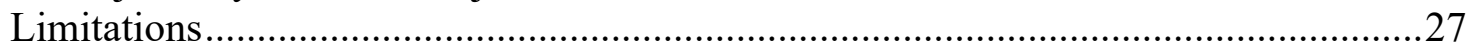

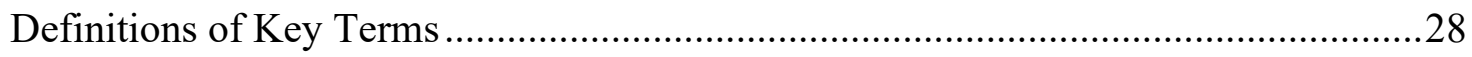

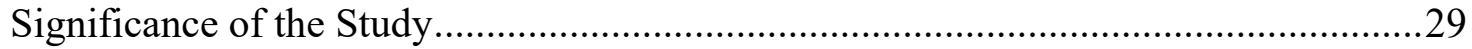

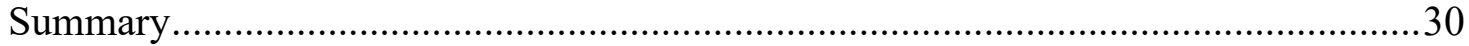

SECTION TWO: PRACTITIONER SETTING FOR THE STUDY .................................32

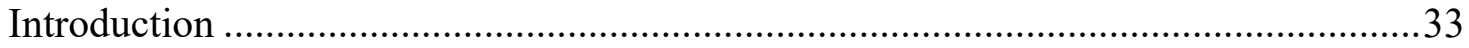

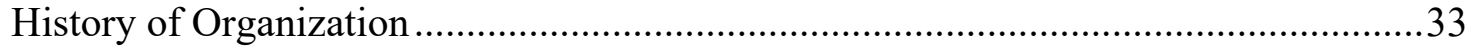

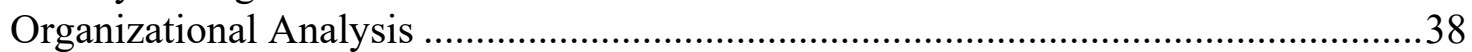

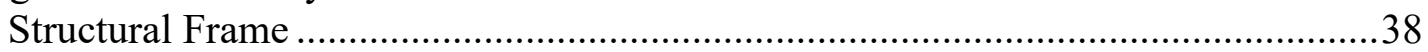

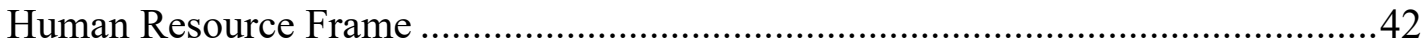

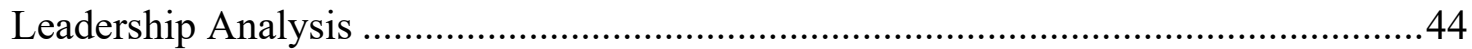

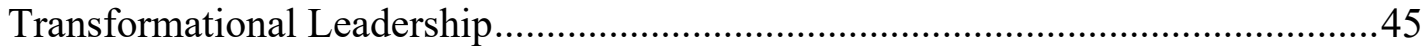

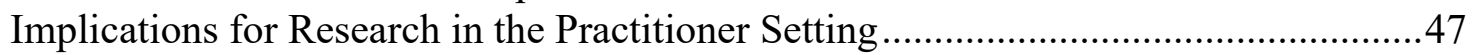

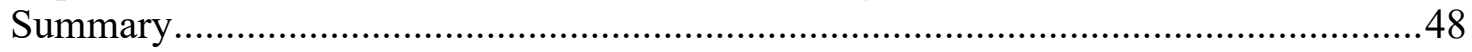

SECTION THREE: SCHOLARLY REVIEW FOR THE STUDY ……………….........50

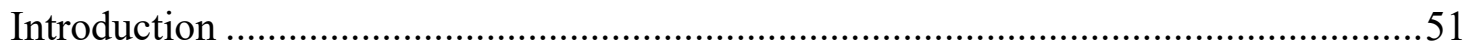


Experiences of Race, Gender, Class and Sexual Orientation ...................................53

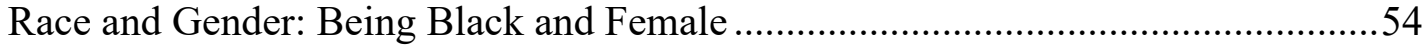

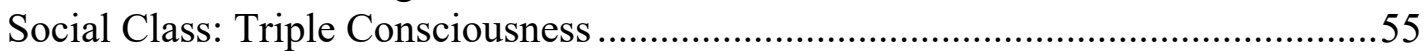

Societal Impact of Social Class .....................................................................56

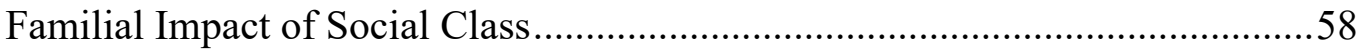

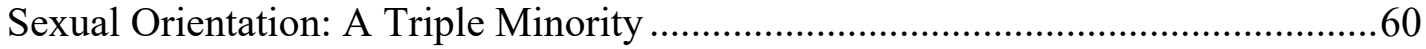

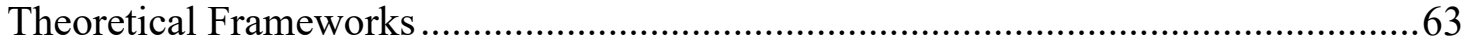

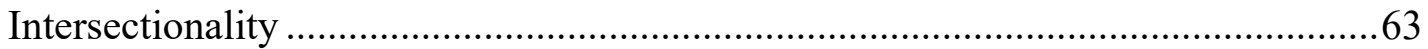

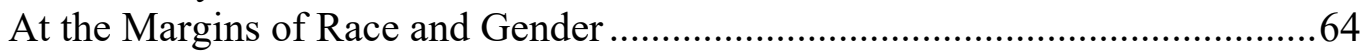

At the Margin of Class/Socioeconomic Status ................................................66

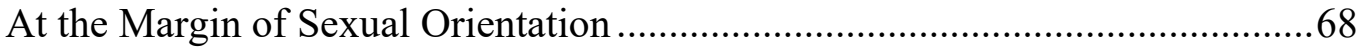

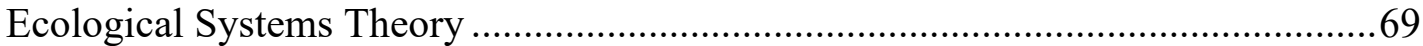

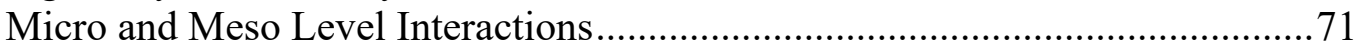

Exo and Macro Level Interactions ................................................................ 73

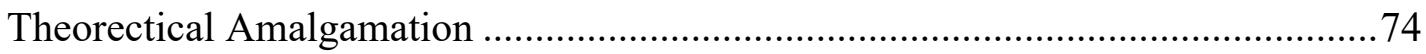

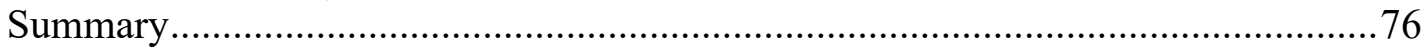

SECTION FOUR: CONTRIBUTION TO PRACTICE .............................................. 79

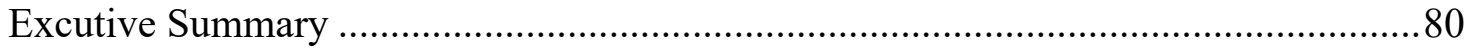

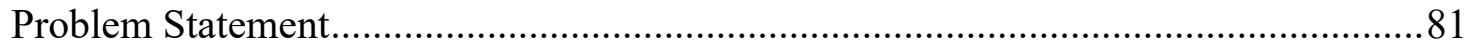

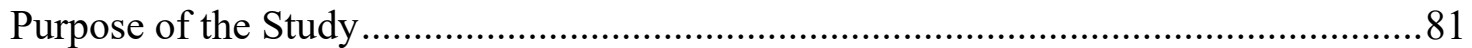

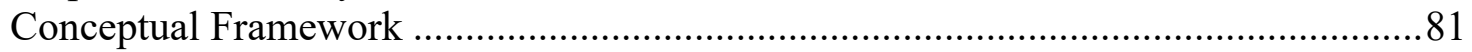

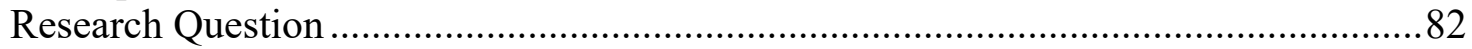

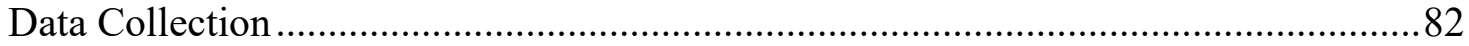

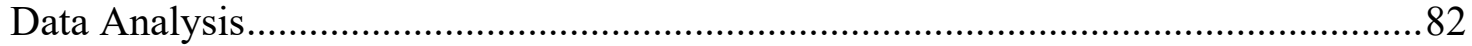

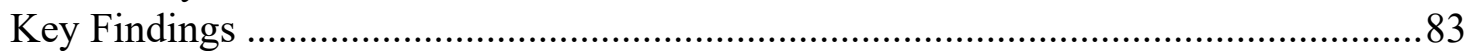

Implications for Research ............................................................................. 83

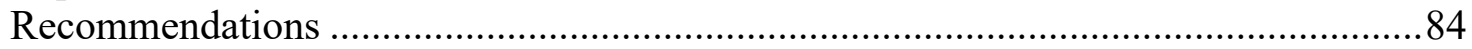

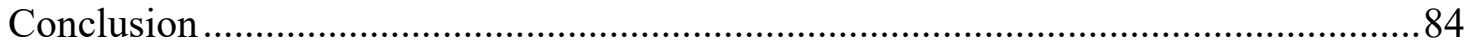

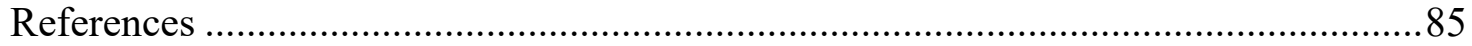

SECTION FIVE: CONTRIBUTION TO SCHOLARSHIP ....................................... 86

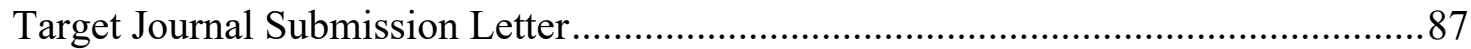

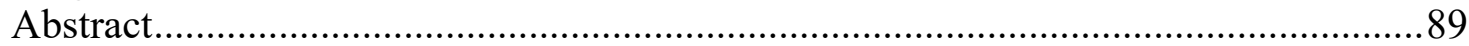

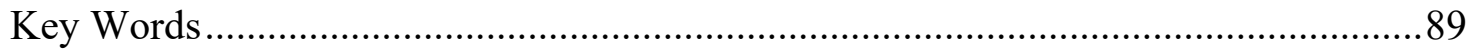

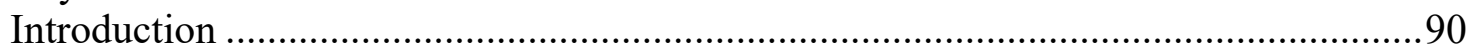

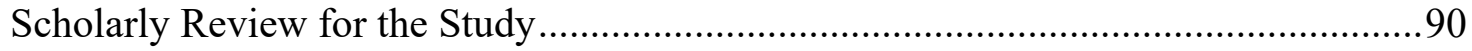

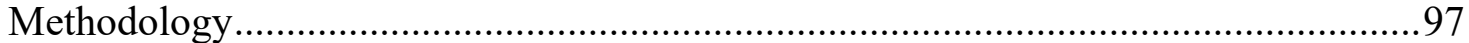

Findings from Participants Narratives on their Journeys to and through a PWI.........102

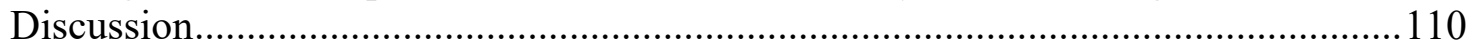

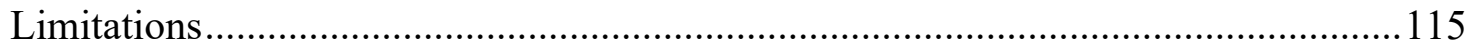

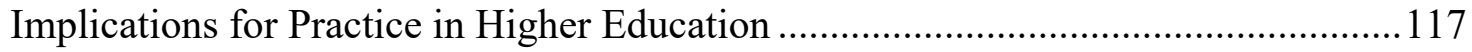

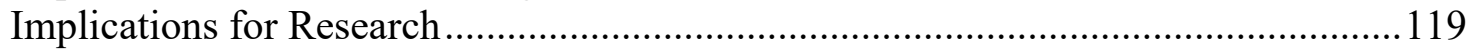

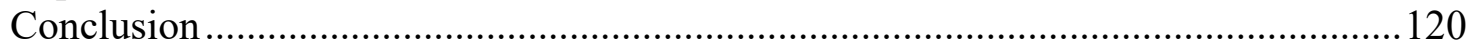


SECTION SIX: SCHOLARLY PRACTITIONER REFLECTION …………………....127

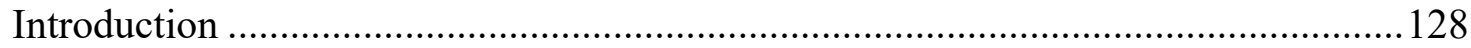

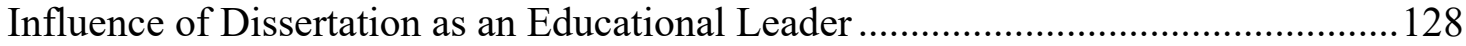

Influence of Dissertation as a Scholar .................................................................129

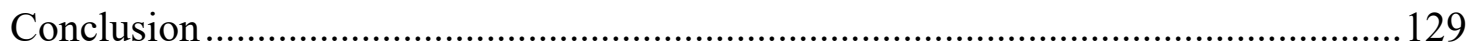

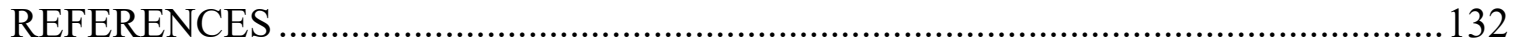

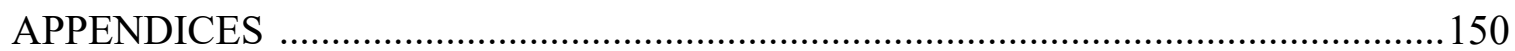

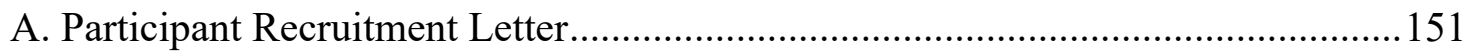

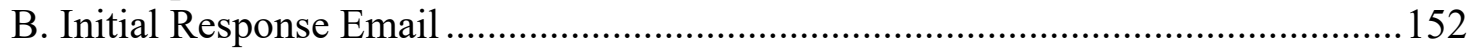

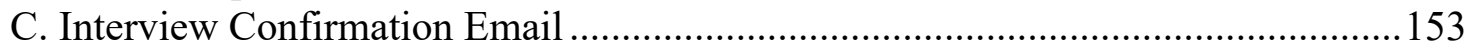

D. Informed Consent and Demographic Survey .........................................................154

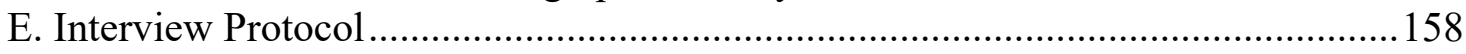

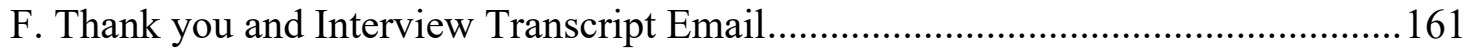

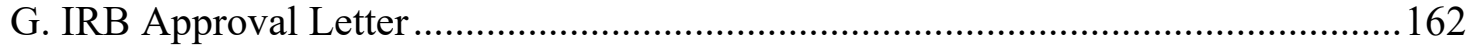

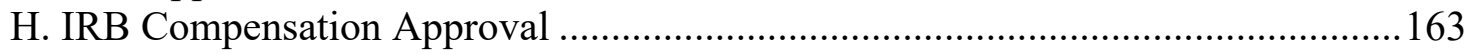

VITA 
Table

\section{LIST OF TABLES}

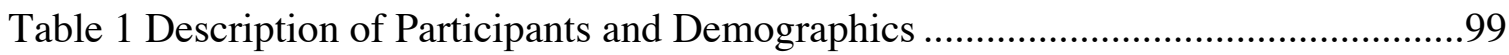

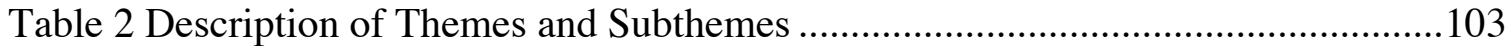


Figure

\section{LIST OF FIGURES}

Figure 1 Mintzberg's Organization Model .............................................................40

Figure 2 Intersctionality and Ecolgoical Systms Conceptual Model .............................76 


\begin{abstract}
African American females are enrolling and graduating college at increasing rates and outpacing their male counterparts to graduation. While their graduation rates increase, narratives of their journeys to and through college are sparse in the literature. This qualitative study examines the narratives of persistence of 10 Black female undergraduates enrolled at a Mid-Western Predominantly White Institution (PWI). Through the lenses of Crenshaw's intersectionality and Bronfenbrenner's ecological systems theory, this study explores factors that impede or promote persistence through the socio-environmental contexts of Black female undergraduates' journeys to and through a PWI. Using a semi-structured interview protocol, participants share stories of persistence beginning from childhood. Interview data underscore family context, faith, and issues of race, gender, and class as influential factors of persistence toward graduation at a PWI. Implications for practice and research are presented, and recommendations for administrators and practitioners are offered.
\end{abstract}

Keywords: persistence, Black, African American female, systems theory, intersectionality 
SECTION ONE:

INTRODUCTION TO THE DISSERTATION-IN-PRACTICE 
Winning When the Odds Are Against You: A Narrative Inquiry of African American Female Persistence at a Predominantly White Institution

"Nevertheless, she persisted."

$\sim$ n.d.

The journey begins. It is 2:30 am as I gaze from my bedroom window. I glance around the bedroom, as my two sisters with whom I shared the room with are asleep. As my eyes gaze through the window, I wondered if my mother would come home...come home after being gone two days. Although her return was uncertain, one thing was certain: when I woke up in the morning, it was my responsibility to get my sisters and myself up and dressed for school. School, my mother taught me, was the "only way out of the hood." Who would have thought those words would resonate with me for the rest of my life. Attending school and making good grades was my way of coping with my environment. It was my way of drowning out all of the adversity around me, thus giving me a positive focus beyond my immediate surroundings. Education was my motivation to get out of the hood or as some would say, "make it off the block." Although I make the reference of education being my motivation as a young girl, it still resonates with me as I write this dissertation. I am just as driven now as I was as a young girl.

During my journey to college, I witnessed many tragedies in my neighborhood. Living in the southeast area of Kansas City was far from living a suburban life. I saw my peers drop out of high school and live life on the streets. I witnessed everything from drive-by shootings, drug deals on the corner, to my mother wrestling with addiction - the reason she would not return home for days at a time. All I knew then was that I did not want to live out what I had become accustomed to witnessing. During my latter years of high school, the subject of college was not pointedly emphasized. Although, I can remember my mother's words, "When you graduate, you're going to college." I did not put much thought into attending college until my senior year. 
At that point, I remember putting all of my energy into my education; and the trials I experienced eventually became my triumphs. Somehow, I found resiliency and strength amidst what I witnessed and experienced as I journeyed through my childhood and matriculated through college.

I have come to appreciate the trials and the triumphs not only in my life, but also in my educational journey, as it has been one of the most fulfilling journeys I've ever experienced. My quest for education led me to be a first-generation college student. Additionally, I am a two-time, soon to be three-time graduate from a Research I institution. Up until my decision to pursue my doctoral degree, I had not fully reflected upon my pre-college or college experiences. I am now more aware of the tenacity and perseverance it took to overcome my environmental circumstances and persist through college. My own reflections of my experiences and persistence through college, as a Black female, is what has led me to examine the narratives of other Black females’ persistence at Predominantly White Institutions (PWI).

\section{Background of the Study}

Historically, the experiences of race and gender — specifically being Black and femaleare factors that challenge the educational pursuit and persistence of Black females (Rick, 2014; Thompson \& Jackson, 2007). Black women in higher education, specifically at PWIs, are adversely affected by racism and sexist oppression (Zamani, 2003). Black women have not only contended and taken on the weight of racism against Black people, but they also experience the adversity of sexist attitudes and actions against Black women. Black women are the target of the same racist and sexist experiences as that of Black people and women, in general. However, in society, the African American female is positioned behind that of White men, White women, and Black men (Zamani 2003). Issues of gender and race and oppression for women of color 
continue to be systemically perpetuated and embedded in our society as White supremacy and patriarchal behavior continues to exist, placing African American women at the margins of oppression. Crenshaw (1991) explains,

Racism as experienced by people of color who are of a particular gender - male - tends to determine the parameters of antiracist strategies, just as sexism as experienced by women who are of a particular race — white — tends to ground the women's movement. The problem is not simply that both discourses fail women of color by not acknowledging the "additional" issue of race or of patriarchy but the discourses are often inadequate even to the discreet task of articulating the full dimensions of racism and sexism. Because women of color experience racism in ways not always the same as those experienced by men of color and sexism in ways not always parallel to those experiences of white women, antiracism and feminism are limited, even on their own terms. (p. 1252) Discourses of gender and racial injustices affecting African American females are conveyed in relation to or in the context of White women. The narratives in literature neglect their experiences of racism and sexism that are exclusive to other groups-Black males and White women. Until practitioners and educators acknowledge the depth of these experiences, societal issues of domination continue for Black women.

The formal educational system as it relates to the education of Black women was not ubiquitous. African American men and women were not afforded the same literacy opportunities as White women and White men (Thomas and Jackson, 2007). Zamani (2003) juxtaposes the positionality of Black women in society to their position in the educational system by positing that, "The American system of education is a microcosm of the larger society, reflecting and reinforcing its strengths and flaws" (p. 7). This microcosm, as it relates to the history of 
education for Black people, "reflects the legacy of struggle, and oppression that has also come to characterize significant elements of the Black experience" in society (Douglas, 2012, p. 11). Blacks, in comparison to White people, have historically experienced education in a couple ways: schooling as learning occurred outside of a formal institutional structure and education as learning occurred through a formal institutional structure (Douglas, 2012). Douglas' (2012) work on Black Bermudian masculinity and success in community pedagogical spaces, highlights the difference between schooling and education. Douglas (2012) and Shujaa (1994) both suggest that Black people experience schooling and education as two distinct experiences, while also noting that they often intersect.

Black people, in particular Black females, were not afforded the same formal schooling opportunities as White men and White women (Evans, 2016). Between 1800 and 1835 Black females most often engaged in informal schooling . In fact, during slavery, they risked their lives to teach other enslaved adults and children how to read and write, even at the expense of losing their lives as educating enslaved children and free or freed Black people had become punishable by law for some southern states in the early 1800s (Anderson, 2017; Ricks, 2014). Anderson (1988) describes the sentiments of former slaves as having a "...fundamental belief in the value of literate culture" and a demand for "securing schooling for themselves and their children" ( $p$. 5). Learning was a mechanism to resist oppression and defy the historical stereotype that Black women were intellectually inferior (Evans, 2016; Ricks, 2014). Despite the fact that Black females lacked access to formal schooling through educational institutions, they worked and continue to work hard to change their plight through seeking and obtaining formal schooling. In fact, in 1850 - during the Antebellum period, Anna Cooper, a pioneer in the academic movement for equal access to education and born enslaved, completed her bachelor's degree through a 
formal educational institution. At a time when education opportunities were scant, Anna Cooper was an advocate who fought against the "obstruction of universal academic access (Evans, 2016; p.12) and believed that education was a human right. Coopers fervor and voice have contributed greatly to the academic strides made for Black females who enter college. Today Black females continue to enroll and persist in higher education institutions (Ricks, 2014), which is the focus of this study.

\section{Movement Toward Equality in Education: 1860-1935}

To situate the movement toward increased access to higher education, it is important to mention historical strides made toward universal access to education. During slavery strides toward equal education were made by former slaves whose primary purpose was to secure education for future generations and fight for universal education, which lead to the establishment of public schools between 1860 and 1862 (Anderson, 2017). Evans (2016) proposes, “...it was the arduous rise of the select few African American men and women who strove for education in the shadow of slavery (p. 31). Enduring pain, hardship, and blatant violence, racism and sexism, Black men and women stayed the course to educate themselves and generations that followed .

As Black people continued in their journeys toward equal education, there were a few degree-granting institutions of higher education specifically created for Black people by White abolitionists and Christian denomination charters (Lincoln University, Cheney University, and Wilberforce University; Anderson, 1988; Stewart 2017). These institutions are now known as Historically Black Colleges and Universities (HBCU). The creation of these three Black institutions paved the way for legislation that would confront the inequity of access to education for Blacks. The Plessy v. Ferguson 1896 court case was monumental for African Americans 
taking a stance against racial segregation in public spaces. The court rendered a "separate but equal" ruling, implying that the nation would continue with segregation and have separate but equal facilities, including educational institutions, which Evans (2016) contends was one reason Black women increased . Although the ruling continued with segregation and enforcement of discrimination, it was a step in the right direction.

The Brown v. the Board of Education of Topeka, Kansas (1954) court decision was the impetus for the desegregation of schools and overturned the Plessy v. Ferguson's separate but equal doctrine in American education (Ricks, 2014). The aim of Brown v. the Board of Education 1954 was to provide equal opportunities to education for Blacks. This ruling was a considerable victory for African Americans, as the "ruling promised to fix or repair a faulty system of education and provide equal educational opportunities for all children" (Ricks, 2014, p. 12). Another profound gain toward equality in access to education was the Civil Rights Act of 1954, which was the impetus toward the elimination of racial and gender discrimination in education. Moreover, the Title IX Legislation of 1972 prohibited discrimination based on gender in higher educational institutions that received federal governmental funding. Although these rulings and legislation have been eliminated, racial and gender discrimination in education continue to exist. Trachtenberg (2018) postulates, “...American higher education has not yet achieved the goals of racial justice to which our institutions ought to aspire. Overt and subtle discrimination remain real problems" (p. 89). Now, over sixty-five years later, African American females continue to face issues of race and gender discrimination and oppression as they persist at PWIs (Patton \& Croom; 2017; Ricks, 2014; Stewart, 2017). 


\section{Enrollment and Persistence of Black Students}

Progress has been made to make access to higher education equitable and the enrollment of Black students, females in particular, continue to increase. As a matter of fact, there has been a significant increase in enrollment and degree completion of Black females in higher education (Booker, 2016; Thomas \& Jackson, 2007; Winker-Wagner, 2009). According to the National Center for Educational Statistics (2019), from 2007-2017, enrollment of Black female students rose from $34 \%$ to $40 \%$. However, persistence to graduation for Black students overall remains low. In a longitudinal study conducted by the National Center for Educational Statistics (2019), from 2011-2017, 39\% of first-time Black college students who were enrolled at a public 4-year institution graduated with a bachelor's degree, compared to the overall completion rate of 59\%. The degree attainment rate for African American students is also low relative to $65 \%$ of White students who graduated with their bachelor's degree during the same time. Enrollment of African American students is projected to rise twenty percent by the year 2026 (NCES, 2019).

While these degree attainment and enrollment rates for Black students are impressive, Toldson (2020) suggests, "Behind every statistic, there is a person with dreams, fears, aspirations, and needs" (p. 4). With the increased projection of Black student enrollment and low graduation rates at PWIs, are White institutions ready to meet the needs of Black students who enroll in these universities? Are there adequate programs aimed at supporting the fears, dreams, aspirations, and persistence of enrolled Black students? The answers are found in the literature.

The majority of Black students who enroll in college matriculate at PWIs (Stewart, 2017). Moreover, they continue to enroll at an increased rate (Booker, 2016; NCES, 2019; Winkle-Wagner 2019). Yet, as Caldwell and Stewart (2001) point out, even though PWIs heavily recruit Black students to further their quest for diversity and inclusion, "the campus climate, 
curriculum, and organizational structures were never intended to be inclusive" (p. 233).

Consequently, Black students enroll in PWIs with inherited disadvantages from the institutionnot to mention the ones they sometimes bring from their childhood, such as being from low socioeconomic homes, poor neighborhoods, and experiences of discrimination (Winkle-Wagner, 2009). From the beginning of their college journey, Black students, in particular Black female students, encounter a climate, programs, and practices that do not adequately support their existence nor persistence on campus. Literature suggests Black female students experience persist at PWIs with limited programming specifically targeted to support their emotional and academic needs (Miles, Hones, Clemons, \& Golary, 2011) and stereotype threats of their intellectual fitness to be a student on campus (Perna, 2000; Williams \& Nichols, 2017).

If institutions strive to meet the needs of African American females, they must create settings or spaces specifically designed to foster the identity of the Black female in contexts that are not gender or racially based (Commodore, Baker, \& Arroyo, 2018; Hughes \& HowardHamilton, 2013). These types of spaces should include academic and social components that allow Black female students to express themselves, learn from one another, and share resources (Hughes \& Howard-Hamilton, 2013; Shaw, 2017). Henry, West, and Jackson (2016) suggest that Black women need opportunities "to engage in activities and interpersonal exchanges that defy the ways in which they are stereotyped within hip-hop culture" (p. 248). Further, if PWIs continue to recruit Black students, particularly Black female students, the institution must go beyond tolerating them; they must seek to be inclusive and supportive of them—acknowledging that while they are successful, some struggle successfully (Shaw, 2017; Strayhorn, 2017; Winkler-Wagner, 2009). Movement toward supporting the needs of Black female undergraduate students involves understanding their experiences, triumphs, and challenges. 


\section{Challenges to the Persistence of Black Female Students}

Challenges are all too familiar for Black women. Not only do Black women contend with multiple oppressive factors of being a binary minority, that is, matriculating through college with the contentions of being Black and female (Booker, 2016), but they also tend to have to navigate PWIs as one or the other (Patton \& Croom; 2017; Winkle-Wagner, 2009). Said differently, Black female students often encounter interactions on campus where they have to either assimilate with White culture and suppress their Blackness or have to contend with the oppressive stereotype of being a Black female. Crenshaw (1991) posits that when Black females have to deny parts of themselves — being Black and female — it denies or invalidates the fundamental experiences of subordination of the Black female. The strain of navigating life as Black or female can have detrimental social and academic challenges. Hughes and Howard-Hamilton (2003) and Tuitt (2010) also propose that Black females attending college are assimilating at PWIs that are grounded in White, western values. Black females are then immersed into this culture, as part of them is ignored or invisible. Invisibility, as defined by Black female students, is the struggle to be validated in the classroom, having the pressure to perform better than White students and having to "act" a certain way or act "White" to fit in on campus (Ricks, 2014; Robinson \& Franklin, 2011; Winkler-Wagner, 2009). Coined by W.E.B. Du Bois (1903/2003), he makes the poignant assertation that African Americans experience this double consciousness, "a sense of two-ness - being American and being Negro - two warring ideals in one dark body" (Bruce, 1992, p. 300). This "double-consciousness" as it pertains to persistence, suggests that African American females persist while vacillating between two identities, moving back and forth between Black culture and White norms (Jones \& Shorter-Gooden, 2003). The inward battle of “double consciousness" can seriously affect educational success. 
Despite feelings of invisibility and experiences of social silencing at PWIs, Black females are persisting through college and finding the fortitude to push forward through graduation. According to the National Center for Education Statistics (NCES), of all the bachelor's degrees earned by Black students in the United States in the 2015-2016 academic year, 67\% were female. However, it is worth mentioning that the persistence of Black males span the literature quite significantly and has been the focal point of persistence amongst African Americans. The increase of scholarly research on Black male persistence "has shined a light on the widening achievement gap between Black males and Black females" (Miles, Jones, Clemons, \& Golay, 2011, p. 108). With the abundance of literature centering on the experiences of Black male persistence and the increased rate of Black females earning more degrees over Black males, there is a need to explore the narratives of persistence for African American females. Black female students are indeed persisting, but at what cost? If we are to answer this question, we must go beyond the numbers to hear the stories and journeys of the persistence of Black female college students.

\section{Statement of the Problem}

While there have been a number of studies addressing the enrollment and persistence of Black males (Byrd, 2016; Harper, 2009; Simmons, 2013; Ward, 2007), the body of scholarship on the persistence of Black females is limited (Patton \& Croom, 2017). Despite rising enrollment and degree attainment of Black female undergraduate students at PWIs, we still know very little about their narratives of persistence. Most literature is centered in the larger discourse of Black students in higher education. While this scholarship is helpful in illuminating a general understanding of Black students in higher education, one can only understand the "raced, 
gendered, and classed experiences of Black women" (Patton \& Croom, 2017, p. 2), when they are the storytellers.

Cook and Williams (2015) suggest the narratives of individuals create one's social reality, thus offering a more in-depth view of the individual's reality. Without personal narratives, universities will continue to develop support programming based upon what the institution thinks is adequate versus what Black female students state as needs and supports (Hannon et al., 2018 ; Robertson \& Mason, 2018; Sims, 2008; Rosales, \& Person, 2003). Moreover, without the stories of African American females, PWIs continue to be inadequately equipped to support African American female students. To support the persistence of Black females on campus, educators, administrators, and practitioners should hear their narratives to employ the three A's: acknowledge their experiences, address their needs, and assist in their journeys.

Some African American female undergraduate students begin their journeys before entering college. Several pre-college factors influence the persistence of Black female undergraduates: (a) class/socioeconomic status, (b) family context, and (c) psychological and emotional coping skills (Guiffrida, 2006; Perna, 2000; Smith, 2008). First, Black undergraduate females who choose to attend college are more likely than White students to come from lower socioeconomic (SES) backgrounds (Guiffrida, 2006; Perna, 2000; Reid \& Moore, 2008; Smith, 2008). For some Black families, living in a low-income household or living in poverty contributes to a student's decision to enroll in college. Financial barriers may be seen as a double-edged sword. For some Black students, the lived experiences of growing up in a lower socioeconomic household might fuel one's aspirations and determination to attend college and serve as a source of motivation to persist. On the other hand, growing up in a lower SES home 
can impede the persistence of some Black female students as the obstacles of trying to afford college becomes greater than the determination to persist (Cary, 2018).

Secondly, Guifford and Reynolds (2011) and Byrd (2016) propose that while growing up in low socio-economic homes can influence enrollment and persistence in college, family support is another pre-college experience that affects college enrollment and persistence in college. The support of the institution of family, especially the Black family, has historically been the foundation of survival for Black people (Douglas, 2016; Douglas \& Arnold, 2016; Douglas \& Peck, 2013; Guifford \& Reynolds, 2011). Social support of the family, including fictive kin and the messages one receives about the importance of education, can influence the Black female's decision to attend and persist in college (Cook \& Williams, 2015). Black women have taken up the mantle and the notion that furthering their education is an opportunity to live a better life, to increase their SES, and to make their parents proud (Guifford \& Reynolds, 2011).

Although having a solid familial or social support system and positive messages about college attendance is ideal, there are times when Black female students lack these types of supports. Smith (2008) suggests there are some students who receive "little emotional support or encouragement regarding college attending. Any attempt to pursue a college education come from their own agency and avoidance of negative role models" (p. 150). Students who experience a weak support system might have underdeveloped or underutilized coping mechanisms that lead to lasting psychological and emotional distress that negatively contribute to their academic success and persistence when entering college (Guiffrida, 2006; Orrock \& Clark, 2018).

Finally, the psychological and emotional effects for some Black female undergraduates when entering college present themselves in a number of ways. Some students experience 
feelings of alienation, isolation, intimidation, anger, anxiety, depression, and discrimination (Henry et al., 2011; Lett \& Wright, 2003), which makes it difficult to focus and persist at a PWI. Therefore, without fully understanding all of the pre-college factors that affect persistence, educators, administrators, and university officials have a limited narrative of the "why or how" of Black female student persistence. Having a holistic frame of the Black female's experience allows university officials to understand and evaluate how effective or ineffective programming and practices may add to or detract from the obstacles these students face. To further postulate the dynamic positioning of African American women and the expressed need for support, Crenshaw (1991) explains:

Women of color are differently situated in economic, social, and political worlds. When reform efforts undertaken on behalf of women neglect this fact, women of color are less likely to have their needs met than women who are racially privileged... women of color occupy positions both physically and culturally marginalized within dominant society, and so information must be targeted directly to them in order to reach them. (p. 1250) Because the experiences of Black women are multiplicative and evolve around the margins of multiple oppressive identities, it is often difficult to assess and address the harm that is caused to them from social interactions. When political and social policies do not acknowledge and consider the depth of the experiences between being a woman and a woman of color in society, efforts towards change are inadequate to specifically meet the needs of African American women. The same can be said in the context of institutions of higher education. Administrators, faculty, and practitioners cannot continue to create blanketed programming and institutional supportive services for Black students in general. There has to be targeted programming 
specifically implemented to meet the academic and psychological needs specifically for Black female students, as they are not a monolithic population.

\section{Purpose of the Study}

The purpose of this study is to examine the persistence of undergraduate Black females enrolled at PWIs, as their voices are largely neglected in the literature. For this study, persistence is defined as the continuation of educational pursuits in the attainment of a bachelor's degree (Booker, 2016). The study aims to understand the experiences, including pre-college and college experiences that contribute to Black female undergraduate persistence through graduation. While stories of race and gender are the tip of the iceberg for the study of persistence at a PWI, it is otherwise vital to study additional factors that impede or contribute to persistence.

Understanding the complexities of Black females renders a more accurate account of the stories of persistence for Black female students. Studying all factors related to the experiences of African American female persistence may provide a rich contextual understanding of events that happened before entering college. This deeper understanding helps to provide insight into who these Black women are and what other circumstances affect their decision even to pursue college.

Additionally, this study sought to provide a platform for Black female undergraduate students to attribute meaning to those experiences through their own words. Thus, the proposed study will illuminate meaning of Black female undergraduates' journeys to and through college to yield a better understanding of the factors, beyond race and gender, that contribute to their persistence, as race and gender are only part of the narrative. The results of the study may inform policies, supportive services, programming, and practices of PWIs to meet the needs of African American female college students. 


\section{Research Question}

While research has grown in the study of the persistence of African American female undergraduates, there is still little known about their journeys to and through a PWI. The research question that guided this study on African American female persistence at a Predominantly White Institution is "How do Black female undergraduate students describe their journeys to and through a Predominantly White Institution?"

\section{Theoretical Frameworks}

The theoretical frameworks utilized for this study are Crenshaw's (1991) intersectionality and Bronfenbrenner's (1979) ecological systems theory. These theories help to explain the context of lived experiences of individuals (Ashford \& LeCroy, 2013; Crenshaw, 1991; Bronfenbrenner, 1979). The conceptualization of both theories in this research study helped to explain how Black undergraduate females navigate higher education within the context of their social environment and the intersecting identities of their race and gender. Further, incorporating tenets of each theory illuminates the African American female student persistence phenomenon and provides in-depth, rich information narratives (Merriam \& Tisdell, 2016).

\section{Intersectionality}

Intersectionality theory explores the identities of women of color and offers a multidimensional view of the marginalization of gender and race experienced by Black women (Crenshaw, 1991; Strayhorn, 2017). It further explores the intersections of class, sexual orientation, or ability, which marginalize women of color. Intersectionality is widely used in student affairs as a model or framework to explain the experiences of marginalized people (Harrison, 2017; Shields, 20018; Strayhorn, 2017). It has the utility to examine lived experiences of privilege and power at various levels of intersectionality. Crenshaw (1991) describes these 
levels as: a) structural intersectionality—ways in which one's interactions and experiences of marginalization occur in a particular setting or social location, b) political intersectionalityobserving how political agendas and policies further marginalize Black females, and c) representational intersectionality.

Representational intersectionality focuses on the oppressive experiences of how African American women are represented and viewed in the culture-at-large-including the media, governmental entities, and the labor markets (Carastathis, 2014; Crenshaw, 1991). It is not enough to identify women of color by gender and race, as a more nuanced analysis is needed to account for the breadth of their identities. Women of color interact with multiple interconnected social systems (Haynes, 2013). In fact, over the past ten years, the use of intersectionality has shifted to a more holistic methodology, exploring how Black female students journey to and through PWIs (Bright, Malinsky, \& Thompson, 2016; Harrison, 2017; Howard-Hamilton, 2003; Mattis, Grayman, Cowie, Winston, Watson, \& Jackson, 2008; Smith 2008; Winkle-Wagner, Kelly, Luedke, \& Reavis, 2019). Intersectionality theory also shares some tenets of ecological systems theory (Bronfenbrenner, 1979) in that it too can be used to frame an individual's interaction with the social environment.

\section{Ecological Systems Theory}

Ecological systems theory is a framework developed by Bronfenbrenner (1979) to categorize an individual's interaction with their social systems. This theory is widely used in the field of social work and counseling to explore and organize how an individual experiences social systems and how these interactions or transactions shape one's life from infancy to adulthood (Bronfenbrenner, 1979; Pierson, Boydell, Ferguson, \& Ferris, 2011). Bronfenbrenner (1979) also posits that an individual's interaction with these systems provide meaning to those lived 
experiences. Ecological systems theory further examines the strengths, resiliency, and selfdetermination of how individuals encounter and surpass the transactions with their environment.

Ecological systems theory outlines four levels of inquiry to explore intra-and interdependent interactions of a person and their environment: the microsystem, mesosystem, exosystem, and macrosystem (Orrock \& Clark, 2018). The microsystem is face-to-face interactions that occur with the individual in a particular setting (Bronfenbrenner, 1979; Leonard, 2011; Pierson et al.). An example of a microsystem might be interactions at home with a person's family system or interactions with a therapist. The mesosystem includes interactions that may occur in the community setting like school, church, or peer groups (Bronfenbrenner, 1979). The exosystem might include the indirect impact and effects of mass media, religious organizations, human service agencies, and their portrayal of a population. Finally, the macrosystem is an individual's interaction with society and the culture-at-large (Bronfenbrenner, 1979). The macrosystem frames the way in which an individual experiences or receives messages from religious, ethnic, the media, or economic structures. All of these systems or social interactions are interdependent and influences one's life.

The use of both intersectionality and ecological systems theories are compatible as they provide a framework for understanding racial identities and experiences in a couple of ways. First, both theories can elicit a multi-perspective look into micro, meso, exo, and macro systems as a way to understand the experiences and interpret one's behavior and interactions with their environment. To further this point, Ozaki and Renn (2015) posit both of these frameworks take into account the racial and other marginalized identities that vary from individual to individual within the context of their social environments and throughout the lifespan. Lastly, the two 
theories build upon empowerment and acknowledge systems of oppression that affect an individual, especially in education.

\section{Design of the Study}

\section{Methodology}

The methodology employed in this qualitative research study is narrative inquiry. Narrative inquiry is a qualitative method useful in capturing the individual experiences of a single person or a group of people (Creswell, 2013) and is a "way of characterizing the

phenomena of human experience" (Connelly \& Clandinin, 1990), p. 1. I chose narrative inquiry due to its utility of allowing for sense-making, interpretation, and meaning of ones' thoughts and actions (Merriam \& Tisdell, 2016). Narrative inquiry works best when one wants to explore a phenomenon in the midst of the ongoing experience, as the inquiry is a living narrative of the participant experiences (Clandinin \& Huber, (in-press). Further, narrative research allows the researcher to understand participant's stories as temporal transitions-guiding the researcher's attention toward the participant's past, present, and future (Connelly \& Clandinin, 2006). Merriam and Tisdale (2016) share that narrative inquiry allows the researcher to use a participant's first-person account and analyze it as data and shed light on their experiences. As Haynes (2013) explains it, narrative inquiry is "invisible to standard objective methodologies" (p. 108) as it emphasizes subjective accounts of one's experiences and allows participants to ascribe meaning and interpretation of their frustrations, setbacks, comebacks, and triumphs through their personal stories with their voices. Narrative inquiry "respects the authenticity and integrity of the narrators' stories, to see them as subjects creating their own history rather than as objects of research" (Casey, 1995, p. 232). 
Because this research study is to understand the journeys of African American female undergraduate students, narrative inquiry is most appropriate as it explores their narratives of persistence within their social, cultural and institutional settings (Moen, 2006). Moreover, participants are able to provide a detailed account and sequence of events linking their individual interactions and responses and their contexts - beginning with childhood through their current stage of life - to help the researcher understand their stories.

\section{Setting}

The setting for this study took place at the University of Missouri-Columbia (MU). MU, established in 1839, is a public predominantly White land grant university in the Midwest, located in a town with a population of 121,000 (U.S. Census Bureau, 2019). MU is centrally located between two urban cities, Kansas City, Mo and St. Louis, MO. Because of its location, MU now draws a large number of its Black student populations from these large urban areas. The total enrollment in fall of 2018 was 29,866 (University of Missouri, Student Body Profile, 2019). According to the MU student profile (2018), African American students constitute $7 \%$ of the total student population, while $75 \%$ of enrolled students are White. Concerning enrollment by gender, women represent $54 \%$ of the demographic; and men account for $46 \%$ of the total enrolled population.

While student enrollment data is critical to reflect upon, faculty demographics are also necessary for understanding diversity on a campus (Winkle-Wagner, 2015; Winkle-Wagner, Kelly, Luedke, \& Reavis, 2019). According to MU's Institutional Research \& Quality Improvement data (2018), in 2017, there was a total of 1,969 faculty (including tenure track, ontrack for tenure, and non-tenure track faculty). Of the total faculty, Asians represented the largest minority faculty demographic at $13.7 \%$, while Hispanic or Latino faculty represented $3.8 \%$. 
Black or African American faculty represented 3.3\%, and White faculty represented $72 \%$.

\section{Participants}

The research question that guided the study influenced the decision to use purposeful and snowball sampling for participant recruitment (Creswell, 2014; Merriam \& Tisdell, 2016; Ryan, Coughlan, \& Cronin, 2007; Starks \& Trinidad, 2007). Purposive and snowball sampling provide the researcher with the opportunity to elicit in-depth information from participants who are experiencing the subject matter (Merriam \& Tisdell, 2016). Miriam and Tisdell (2016) further share that, "Purposeful sampling is based on the assumption that the investigator wants to discover, understand, and gain insight and therefore must select a sample from which the most can be learned" (p. 96). Therefore, to gain more insight and more in-depth understanding of Black female persistence at a PWI, African Americans who identify as Black or African American and cisgender female were the primary participants of the study.

In qualitative research, the number of participants or sample size is ambiguous and depend primarily on qualitative data saturation (Merriam \& Tisdell, 2016). Participants met the following criteria: a) identify as African American or Black, b) identify as a cisgender female (gender identity corresponds with female sex assigned at birth), c) currently enrolled at MU as an undergraduate student, and d) have completed one year (at least 24 hours) of academic coursework. Notably, MU calculates retention rates as a student being fully enrolled in at least 12 hours in the fall and spring of the first year and enrolling in the subsequent fall (University of Missouri, 2018). Participants were recruited via email listservs of spaces and organizations typically occupied by African American students such as the Oldham/Gaines Black Culture Center, the Mizzou Black Women's Initiative, the Center for Academic Success and Excellence (CASE), Women of Color, Honor, and Ambition (WOCHA), and Urban Empowerment--a local 
Black church. Participation was limited as the call for research was distributed during the university's transition to remote class at the start of the COVID-19 pandemic. As such, I used snowball sampling to recruit more participants (Creswell, 2013; Merriam \& Tisdell, 2016). Students who desired to participate and met the criteria were asked to recommend other students who might be interested in the study.

\section{Data Collection}

Before beginning the study, I obtained Institutional Review Board (IRB) approval through the university to conduct research on campus. IRB approval ensures that subjects are treated ethically and humanely during the research study (Creswell, 2016). After IRB approval, I sent recruitment emails (see Appendix G) to the identified listservs. Data collection began when interested participants expressed their interest in the study via an email response. I responded with an interest email (see Appendix B) asking participants to reply to a doodle poll containing a list of available dates and times the participant may choose for an interview. After the initial date and time were scheduled with the participant, a confirmation email with the date, time, and place of the interview was be sent to the participant (see Appendix C). The confirmation email also asked participants to complete a brief demographic survey (see Appendix D) prior to the interview, with the link to the survey included in email. Once the demographic questionnaire was complete and Zoom calendar invitations were sent out to finalize participant interview dates and times, qualitative data collection commenced.

\section{Interviews}

To collect data, I interviewed 10 participants. I conducted two rounds of 45-minute interviews. Prior to the start of each interview, the researcher discussed informed consent and advised participants of the risks of participating in the study (Creswell, 2014; NASW, 2017; 
AERA, 2011). During data collection, I was offered departmental funding for each participant to receive a $\$ 50$ incentive for completing both rounds of interviews (see Appendix H). Once I secured the funding, I amended the IRB for approval and included it in the informed consent. Further, the researcher used an interview protocol (see Appendix E) to conduct semi-structured, in-depth interviews as interviews allowed participants to share the personal and objective meaning of their lived experiences (Creswell, 2013; Creswell, 2014; Merriam \& Tisdale, 2016).

The first interview began with Casey's (1993) grand narrative question tell me the story of your life to begin the participants' account of their stories to persistence. I chose this question as to not lead the participants into following a narrative in which I constructed. The question allowed for free-recall of participants and allowed them to situate their stories. In my expertise as a licensed clinical social worker and therapist, for many years I have conducted client interviews and assessments, and it is critical to the helping process and intervention planning, that the social worker "start where the client is at" to develop a collaborative therapeutic relationship, allowing them to share their story freely, where they would like to begin. Doing so allows for recall of events as to not taint, misconstrue, or guide their narratives. Free recall permits social work clients to situate their story in a way that prioritizes their problems. As such, Casey's (1993) grand narrative question supports free recall, as each participant introduced their stories at varying times and stages of their lives as they prioritized the problem of practice under research investigation—Black female undergraduate persistence at PWIs.

During the first interview, as the participant shared her story through Mizzou, I wanted to capture her thoughts on the supports which the institution could provide to assist her during her journey - a question that was not originally included in the protocol. Therefore, after interviewing the first participant, I revised the interview protocol to ensure participants' stories 
captured their ideas about programming needed to support their persistence. In qualitative research, evaluating and revising the protocol is not uncommon and is a mechanism to enhance validity of the tool and substantiate data that supports the study. Under the duress of the COVID19 pandemic, instead of face-to-face interviews, each participant completed two 45-minute interviews using Zoom technology. Each interview was audio and video recorded via Zoom, yielding approximately 720 hours of qualitative data, which add to the rigor and trustworthiness (Creswell, 2014) as the time spent with each participant was to elicit thorough and accurate accounts of their stories.

\section{Data Analysis}

According to Rapley (2004), qualitative data analysis is "always an ongoing process" (p. 26) that should follow each interview. As mentioned previously, each interview was recorded using Zoom technology. I viewed each video after the first round. Before engaging in the second interview with each participant, I made a brief list of follow-up questions I desired either clarification or more information. After the second round of interviews, I edited each transcription (initially transcribed in Zoom) verbatim, as I watched the video, ensuring all the words of participants were captured. During the editing process I ensured accuracy of spelling, adding punctuation and expressions of participants. Transcribing interviews is essential to establish rigor (Merriam \& Tisdell, 2016; Starks \& Trinidad, 2007). After editing the transcripts, I read through each transcript in its entirety twice to ensure the accuracy of each. Following the completion of edits, I used member checking to further establish trustworthiness of the study (Creswell, 2014; Hatch 2002).

Through this process, I inductively processed the meaning participants described during their interviews by utilizing axial and chunk coding (Creswell, 2014; Merriam \& Tisdell, 2016) 
Using Dedoose analysis software, I used thematic analysis as outlined by Braun and Clarke (2008) to analyze the data. The steps in Braun and Clarke's (2008) process are: 1) familiarize oneself with the data; 2) generate initial codes; 3) search for themes; 4) review themes; 5) define and name themes; and 5) produce the report. Using Braun and Clarke's process I identified three themes and three subthemes according to each participant's narrative, which will be discussed at length in section four of this manuscript.

\section{Researcher Positionality and Ethical Considerations}

During this research, it was important to consider my own positionality and experiences, as my biases may have the potential to influence the analysis. As implored by Vagle (2018), it is critical for the researcher to bridle one's biases when interpreting the data as researcher bias can influence data analysis. Bridling is an ongoing process of observing, naming, and examining one's own judgements (Vagle, 2018). The use of bridling, as suggested by Vagel (2018) is to “become more familiar with one's judgements so they do not compromise one's openness to the phenomenon" (p. 14). It is the willingness to remain open, hear, listen, absorb, and understand the narratives of participants (Vagel, Hughes, and Durbin, 2009).

When exploring and crafting the present study, I was cognizant of my life story and experiences on campus. I was aware that persistence for me was dramatically different from the participants in the study. Reflecting back to 1993 when I was an undergraduate and fast forwarding to now, the climate of the campus back then is not what is presently. Barriers to persistence in my experience were not as overt as I have observed today. Observing with my own eyes, the discrimination and unwelcoming climate for Black female students, I had to make a conscious decision during interviews to be open to the experiences of the participants...to sit in their stories...to hang on to every word and understand. As I sought to understand their stories, I 
remember rewatching the interview videos to observe the mannerisms, body language, and tone, attending to every word said (Stutey, Givens, Cureton, \& Henderson, 2020). I questioned every interaction asking, "What is she trying to tell me?" I wondered if I had captured the essence of the participants' experience (Dahlberg, 2006), being careful of each as I worked at not acting or responding carelessly with the participants' time nor the energy it took for them to explicate their experiences. It was my duty to wait for the phenomenon to emerge as I extracted meaning from participant stories (Vagel et. al., 2009) while bridling my own experiences and thoughts as a Black female graduate of MU.

\section{Intersubjectivity with the Subject}

Bridling my experiences was completely different than appending and laying them to the side. I realized my epistemological beliefs and the way I have seen and see the world presently is important to the research phenomenon of persistence. Bridling — being aware of becoming intersubjective with my subjects-further improved the data collection and analysis process by making me more cognizant of my own biases and experiences as an African American female student on this campus. As I actively listened to participants during interviews, I would reflect on what similar experiences was like for me. For instance, one participant's mother struggled with substance abuse, much like my mother did. However, our pathways to persistence were not the same. Bridling was useful in this process in that I would have anticipated the participant's story to mirror mine and disregarded the experience and meaning she attributed to her narrative. I respectfully understood and regarded the stories these women shared as their own and that their stories contribute to who they are becoming (Connelly \& Clandinin, 2006).

As a Black female and two-time graduate of MU, I recognized the potential for bias and its impact on data analysis. Additionally, my experiences and journey to and through the 
institution had distinct similarities. As Janak (2018) explains, "Regardless of choice of processbracketing or bridling, reflective practice is no less than an ethical mandate" (p. 91). The inability to recognize one's biases and the potential of those biases influencing data analysis can cause ethical issues in research.

\section{Member Checking}

Another consideration of ethical concerns during data analysis was ensuring validity of the study. To ensure internal validity and to establish trustworthiness, the researcher engaged in member-checking by soliciting feedback from participants about the accuracy of their interpretations in their individual transcripts (Creswell, 2014; Merriam \& Tisdell, 2016). Further, member-checking ensures the researcher is limited to her or his own interpretations, lessening the chance for the researcher to apply personal subjectivity to guide data analysis.

\section{Limitations}

Like any qualitative study, this research presented some limitations. The first limitation relates to recruitment of the study. The study encouraged participation of Black cisgender females who also identified as LGBTQ. All participants in the present study identified as heterosexual. Therefore, narratives are void of the voices of sexual minorities-another factor of persistence for Black females which needs to be studied in future research. Recruitment was also affected due to the onset of COVID-19. The pandemic's arrival occurred at the beginning of the recruitment process. Although recruitment emails went out to the intended targets, I was limited in who would participate in the study. I am conscious that at the time, not all students had adequate internet or internet access for participating in the interviews via Zoom, which limited participant responses and participation. 
Additionally, zoom presented limitations in that some students appeared guarded in their responses. For instance, as one participant described the relationship with her mother, she was interrupted by her mother's presence in the room she chose to conduct the interview. As the interview moved forward, there were times when the participant whispered because her mother was in a room nearby. Holding interviews in person and in a private location could have strengthened the participant's narrative and the connection between me and the participant. Connelly \& Clandinin (1991) suggest interviews should be a collaborative process between the researcher and the participant over time. In this case, Zoom, coupled with the pandemic, limited my face-to-face time with participants. I also would like to note that during the time of interviews, some participants were experiencing "zoom fatigue," as campus classes had transitioned to remote learning and participants spent their entire days attending class via zoom. Zoom fatigue may have limited the response of the participants, thus, eliminating some portions of their stories as they might have become weary during the interview.

Finally, interview transcripts were sent to each participant with instructions to review their transcript for inaccuracies in interpretation. Of the ten transcripts sent to participants, only one participant responded with corrections in interpretation. More feedback from participants would have helped address any misinterpretation in their narratives. Otherwise, it is the assumption of the researcher that all accounts of participant narratives are accurate.

\section{Definitions of Key Terms}

Black. The terms Black and African American are used interchangeably throughout this study. These terms represent the cultural integrity of those who identify as or have connections to the ethnic identity amongst Black Americans (Martin, 1991). 
Female. The current study includes cisgender females. A cisgender female is one who identifies as the female sex they were assigned at birth (Smith, Shin, \& Officer, 2012).

Persistence. A termed used in research literature to describe the matriculation of students through graduation.

Resiliency. A term used in social work practice to acknowledge the uncanny ability of an individual to recover from adversity and resume functioning.

Journey. The story of persistence as explained by participants.

\section{Significance of the Study}

Historically, Black women placed significant value in education and educated others at the expense of their own lives (Booker, 2016). Today, the legacy lives on, and African American female students are enrolling and persisting in college at and surpassing their male counterparts (U.S. Department of Education, 2018). With the increase in enrollment and persistence, little scholarly attention has been given to Black female undergraduate students. The discourse surrounding African American male persistence has been the leading topic in national conversations (Miles et at., 2011 \& Stewart, 2017) and has resulted in the creation of college supports and mentoring programs on a national level to support them (Franklin \& Robinson, 2011; Miles et al., 2011; Simmons, 2003; Warde, 2008). For example, in 2014 former president Barak Obama created the My Brother's Keeper initiative to address matriculation from elementary to higher education by providing mentors, role models, and support for Black boys and men (The White House, 2015). Even with these added supports, Black women continue to out-persist and outpace them through graduation. These women are persisting juxtaposed the academic and social support Black males receive on and off campus. This study contributes to 
the growing literature that centers on African American female undergraduate persistence and their need for support and programs at PWIs.

This study implores administrators and practitioners of PWIs to further understand the lived experiences (pre-college and college) of Black female undergraduate students on campus and enhance programming and retention efforts for this population (Reid \& Moore, 2008;

Rosales \& Person, 2003; Strayhorn, 2017). Administrators should be aware of how the intersections of race, gender, class, and sexuality are overarching factors of persistence on their campuses (Carey, 2018; Harrison, 2017; Orrock \& Clark, 2015; Patton, Crenshaw, Haynes, \& Watson, 2016; Shields, 2018). Without hearing their stories, there will continue to be a lack of creation of educational supportive services and programs that support Black females across educational settings (Cooper, Porter, \& Davis, 2017; Crenshaw, 1992; Orrock \& Clark, 2018; Patton et al., 2016; Hannon et al., 2018; Harrison, 2017; Reid \& Harrison, 2008).

\section{Summary}

Scholars have added to scholarly literature on the persistence of Black female undergraduates by exploring barriers to education at the secondary and post-secondary levels (Carey, 2017; Gilford \& Reynolds, 2011; Smith, 2008). Yet, there is still much research to be done, especially at PWIs. Black females have enrolled at increasing numbers over the past two decades and African American female persistence is higher than that of their male counterparts. However, research on their persistence is limited. African American female persistence has not come without challenges. Challenges of race, gender, class, and sexuality are essential experiences to recognize as these students journey to and through a PWI.

While challenges of race gender, class, and sexuality are often explained in the literature as occurring during persistence in college, they are also challenges experienced in the African 
American female student's journey to college. Pre-college experiences are just as imperative to consider as they influence the way in which Black females persist in college. Understanding both contexts offers administrators and practitioners an opportunity to specifically develop targeted strategies to meet the needs of Black female undergraduates. If there is no holistic understanding of the journeys and experiences of Black females, they remain invisible, but yet so valuable to the bottom-line for institutions.

The day-to-day challenges in the experiences of persistence, according to research, is distressing for Black females. Through the challenges, Black undergraduate females have managed to be triumphant. Allowing these experiences to permeate through research may inform policies, supportive services, and programming for university administrators. As Franklin and Robinson (2011) explained so eloquently, “Although many African American women are successful in their educational endeavors, the challenges and struggles they face should not go unnoticed" (p. 38). 
SECTION TWO:

PRACTITIONER SETTING FOR THE STUDY 
This section highlights the history of the University of Missouri, the proposed setting for this research study. A detailed description of the organizational structure of this PWI and Research I Institution, in which Black undergraduate females enroll, will also be explained. Further, this section offers an analysis of MU's leadership structure. Finally, the implications of implementing this research study at MU will be discussed.

\section{History of Organization}

The research study was conducted at the University of Missouri-Columbia (MU). MU is centrally located in Columbia, Missouri, a Mid-western state in the United States. Columbia, Missouri is a town in which its diversity is closely correlated to the population demographics of MU. In 2018, Columbia's population was 123,180 . Approximately $77 \%$ of the population is White. While $10 \%$ of the population is Black (U. S. Census Bureau, 2019). Similar to the disparity of the demographic population of the city, MU's total student enrollment in fall 2018 was 29,866 , with Black students representing the largest minority population with $7 \%$, while 76\% of enrolled students were White (University of Missouri Student Profile, 2019). International students represented, $6 \%$, Hispanics represented $4.2 \%$ of the student population, non-Hispanic represented 3.2\%, Asians represents 2.4\%, and Native Americans represented .4\%. The disparity in Columbia's population and MU's student enrollment is reflective of the historical context of both.

Founded in $1839, \mathrm{MU}$ is a public predominantly White land grant institution. Land-grant institutions were created to make education affordable for those who studied agriculture and mechanical arts, through a policy known as the Morrill Act of 1862 (University of Missouri, 2019). Through the Morrill Act of 1862, MU sought to provide more access to higher education to all citizens. Although this act [Morrill Act of 1862] passed in 1862, it is noteworthy to 
mention that slavery was not formally abolished until 1865 . While the law was mandated to provide equitable access, there were particular citizens excluded: African Americans were among those citizens who were excluded. It was not until 1950 that the first African Americans were accepted and enrolled at MU (Middlebush, 1950). Previous to 1950, two other students, one male, and one female, attempted to enroll at MU in 1936 and 1939, respectively, and were denied admission based on their race (Dache, Quaye, Linder, \& Mcguire, 2019). The foundation and origin of the Morrill Act acknowledge the oppressive history of discrimination and racism that saturates the current cultural climate. Feelings of being excluded and unwanted at the institution are still felt by students, faculty, and staff of color on MU's campus. According to the 2017 Campus Climate Assessment (University of Missouri, 2019), lack of sense of belonging and an unwelcoming campus environment were the top two reasons students considered leaving MU. Of all respondents who "seriously considered leaving the university", undergraduate students of color, representing $42 \%$ of the respondents in this category, were the most vocal about leaving the university because of lack of belonging and an unwelcoming campus environment.

\section{Campus Climate and Campus Uprising}

The unwelcoming cultural climate that began in 1839 persists today at MU. In the fall of 2015, an African American student activist group, including a student group known as the Concerned Student 1950, protested against the university and its leaders for acts of discrimination, a hostile racial climate, and a lack of belonging on campus. The group's name pays homage to the year the first Black students were admitted to the university. The uprising became a social justice movement as they fought for their human and civil rights (Douglas \& Shockley, 2017). The Concerned Student 1950 movement mirrors the historical plight and fight 
of Blacks as they were and continue to be "victims of hateful behavior" and a people who still fight for their culture through "marches, protests, and demonstrations" (Douglas \& Shockley, 2017, p. 200). Triggered by the protest of 2015, the Campus Climate Assessment was the "result of a comprehensive process to identify strengths and challenges of the campus climate, with specific focus on the distribution of power and privilege among differing social groups at MU" (University of Missouri, Campus Climate Assessment, p. 11). The assessment was a response from MU leadership as a means to assess and address discriminatory practices and conduct toward students of color.

Through the protest, Concerned Student 1950 voiced their dissatisfaction with negligent responses to racial injustice experienced by marginalized students and inaction of administrators to acts and complaints of injustice and racism toward Black students (Trachtenberg, 2018). It was the group's intention to create awareness of the hateful climate and make demands for change (Trachtenberg, 2018), as described by Douglas and Shockley (2017), "to the White power structure...for the purpose of making things fair and just for Black people" (p. 200). The demands made by Concerned Student 1950, challenged a system that values White supremacy and has historical roots in oppression. Specifically, one of the group's demands was that MU “increase retention rates for marginalized students, sustain diversity curriculum and training, and promote a more safe and inclusive campus" (Hollis, 2019, p. 154; Trachtenberg, 2018, p. 84). This particular demand made by Concerned Student 1950 reflects the importance of inclusion and diversity for Black students on campus. However, this demand has a more pointed significance for Black females who are persisting on MU's campus as they continue to struggle for inclusion on campus. 


\section{The Racial and Gender Composition of the Uprising}

Concerned Student 1950, whose founding members decided to keep their names anonymous, was comprised of four males and seven females (Dache, et al, 2019). Three of the seven females identified as queer (Dache, et al, 2019). This composition is significant for two reasons. First, the gender and race composition is a reflection of the gender and racial demographic disparity of African American male and female enrollment at MU. Secondly, the notation of sexual orientation identity is also a reflection of the marginalized identities of Black

females on MU's campus. In 2018, Black females constituted 59\% of all Black students enrolled at the institution (University of Missouri, Student Profile, 2019). Yet, the focus of scholarly research has been male persistence and support, despite the fact that over half of enrolled Black students at MU are female. One can assume that the overwhelming representation of Black female students who were involved in the formation of Concerned Student 1950 is indicative of the feelings of exclusion and services and supports needed for African American female students as they experience racial and gender injustice while persisting at a PWI. This finding further supports the need for this proposed study, which is to hear and understand the needs of African American female students at PWIs and foster a sense of belonging and inclusion in the campus community.

\section{Movement Toward Inclusion}

The Concerned Student 1950 protest demands for inclusion, diversity, and safety and the call for MU system's president removal from office drew widespread local and national attention. The movement garnered support from residents and campus employees, as well as prominent allies such as Black players on the MU football team and their head football coachwho has since retired (Trachtenberg, 2018). In an effort to evoke change for MU and what would 
become a turning point for the protest, a graduate student began a hunger strike until university administration met the demands of Concerned Student 1950 (Kezar, Fries-Britt, Kurban, McGuire, \& Wheaton, 2018; Trachtenberg, 2018). The hunger strike gained no action from university administration. However, after two days of inaction, MU's Black football players and their head coach, stood as allies with Concerned Student 1950 and refused play nor engage in any sports related activities until the system president was removed or resigned from office (Kezar, et al., 2018; Trachtenberg, 2018). After the support of the football team, there was finally movement toward inclusion for Black students. The UM system president and chancellor of the MU campus resigned two days after the football team stood in solidarity with the Concerned Student 1950 and the hunger strike. In 2016, the Board of Curators hired a Chief Diversity, Equity, and Inclusion (IDE) Officer for the UM System, who has since resigned (University of Missouri, 2019). This officer also served a dual appointment as Vice Chancellor for Inclusion, Diversity, and Equity.

The local and national attention of the protest of fall 2015 instigated a diversity audit by MU administrators and led to the deployment of a campus climate survey to assess the implicit thoughts and feelings of inclusion and diversity of faculty, students, and staff. Survey results indicated that underrepresented students, faculty, and staff felt less comfortable on campus (University of Missouri, 2019). To address the campus climate and issues of diversity and racism, MU adopted the Inclusive Excellence Framework (IE) for all four campuses, to be implemented at all institutional levels to increase diversity and create a welcoming atmosphere for all students (University of Missouri, IDE, 2019). 


\section{Organizational Analysis}

Universities are large and complex institutions. Bolman and Deal (2013) suggest that the more significant institutions are in size, the more complex the structure. Because of MU's complex structure and massive size, this analysis uses a structural and human resource view of the institution.

\section{Structural Frame}

From a structural frame, MU can be viewed as an organized anarchy. Manning (2001) metaphorically describes higher education institutions as organized anarchies because they are often so complex that each discipline within the institution has individual views of a problem and may identify multiple solutions. Considering various aspects of the problem is essential in studying the persistence of Black undergraduate females. Faculty, staff, and students will have varying views of African American females' persistence. For example, "faculty experience the organization from their various disciplinarian points of view, administrators from their different understanding, and student's from yet others" (Manning, 2011, p. 14). The university hosts periodic town hall meetings for leaders, faculty, staff, and students to allow them to share their views of problems on campus. Because of the protest in fall 2015 and numerous town hall meetings to address the campus climate of inclusion, diversity, and equity, MU responded with the restructuring of the institution, again, by hiring a University of Missouri System Chief IDE Officer. The chief IDE officer, at the time, worked with MU's stakeholders to implement the Inclusive Excellence (IE) framework to anchor system-wide diversity and inclusion initiatives (University of Missouri, 2019).

The intended impact of the IE framework is to "embed diversity and equity into the fabric of MU. It is metric-driven, requiring the university's units to use data to measure the 
effectiveness of their programs and practices" (University of Missouri, 2019). To assess progress in institutional and educational practices, the IE framework identifies five dimensions to effect change: a) Access and Success, b) Institutional Climate and Intergroup Relations, c) Education and Scholarship, d) Institutional Infrastructure, and e) Community Engagement (University of Missouri, IDE, 2019). Departments are provided funding allocations and given autonomy to create and prioritize goals within the framework that promote inclusion and diversity efforts. The goals formulated utilizing the framework are then evaluated by each academic department and IDE to determine how effective the academic unit implemented change within the unit (University of Missouri, IDE, 2019). With a structure and campus climate that has its foundations in exclusion, it is difficult to imagine that a structural framework can change the fabric of this institution. Although every step to facilitate change is a step in the right direction, the framework is useful for administrators to receive feedback.

Feedback drives the practices of an organization (Manning, 2011). Therefore, it is important for one to understand the structure of all levels of an organization to analyze how it evaluates its programming, dysfunctions, progress and effectiveness in problem-solving. Because of MU's unique structure, it is considered a professional bureaucracy. Mintzberg (2005) established a frame for understanding a professional bureaucracy and details the five basic parts of an organization: a) strategic apex; b) middle line; c); operating core; d) technostructure; and e) staff (see Figure 1). 


\section{Figure 1}

Mintzberg's Model. Adapted from Mintzberg's Five Basic Parts of an Organization (2005).

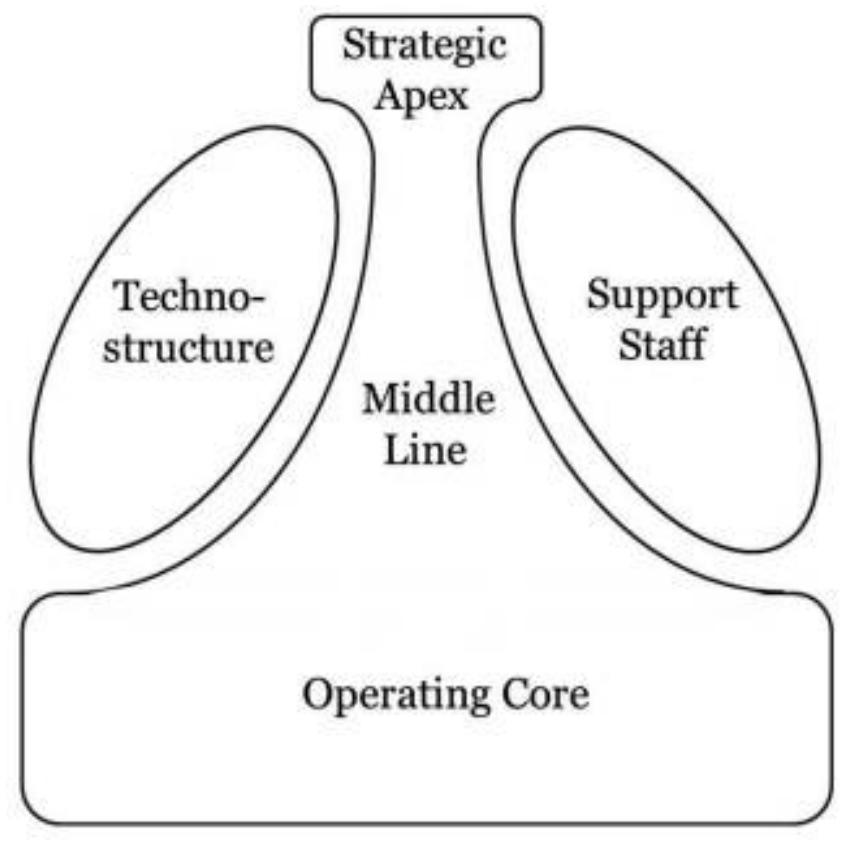

At the base of the model is the operating core. The operating core are those who deliver services and the professional experts in their field. Professors are considered the operating core at MU. Directly above the operating core is the middle line which consists of administrators who supervise and coordinate resources for the operating core. The provosts and deans of MU operate in the middle line, supervising and supporting professors. At the top of Mintzberg's (2005) model is the strategic apex which consists of those who establish, implement, and evaluate the mission of the institution. The Board of Curators, Presidents, and Chancellors represent the strategic apex of the university as they determine and execute the mission and evaluate the goals of the university system. Alongside the administrative components of the model is the technostructure and support staff who undergird the work of the administrators by providing technical, analytical, and task support (Bolman \& Deal, 2013). 
As with many bureaucracies, organizations are slow at accepting change (Bolman \& Deal, 2013). When leaders attempt to gain greater control of the work of the operating core, there may be resistance to change. Although there may be some disagreement, followers will often agree to changes as long as they feel the process was valid (Bolman \& Gallos, 2011) and their opinions were heard.

When communicating solid goals and strategies for change within the organizational structure, the use of vertical and lateral coordination is ideal when cultivating change (Bolman \& Deal, 2013). To garner buy-in for change at all levels, the blend of the two procedures is most efficient (Bolman \& Deal, 2013). Vertical coordination is useful when maintaining the status quo of an organization, and when the culture or environment is stable and predictable. Vertical coordination involves governing change through authority, rules, and policies and is a top-down strategy that uses command and control. Leaders give directives through the chain of command with little input from followers. On the other hand, lateral coordination involves collaboration and hearing the voices and contributions of the followers when difficult or complex issues or problems arise. Often the quickest form of change, lateral coordination consists of having faceto-face meetings and gathering committees and task forces to collaborate on policy and other issues affecting the organization.

MU utilizes a mix of both, lateral and vertical functions, as a way to coordinate and communicate system-wide goals. For example, during the Protest of 2015 when implementing the policy to add a system IDE chief officer, it was communicated through top officials that the change would be executed. In addition to using this top-down approach, the curators invited Concerned Student 1950 to taskforce meetings to hear their concerns and held various town hall meetings for faculty, staff, and students to voice their concerns about the racial climate on 
campus (University of Missouri, 2019). When issues arise in organizations, it is imperative the leader of the organization discern which function, vertical or lateral coordination, is most useful in problem-solving. However, it may be effective to use both to implement changes, depending on the severity of the challenge (Bolman \& Deal, 2013). The coalescing of the two approaches allows for policies and rules to be quickly communicated and allows the followers to have dialogue and decision-making on how these policies and procedures will be executed. Further, the two approaches provide opportunities to elicit feedback from its followers.

MU utilizes vertical and lateral coordination processes to understand the issues affecting African American undergraduate female students. Through the IE framework, policies and goals have been implemented using lateral coordination to foster inclusion for underrepresented students. However, we know little about the actual experiences of African American female students. In order to promote a more inclusive environment and create policy and programming specifically for Black female undergraduate students, using a lateral coordination structure to establish taskforces, townhalls, and focus groups that offer a space to solely hear their stories is beneficial to support their persistence (Shaw, 2017).

\section{Human Resource Frame}

To move toward the implementation of change, a leader is mindful that in addition to focusing on the structure, he or she should also focus on human needs and relationships to execute and carry out change. The human resource frame (Bolman \& Deal, 2013) offers a unique view of how to develop people to carry out goals. Bolman and Deal (2013) suggest the organization be selective in hiring the right people and keep them. MU has strategically set its goals to hire more faculty and staff of color and to incentivize their hires to retain them. MU is 
intentionally targeting recruitment and retention efforts on underrepresented populations to ensure it is fostering diversity on campus (University of Missouri, IDE, 2019).

Further, the human resource frame suggests that organizations invest in people, whether new hires or those with longevity. Investment communicates the high commitment of the leader to its followers and contributes significantly to the accomplishment of the organization's stated goals (Bolman \& Deal, 2013). To execute the IE framework and goals, the university system offers stipends and other non-tangible but valuable perks for faculty, staff, and students for their commitment to various programming established around diversity and inclusion. Departments who submit a proposal to implement diversity initiatives and are approved for diversity programming are awarded monetary funding to carry out their goals.

In 2018, of those who applied, the UM system awarded 1.4 million dollars in funding to those departments (University of Missouri, IDE, 2019). According to Gill (2010), incentives and rewards produce maximum outcomes (Gill, 2010). An example of programming which received funding for the 2017-2018 academic year is the Faculty Institute of Inclusive Teaching (FIIT). FITT "brings together a cross-disciplinary network of faculty to explore promising practices around diversity and inclusiveness in the undergraduate classroom" (University of Missouri, IDE, 2019). Faculty who participated in the program received a $\$ 1000$ stipend for committing their time and learning new strategies to foster inclusivity in the classroom.

Lastly, organizations empower people and promote diversity within the organization. A strong leader empowers and encourages autonomy and support to carry out goals. The university allows departments who receive funding to have the autonomy to structure their program and execute their goals. For instance, the College of Human Environmental Sciences (HES) hired a Faculty Fellow for Diversity and Inclusivity to chair their IDE task force, focusing the group's 
efforts on goals established within the IE framework. The fellow and taskforce used the UM system IE framework to formulate goals and programming that foster inclusivity of underrepresented faculty, staff, and students. Programming efforts include the creation of the “The Plug," a semi-annual gathering of underrepresented students and faculty and staff to foster inclusivity and the creation of the HES Black Student Organization (BSO) to encourage a sense of belonging to the college and to recruit other Black students (University of Missouri, HES, 2019).

Since the implementation of the IE framework in 2017, MU has taken to steps to address racism and cultivate a more inclusive environment by empowering its leaders to create goals; yet there is still more progress to be made. Not all at the university are invested in such an endeavor. Not all are committed to nor interested in the use of the IE framework that "reaffirms the University of Missouri's commitment to growing and sustaining a diverse and inclusive learning, living, and working environment" (University of Missouri, IDE, 2019). Some simply choose the path of least resistance (Johnson, 2018) by continuing with the foundational values of the university, which were founded on White male privilege. Those at the university who continue on this path further contribute to and perpetuate the oppressive institutional culture of the university.

\section{Leadership Analysis}

Leaders play an important role in effecting and sustaining change in an organization. Describing leadership is complicated as leadership is conceptualized in a variety of ways (Northouse, 2016; Shultz, 2010). Northouse (2016) defines leadership as " a process whereby an individual influences a group of individuals to achieve a common goal" (p. 6). Furthermore, leadership includes the responsibility of the leader to respond to the needs and issues that arise 
amongst its followers and have the adaptability to cope with change (Bolman \& Deal, 2013; Kotter, 2011). MU's priority is to foster an environment that is diverse and encourages the success of all students. The university has centered most of its initiatives around recruitment, retention, and creating a supportive and respectful climate for underrepresented students (University of Missouri, 2019). The purpose of the present study is to raise awareness and inform university administrators, faculty, staff, and practitioners of the needs of Black undergraduate females. To change and improve the cultural climate of the MU campus, recruit and retain students of color and, ensure academic persistence and success of African American students, specifically Black female students, the administration has to hear their stories and their needs.

\section{Transformational Leadership}

As with any organization, changing the culture of an organization to be inclusive requires a transformational leader. A transformational leader is "concerned with emotions, values, ethics, standards, and long-term goals" (Northouse, 2016, p.162). Gill (2010) posits that a leader who effectively communicates these aspects of the organization produces a shared sense of culture amongst its followers. Further, a transformational leader is one who assesses the climate of the followers, meets their needs, and treats them all as human beings (Northouse, 2016). The transformational leader has to present a solid vision and strategy of how to accomplish the goals. Kotter (2011) holds the same view, stating, "What's crucial about a vision is not its originality but how well it serves the interests of important constituencies - customers, stockholders, employees - and how it can be translated into realistic strategy" (p. 46). MU leadership communicates a clear vision with concrete goals. It also communicates its vision and goals to university employees, students, and constituents. However, to foster transformation, 
organizational leaders and its followers have to become united during the process of transformation on campus.

To encourage change as a transformational leader, Northouse (2016) identifies steps a leader should take. First, leaders should empower and equip their followers for change. The university does offer diversity training and programming for faculty, staff, and students. Second, leaders should have a strong sense of moral values, confidence, and competence. Having a strong sense of self builds trust with followers and induces an environment in which followers want to emulate. Thirdly, Northouse suggests that leaders create a compelling vision for the organization as the vision becomes the focal point for the organization. MU has incorporated diversity and respect as part of its core values and is communicated via most media and marketing outlets.

Finally, a leader is involved in shaping the culture of the organization by communicating the beliefs, values, and norms which contribute to the organizational culture (Gill, 2010; Kotter, 2011; Levi, 2017; Northouse, 2016). The willingness of the leader to communicate these elements gives way for the leader to be acknowledged as a "social architect" (Northouse, 2016, p. 176). A social architect is one who leads and has the propensity to create the desired culture and climate of an organization. Bolman and Deal (2016) posit in the human resource frame that organizations are cultures. The authors further postulate, "Culture is both a product and a process. As a product, it embodies wisdom accumulated from experience. As a process, it is renewed and recreated as newcomers learn the old ways and eventually become teachers themselves" (p. 263). Understanding the product and process of culture, prompts progress for change within the organization by followers embracing the vision and becoming a more cohesive and effective organization. 
MU has certainly had its challenges with changing the culture of the institution, especially in wake of the Protest of 2015. With the resignations of past top leaders - the president and the chancellor — and the hiring of a new president, chancellor and vice chancellor for IDE in 2016, the culture of the university was challenged to change. Currently, the university is attempting to challenge its employees to dismantle the systemic oppressive culture that it was built upon and to foster a more inclusive faculty, staff, and student body. While all are not impressed and on board to commit to the new vision, MU leadership is constantly communicating the goal of creating an inclusive environment.

\section{Implications for Research in the Practitioner Setting}

The University of Missouri-Columbia is embarking upon change within the institution as the leadership (the system president, chancellor and vice chancellors) continue to implement and execute the IE framework to challenge the culture of a university grounded in White patriarchy and oppressive attitudes. The context of this institution is significant to the researcher's study of African American female persistence at a PWI and yield several implications. First, as an institution that denied admission of its first African American female applicant on the basis of racial discrimination in 1939 (Bluford, 1939, The State Historical Society of Missouri), it is noteworthy to mention that the former vice chancellor of IDE, who resigned in 2019, was succeeded (on an interim basis) by a Black female. She was the first African American female to occupy this position and is a graduate of MU (she was succeeded by Dr. Maurice Gibson in 2020). The then interim vice chancellor's social position of being Black, female, and a graduate

of MU contributes to the context of this study, begging to shed light on stories of persistence that are dim and void in the literature. 
Further, the new appointment for the vice chancellor of IDE comes at a time when MU is strategically focused on recruitment and retention of African American faculty, staff and students, as indicated in the IE framework. As explained in the Inclusive Excellence Impact report released in 2019 (University of Missouri, IDE, 2019), since the implementation of the IE framework, there continues to be stagnant enrollment, decreasing retention and recruitment of Black faculty and students, lack of cultural competency amongst leaders and administrators, and an unwelcoming climate for underrepresented faculty and students. Data such as this, places the African American female at risk for persistence. Hearing and understanding the holistic (precollege and college) stories of African American female persistence will inform leaders, administrators, practitioners, and faculty of strategies to support African American females on campus and contribute to the gap that exists in the literature.

\section{Summary}

This section began by offering current demographical information and the historical context and current climate of the institution in which the study took place. I offered an organizational analysis of the university's structure and how it receives feedback and communicates change to create a welcoming and supportive environment that is inclusiveparticularly for Black females at a PWI. Finally, a leadership analysis of the university was provided to describe the leadership qualities and processes needed to foster and sustain an inclusive culture that will support African American female student persistence.

In summary, to become an inclusive and supportive institution, one that understands the needs of African American females at a PWI, MU leadership should recognize the structural and human resource strategies that are useful to effect and sustain change that foster the support of Black undergraduate female students. Further, administrators should clearly communicate a solid 
goal at all levels of the institution to implement change and hear the voices of its followers. Moreover, administrators should invest in the goal and promote diversity to implement and sustain change that support African American females. Lastly, to change the systemic oppressive culture of the institution, administrators have to exert transformational leadership by communicating a clear vision for change, build relationships at all levels of the institution (faculty, staff, and students) to cultivate a culture of change and inclusion to understand and support the needs of African American female students persisting at the university. 


\section{SECTION THREE:}

SCHOLARLY REVIEW FOR THE STUDY 
African American females have made progress toward college enrollment and achievement in higher education, according to graduation and degree attainment rates (Patton \& Croom, 2017). By 2010, Black women held 66\% of all bachelor's degrees attained by African Americans (Jones-DeWeever, 2014; Bartman, 2015). According to the National Center for Educational Statistics (NCES), in 2014, African American female undergraduate college students accounted for $62 \%$ of enrollment for all Black students. Even though African American female enrollment outnumbers men, the underachievement of African American males has been the more prominent focal point of research within and across Black education (Everett \& Croom, 2017; Goldin, Katz, \& Kuziemko, 2006, Thomas \& Jackson, 2007). While African American female undergraduate persistence has been given some scholarly attention, there is more scholarly research to be conducted on their lived experiences and persistence in higher education (Hannon, Woodside Pollard, \& Roman, 2018; Hooper, Wallace, Doehler, \& Dantzler, 2012; Robertson \& Mason, 2018; Sims, 2008).

The purpose of the study was to shed light on a narrative that is sparse in the literature. Though there is statistical evidence that affirms African American women are enrolling and persisting over their male counterparts, this gap in literature continues to exist. This study seeks to contribute knowledge and understanding of the experiences of African American female undergraduates enrolled in a PWI. The study provides a platform for African American female undergraduate students to describe and make meaning of their experiences, using their narratives. Lastly, the results of this study may be utilized as a conduit to inform the creation of supportive services and practices of university administration, faculty, and practitioners that positively contribute to the needs of Black female students at PWIs. 
To contribute to the scholarly research on African American female undergraduate persistence, it is necessary to investigate and review historical and current literature that illuminates the experiences of Black female undergraduates who persist at PWIs. The first section of the literature review will offer an overview of the problem and the purpose of the study. The second section will discuss extant literature of the pre-college and college experiences of African American female students that influence persistence in higher education. The review concludes with synthesizing literature on the frameworks of intersectionality and ecological systems, as a means to frame the factors that influence African American female persistence at a PWI.

With the growing number of African American females enrolling in college, PWI administrators must support Black female students in a variety of ways that positively affect their persistence (Ricks, 2014). Moreover, while scholars have increased scholarly research on the persistence of African American females, the narratives are limited to the context of their racebeing Black (Harrison, 2017; Patten, Crenshaw, Haynes, \& Watson, 2016; Vega, Moore \& Miranda, 2015). This study contributes to the narratives of Black females through the lenses of race and gender and other marginalized identities that Black female undergraduates hold. Crenshaw (1991) suggests that one cannot accurately articulate the lived experience of women of color without understanding them within the context of both race and gender and other identities they hold.

Discourses of lived experiences of African American females have increased in the scholarly literature; however, their stories are often shared in comparison to White women, African American males, and White men (Patton \& Croom, 2017; Zamani, 2003). Thus, narratives of their experiences are from a limited point of view. As Patton and Croom (2017) 
explain it, "Scholars and practitioners know little about the experiences of Black undergraduate women, and what is presumed to be known has in large part been constructed outside Black women's communities, devoid of a critical lens and treated as insignificant" (p. 1). What we know about Black female undergraduates is in relation to the Black population at-large or through comparison with other groups of people. The present study will not reify or replicate these problematic approaches but will instead seek to center the voices of African American women.

\section{Factors that Influence Persistence: Race, Gender, Class, and Sexual Orientation}

Most remarkably recorded in the literature on Back female persistence has been scholarly research that focuses on the rate in which Black female undergraduates are matriculating through graduation (Patton \& Croom, 2017). However, little is known about how race, gender, class and sexual orientation influence or impede the persistence of Black female undergraduate college students. For example, what we know is that Black females are outpacing their male counterparts in degree attainment, and yet scholarly narratives focus on the persistence of African American males (Patton \& Croom, 2017; Winkle-Wagner, 2009). The intersections of gender, race, class, and sexual orientation are seen as challenges to persistence. However, they influence the decision of African American women to attend college and are ironically the tools they use for persistence (Patton \& Croom, 2017). For many Black college women, issues of race, class, gender, and sexual orientation are factors of persistence that present themselves before college and factors that contribute to persistence through their college journeys (Smith; 2008; Zamani, 2003). 


\section{Race and Gender: Being Black and Female}

The intersections of race and gender for African Americans have historically created a barrier for African Americans in the educational system, even in their adolescent developmental years (Harrison, 2017). Archer-Banks and Behar-Horenstein (2012) and Harrison (2017) suggest one begins to become aware of his/her identity as early as middle school and that it becomes more complicated during these times as African Americans cope with negative perceptions and stereotypes from others. Adolescence is also a time when African American females begin to contend with the concept of "double consciousness"- having to navigate life with two selves, being Black and female (Winkle-Wagner, 2009). This notion suggests that African American females navigate these two selves to adjust to White mainstream culture, having the subjective experience of living up to the standards of others, but denying one's sense of self. Living a life of double-consciousness comes with its own negative experiences.

The adverse experiences of race and gender discrimination can cause lasting emotional effects for Black females. As early as elementary school, Black females experience discrimination by being labeled a "Black girl" versus a "White girl." This racialized experience may cause emotional distress, low self-esteem, and identity confusion. The weight and emotions of this experience may affect persistence in secondary and post-secondary institutions if they are not addressed or solved (Miles, Hones, Clemons, \& Golary, 2011). Winkle-Wagner (2015) explains that "college success often connects with prior educational experiences in primary or secondary schooling" (p. 173). This connection inhibits the ability for African American females to socially and academically integrate into the predominately-White campus and feel connected in the classroom and on the campus-at-large. Issues of gender and race interfere with how African American female students interact socially and perform academically at a PWI. 
Everett and Croom (2017) suggest that "the struggle to establish one's racial and gendered self is in addition to the developmental and transitional issues faced by all college students" ( $p$. 82). In Everett and Croom's (2017) critical discourse analysis of 14 articles spanning seven journals which included discourses on Black undergraduate women, the authors found that discourses on race and gender as it relates to African American female undergraduate students are mostly neglected in research. Much of the research focuses on race as the most significant factor in African American female persistence (Everett \& Croom, 2017; Miles et al., 2011). However, Everett \& Croom (2017) explain the necessity for studying the interconnections of Black female undergraduates. Miles et al. (2011) examined the narratives of six Black undergraduate females at a southern PWI and found that the intersection of race and gender contributed to the Black females' integration at the institution. The successful integration of their race and gender (feeling connected and accepted) positively impacted their academic success. Understanding the interconnections of Black females and sharing their narratives of pre-college and collegiate experiences aid administrators in developing support services and programming for undergraduate African American females that support persistence at PWIs (Porter, 2017; Robinson \& Franklin, 2011).

\section{Social Class: Triple Consciousness}

Race and gender are not the only intersections that influence the persistence of African American female undergraduates. Implications brought on by the intersection of class or socioeconomic status are also common in the discourse of the persistence of African American female undergraduates. Black students from working-class families or low-income neighborhoods experience a myriad of issues related to persistence long before college (Perna, 2000; Stewart, Stewart, \& Simons, 2007). In fact, in Perna's (2000) and Smith's (2008) research on Black 
students' decision to attend college, they found that lack of economic and social capital/cultural capital resources shape their decision to attend post-secondary education. Specifically, in Perna's (2000) work where she used longitudinal data from the third follow up to the 1994 National Educational longitudinal Study (NELS), she learned that the use of financial aid was a predictor of college enrollment. African American students in the study had lower family incomes than Whites and Hispanics. Further, Perna (2000) learned that financial aid loans reduced the likelihood of African American students enrolling in college after controlling for other socio/cultural factors such as cultural and social capital, sex, ability, and cost-benefits of attending college. Perna (2000) suggests the negative relationship between financial aid loans and African American enrollment in college may be related to the family's aversion for borrowing and the expectation of repayment.

Smith's (2008) study on the college choice process of first generation Black female students examines the narratives of three Black female single parents from low SES households. Smith (2008) found that, in addition to scarce economic resources, the parents of the participants contended with educational poverty which influenced the choice of the Black students' decisions to not attend college. Smith (2008) also discovered that Black parents who are on the lower economic strata are unaware of financial options for their children attending college.

Societal impact of social class. Moreover, societal views of African Americans from lower socio-economic backgrounds are also indicators of college choice and persistence. Harris (2017) and Williams and Nichols (2012) found that African American adolescent female students and college-age students experience stereotypes of being ghetto and loud, uneducated, and poor. In studies conducted by Henry, Butler, and West (2011) and Sims (2018), participants explained that these stereotype threats and microaggressions, coupled with environmental factors 
(i.e., low socioeconomic status and lack of critical mass), add to the complexity of experiences for Black females as they persist. Williams \& Nichols (2017) explored the stories (using a mixed-methods approach) of 20 Black women's experiences with microaggressions on two PWI colleges and universities campuses in the Mid-Atlantic part of the United States. Williams and Nichols report that Black women experience microaggressions on and around campus such as the assumption of being deviant and aggressive, being intellectually inferior, and being the angry Black woman. These stereotypical views and racial microaggressions occurred in the classroom and social spaces on campus. Although microaggressions may cause barriers to persistence, Williams and Nichols (2017) found that the Black women persisted despite of these barriers.

Black adolescent females contend with the same barriers to persistence. In studying racialized experiences of Black adolescent girls, Harrison (2017) conducted a series of interviews with four sixth-grade Black girls from three different public schools in a southeastern state and discovered Black girls often explained their experiences of microaggressions in the context of negative discourses of Blackness they received from their peers in the classroom. She learned that Black girls receive subtle messages about their in inability to afford clothes, talking "Black" and not being smart enough. Further, the study revealed that Black adolescent girls internalize microaggressions and interactions with their peers. Harrison (2017) suggests these negative discourses and microaggressions, however perpetrated upon adolescent girls, contribute to their academic achievement.

Encounters of microaggressions or encountering blatant racial and gender discrimination occur on a regular basis for Black female students, especially those from lower socioeconomic households; however, they are not reliable predictors of impediments to persistence (Donovan \& Guillory, 2017). However, the stressors do place Black female undergraduates at higher risk for 
underperforming in educational settings (Donavan \& Guillory, 2017). If these social and environmental issues are not resolved in the adolescent years, it is likely that feelings of inferiority, not being smart enough, and having to work harder to prove themselves academically will extend throughout college years (Johnson, 2017; Winkle-Wagner, Kelly, Luedke, \& Reavis, 2019). In their studies of narratives of persistence, Johnson (2017) and Winkle-Wagner et al., 2019) found that high achieving adolescent girls from low socioeconomic backgrounds who went on to pursue degrees at PWIs, with financial scholarships, were challenged by stereotypes about their intelligence during their collegiate experience.

Familial impact of social class. Though some research would suggest African American adolescents from working-class families have lower college aspirations and lower educational outcomes (Stewart, Stewart, \& Simmons, 2017), studies reveal the opposite in that Black undergraduate students who grow up economically disadvantaged use their economic condition as a motivator to attend and persist in college (Arana, Castaneda-Sound, Blanchard, \& Aguilar, 2011; Giuffrida \& Douthit, 2010). Using focus groups and interviews of the caregivers of 11 Black high school girls and one boy $\left(11^{\text {th }}\right.$ and $12^{\text {th }}$ graders) from inner city magnet high schools in Los Angeles, Smith \& Simmons (2006) examined the parenting practices of low socioeconomic status families and their involvement in college aspirations and the adolescent Black girls' and boys' decision to enroll in 4-year college institutions. Smith and Simmons (2006) found that mothers encouraged their daughters to tread through the adversity of being low-income and attend college. They also supported and committed to the young girls' educational aspirations of attending 4-year universities, despite the mother's financial struggles.

Although literature on low-income for Black females in particular was sparse, there were studies on the effects of low socioeconomic status and college aspirations for low-income 
minority youth in general. Research indicates that minority low-income students use family context to persist or as a reason not to persist (Diemer \& Li 2011; Mitchall \& Jaeger, 2018; Arana et al., 2011). Diemer and Li (2011) and Mitchall and Jaeger (2018) used two different methodologies to examine the role of socioeconomic status to persistence. Diemer and Li (2011) used longitudinal quantitative pre-existing data from the Child Development Supplement and Transition to Adulthood to explore the precollege contexts and its effects on persistence. Conversely, Mitchall \& Jaeger (2018) employed a qualitative case study approach and conducted in-depth interviews of seven low-income students, their parents, teachers, and school counselors, to explore their experiences and perceptions parental influence and other social supports had on college access and persistence. Even when using different methodologies, Diemer \& Li (2011) and Mitchall \& Jaeger (2018) had synonymous findings: parents of low-income minority students who encouraged their children to attend college and the children used their parents' encouragement and living situation as motivators to attend college.

Arana et al.'s (2011) study on family support and its influence on persistence lends corroboration to the above findings as the authors imply, "familial encouragement is paramount" (p.247) to the persistence of Hispanic students. However, Arana et al.'s (2011) offered insight into how familial support can have a double bind effect. That is, how family support may impede the persistence of minority students. Arana et al., (2011) examined the experiences of Hispanic PWI persisters (current undergraduates and professionals) who are or have been successful in moving toward agree attainment and nonpersisters (those who dropped out). Using the phenomenological methods of focus groups and face-to-face interviews, the researchers conducted interviews with 16 current students during focus groups, 11 face-to-face/phone interviews with students who did not successfully persist; and interviewed six professional 
graduates. Arana et al., (2011) learned that nonpersisters left college to go back home to work and help their families financially, while persisters used lack of resources as motivation to pursue their education for a better life. Though social class and economic status can be viewed as a marginalized status, students have ironically used these experiences as strengths to mediate the effects of marginalization and as motivators to persist.

\section{Sexual Orientation: A Triple Minority}

An additional challenge to persistence faced by African American females is their sexual orientation. Sexual orientation adds another dimension of the self or one's identity to have to navigate in any context, including at a PWI. Guyton and McGasky (2012) and Patton and Simmons (2008) suggest Black lesbians who attend PWIs are subject to triple minority status by occupying identities of being female, Black, and lesbian and have to contend with additional issues that exist when the intersections of race, gender, class, and sexual orientation collide. Moreover, Patton and Simmons (2008) explain it in this way:

"in some college environments LGBT students face an invisible existence or one filled with the threat of violence and fear of persistent prejudice that can lead to a great deal of confusion and feeling of rejection. The consequences of this invisible existence include student failure, challenges with managing emotions, and retreat from dealing with one's own holistic development.” (p. 198)

Bridges, Selvidge, and Matthews (2003) propose "Lesbians of color often feel that they are required to identify either their race or with their sexual orientation to fit into a culture" (p.115). The struggle to decide which identity (Black or female) to neglect also rises at the intersections of the Black female lesbian student. Studies that explore the intersection of sexual orientation of Black female undergraduates was limited. However, Black male gay persistence was prevalent in 
the literature search. Literature centered on the experiences of marginalization of Black female lesbian undergraduate students attending PWIs was near nonexistent.

My focus of sexual orientation for this section of the review is Black female lesbian undergraduate students. However, during the literature search language on sexual orientation or sexual identity evolved from study to study. Throughout the discussion of sexual orientation, I will use the terminology (queer-spectrum, queer) and acronyms (GLB, LGBT, LGBQ) used respectively by the authors in their individual studies (Garvey, Squire, Stachler, and Rankin, 2018).

The review in this area explores the support systems of Black female lesbians on college campuses. Most lesbian students experience the same limitations in support systems on campus, as do heterosexual Black female undergraduates. In a study aimed at investigating the role of social support and its contribution to academic success of Black undergraduate lesbians at a PWI, Guyton \& McGasky (2012) posit that Black lesbian students experience more discrimination than Black heterosexual females because of negative attitudes and judgments about the lesbian, gay, bisexual, and queer/questioning (LGBQ) community. Henry, Richards, and Fuerth (2011) also mention Black (GLB) students experience negative biases and discriminations from the Black community.

Biases and acts of racism and homophobic attitudes contribute to a negative campus climate, which has a direct impact on persistence (Guyton \& McGasky, 2012; Munoz-Plaza, Quinn, \& Rounds, 2002; Patton \& Simmons, 2008). Utilizing six open-ended, semi-structured interviews of Black female undergraduates who identified as lesbian, Guyton and McGasky (2012) found that though more extreme discriminatory attitudes exist, Black lesbian females have the same limited social support as Black heterosexual females at PWIs due to an 
unwelcoming campus climate. Black lesbian undergraduates also have difficulty fostering networks outside of the lesbian community due to in-group discrimination (Guyton \& McGasky, 2012).

Compiling the pre-existing data of responses from a system wide-campus climate survey of a large PWI, Garvey et al. (2008) explored "how campus climate directly affects academic success among queer-spectrum students” (p. 4). Garvey et al. (2018) sampled 3,370 queerspectrum undergraduate students (i.e., those who identified as undergraduate students and indicated sexual identity other than heterosexual). The study found that undergraduate LGBQ students who experience harassment and discrimination on an unwelcoming campus climate are more likely to experience barriers to persistence. However, LGBQ students who rated their campus climate less oppressive rated their academic success as high. In a similar 2016 campus climate study conducted at the University of Missouri-Columbia, the setting in which my proposed study will take place, the authors found that campus climates matter for students who identify as homosexual (University of Missouri, Campus Climate Survey, 2016). Considering 9,952 respondents and a $22 \%$ return rate for the survey, $18 \%$ represented undergraduate students, 17\% were African American/Black students, and 751 identified as LGBQ. This is important as the findings indicate that LGBQ students, low-income students, and Black/African American students were less comfortable with the overall campus climate than others in privileged categories were. The same was indicative of their experiences of feeling less comfortable in the classroom setting as students report they were recipients of acts of discrimination (University of Missouri, 2019).

Homophobic attitudes, racism, bias, and acts of discrimination toward lesbian students' sexual orientation become a challenge to persistence through graduation. Although literature on 
Black female lesbian students is meager, the lack thereof justifies the necessity to allow Black females with multiple marginalized intersecting identities to share their narratives of sexual orientation and how it influences their persistence at a PWI. Glover (2019) assures readers through her narrative of her journey through college that "willfulness, combativeness, negativity, unhappiness, and criminality are always already mapped onto Black (queer) women's bodies, especially when we refuse to comply with the status quo by advocating in our best interests" (p.164). Until future research is explored and acknowledges the experiences of Black female lesbian undergraduates, their experiences will continue to be invisible and campus climates will perpetuate the biases and stereotypes mentioned by Glover (2019).

\section{Theoretical Frameworks}

The theoretical frameworks used to undergird this study are intersectionality (Crenshaw 1991) and ecological systems theory (Ashford \& LeCroy, 2013; Bronfenbrenner, 1979). Using both of these theories will help to answer the research question: How do Black female undergraduate students describe their journeys to and through a Predominantly White Institution?

These two theories were used to understand the dynamic pre-college and college lived experiences of African American females enrolled at a PWI. Further, the conceptualization of both theories (see Figure 2) shed light on how Black female undergraduates navigate higher education within the context of their social environment and the intersection of multiple identities such as race, gender, class, and sexual orientation.

\section{Intersectionality}

Intersectionality is a phenomenological means to examine the multiple and interconnecting identities of Black women (Crenshaw, 1991). Coined by Crenshaw (1991), 
intersectionality asserts that the lives of Black women or women of color is best understood when one considers the multiple intersecting identities and the interlocking systems of power, oppression, and marginalization of race and gender. Crenshaw (1991) and Carastathis (2014) both share that failure to acknowledge the experiences of both race and gender of Black women fragments their experiences and lives. Unfolding half-truths about their stories further marginalize Black women, keeping their voices silent (Crenshaw, 1991; Strayhorn, 2017).

Intersectionality grew in response to oppressive gender and race relations and sexual violence and dominance of women of color. Crenshaw (1991) describes intersectionality using three categories: a) structural intersectionality, b) political intersectionality, and c) representational intersectionality. Structural intersectionality illustrates the experiences of Black women concerning discrimination and domination according to their gender, race, and class in particular settings and positions of those experiences relative to White women. Political intersectionality refers to how political entities and their competing agendas work to marginalize the issues that Black women face. Lastly, representational intersectionality offers a frame of reference for how Black women are marginalized and objectified by society and the media, resulting in disempowerment (Crenshaw, 1991).

At the margins of race and gender. Crenshaw argues that when the Black woman's experiences are the subject of research, they are juxtaposed to Black men and White women (Byrd; 2016; Crenshaw, 1991). Crenshaw's argument is plausible in extant scholarly literature of Black girls and women in educational settings. For example, in a study of racialized experiences of adolescent Black girls in middle school, Harrison (2017) observed and interviewed four Black sixth grade girls to gain insight on how they describe their experiences in school. She found that Black adolescent girls described their academic experiences comparing themselves to White girls 
who were economically advantaged and constructed the meaning of their identities (being a Black female) through the lens of White girls. The girls also compared themselves with other African American girls through negative discourses that would attribute their behavior as "ghetto" or "loud." Harrison (2017) poses that, "To some degree, the intersection of identities became a way to allow the girls to "other" themselves from girls within their own racial group and therefore allowed them to shelter themselves from accepting negative discourses about Blackness" (p. 1034). To this end, the meaning by which African American female adolescent students ascribe their experiences continues to be situated between race and gender instead of their multiple identities.

Not only is race and gendered discrimination found in the experiences of adolescents, but these encounters continue into the Black females collegiate journey. Byrd (2016) and Williams and Nichols (2012) found that race and gendered discrimination occur on campus and in the classroom setting. Using intersectionality to explore the intersections of race, class and gender and how these marginalized identities influenced the lives of 10 Black low-income freshman attending a PWI, Byrd (2016) learned Black undergraduate females contended and persisted through gender and racial stereotypes and microaggressions imposed on them by males in male-dominant majors. Males questioned the Black females' gender fitness and intellect to pursue a certain major. In Williams and Nichols' (2012) qualitative study of 20 Black females from university and community college settings in the Mid-Atlantic region of the U. S., Black undergraduate females faced microinsults of their intellectual ability. The study further revealed that Black females whose intellect was challenged in the classroom perceived the discrimination was based on their gender as opposed to race, causing them to identify gender as the target of oppression rather than race. 
Race and gender are salient factors of identity in scholarly literature of African American females. However, there has been a shift in focus in this area of research. Intersectionality, in its origin, has been studied as a concept and has now migrated to being used by researchers as an ideal way to study the multiple social identities (i.e., gender, race, class, sexuality, religion, and many more) of Black women (Shields, 2008). The shift of intersectionality being used as theory helps to explore experiences and asks the "how" of a phenomenon (Harrison, 2017; Shields, 2008; Strayhorn, 2017). Shields (2008) explains that identities are fluid and that "the facts of our lives reveal that there is no single identity category that satisfactorily describes how we respond to our social environment or are responded to by others" (p. 304). In Crenshaw's (1989) work, 'Demarginalizing Race and Sex,' she asks that one:

Consider an analogy to traffic in an intersection, coming and going in all four directions. Discrimination like traffic through an intersection, may flow in one direction, and it may flow in another. If an accident happens in an intersection, it can be caused by cars traveling from any number of directions and, sometimes, from all of them. Similarly, if a Black woman is harmed because she is in an intersection, her injury could result from sex discrimination or race discrimination...But it is not always easy to reconstruct an accident: Sometimes the skid marks and the injuries simply indicate that they occurred simultaneously, frustrating efforts to determine which driver caused the harm. (p. 149) The experiences of the lives of Black women are so complex that is it difficult to determine which identity causes more harm. Intersectionality begs to explore the impact of the multiple oppressive identities of the African American female.

At the margin of class/socioeconomic status. The unique tenets of intersectionality offer me the opportunity to explore and explain the multifaceted context of the lived experiences 
of African American female undergraduate students enrolled at a PWI. It further allows me to capture nuances of identities that are rooted in social structures and multiple categories (WinklerWagner et al., 2019). Research supports the supposition of Black females' experiences of multiple marginalization of identities that exist in addition to race and gender. Both Harris (2017) and Morris (2007), through ethnographic studies in middle schools, similarly noted that African American females of low socioeconomic status experience multiple marginalization. Morris (2007), in particular, conducted observations of teachers and classrooms over a two-year period to determine how race, class, gender interpretations and discipline of Black girls from low socioeconomic backgrounds influenced teacher-student interactions. Morris (2007) found that teachers' perception of Blackness, and the student's class and family background, influenced their interactions and discipline methods of the Black girls. Morris (2007) concluded that, "These girls did not experience the same forms of classroom discipline and teacher-student interaction as White girls, Latina girls, Latino boys, or Black boys shown in other research" (p. 510).

Winkler-Wagner et al.'s (2019) study on expectations placed upon Black women in college support the findings of Harrison (2017) and Morris (2007) in that Black females, in addition to marginalization because race and gender, experience discrimination due to their low socioeconomic status. However, Winker-Wagner et al. (2019) uncovered the strength of these females' ability to reject the low socioeconomic stereotype and persist through graduation. After completing four 60-minute in-depth interviews of Black college alumnae who graduated from mid-Western PWIs between 1954 and 2014, Winkler-Wagner et al. (2019) found that White teachers and students challenged the women's academic ability due to being admitted to the university on diversity scholarships (scholarships that are offered to low-income high achieving students). Further, the findings indicate the women were able to reject the stereotypes and persist 
by embracing their own identities, gaining a positive sense of self, and asserting their individual identities through leadership, Christianity, and becoming a change agent for other Black students on campus.

While Winkler-Wagner, et al. (2019) explains the ways in which Black females use their inner strength and personal resources to contend with negative stereotypes to persist to graduation, the study did not mention the participants' use of campus resources to defy these stereotypes. Findings suggest that these women had to seek out support from peers and acquaintances on campus. Thus, Winkle-Wagner et al.'s (2019) study identifies the need for university administrators to understand the experiences of Black female undergraduates and elicit change toward programming efforts to support their persistence.

Students using the power within their own agency and peer networks span the literature with recommendations calling for PWI administrators to increase programming that supports persistence of Black female students. Specifically, Hannon et al. (2018) and Lett and Wright (2013) examined factors of persistence of African American female undergraduates at PWIs. Using qualitative interviews, findings from both studies suggest Black females rely on their own agency and peers to cope with and overcome psychological, emotional and racial issues brought about by discrimination. Further, both studies suggest the need for PWIs to create sustainable programming efforts to meet the social and academic needs of African American female students.

At the margin of sexual orientation. As a social worker and scholarly practitioner in education, I would be remiss not to mention sexual orientation as a nuanced identity of Black females. The review of literature on intersectionality and Black female sexual orientation, specifically, was almost non-existent, though extremely prevalent for Black, gay undergraduate 
men attending PWIs. Guyton and McGaskey (2012) posit that Black lesbians who attend PWIs are a triple minority and are confronted with homophobic attitudes and heterosexism. Employing intersectionality as a secondary framework and using a phenomenological case study of six selfidentified Black lesbian undergraduate females, Guyton and McGaskey (2012) sought to understand the impact of race, gender, and sexual orientation on the composition of social support networks. They found that Black lesbian women leaned on family, friends within the lesbian community, and campus community. However, they received less support from the Black community. The dearth of literature examining intersectionality beyond race and gender through the lens of intersectionality exemplifies the need to hear and understand the stories of Black females that hold a plethora of intersecting marginalized identities.

Using intersectionality as a framework allows researchers to consider all of the challenges faced — pre-college and during college—by Black women. Intersectionality offers a way to categorize the structural, political, and oppressive social tensions experienced by Black females as they prepare for college and as students as they persist at PWIs (Byrd, 2016; Crenshaw, 1991). Most importantly to me choosing this framework is that "intersectionality should actually 'show up' in research" (Strayhorn, 2017, p. 59), and it promotes "irreducibility and inclusivity" (Carastathis, 2014, p. 307). In other words, intersectionality organically frames the experiences of Black women in a way that each individual identity "can only be defined through the intersection of other identities" (Harrison, 2017, p. 1024).

\section{Ecological Systems Theory}

In addition to using intersectionality to explore the multiple identities and lived experiences of African American female undergraduate students studying at a PWI, I also considered the importance of exploring the interactions of participants with their social 
environment through the use of ecological systems theory (Bronfenbrenner, 1979). Ecological systems theory is a framework developed by Bronfenbrenner (1979) to understand an individual within the context of where he or she resides (Ashford \& Winston, 2013). Widely used in the social sciences (e.g., social work, psychology, counseling), the theory investigates and organizes the interactions of an individual's experiences with social systems and how these interactions influence one's development and behavior from infancy to adulthood (Bronfenbrenner, 1979; Peirson, Boydell, Ferguson, \& Ferris, 2011). Further, ecological systems theory offers an antideficit focus of environmental factors related to the persistence of African American female students (Orrock \& Clark, 2018), and focuses on a holistic perspective of one's weaknesses, strengths, failures, and successes.

To categorize an individual's interactions with the environment, Bronfenbrenner (1979) uses four levels of inquiry: microsystem, mesosystem, exosystem and macrosystem. The microsystem is the smallest system and consists of face-to-face interactions an individual has with a system (Bronfenbrenner, 1979; Orrock \& Clark, 2018), such as interpersonal relationships individuals directly engage. Bronfenbrenner describes the mesosystem as experiences an individual has with systems outside of the home, such as the community, school, group settings, or church (Bronfenbrenner, 1979). The exosystem identifies and individual's indirect interactions with social structures that may influence one's development and behavior. Those social structures may include the mass media, social service organizations, friends of family, or neighbors. Finally, the macrosystem is defined as an individual's interaction with society and governmental entities (Bronfenbrenner, 1979). This system involves experiences or messages received from religious, ethnic, political, and economic structures (Bronfenbrenner, 1979). The macrosystem also includes "...one or more setting that does not involve the developing person as 
an active participant but in which events occur that affect, or are affected by, what happens in that setting" (p. 237). For instance, an individual may be impacted by policy changes at the government level, although he or she is not an active participant in legislative hearings. Peirson et al. (2011) assert that it is through the ecological systems perspective that individual experiences with the social environment influence one another and advance or impede the development of the individual.

Micro-and meso- system interactions. While limited in its use to study persistence, ecological systems theory has been used by a few scholars to study the persistence of African Americans and other minorities in educational settings. For example, Orrock and Clark (2018) and Leonard (2011) used the theory to explore the persistence of African American adolescents in urban public high school settings. Most notable about these studies is that African American adolescents are academically successful when they have supportive family interaction at the micro-level and positive interactions at the meso-level school settings. These scholars suggest that a positive school culture, coupled with positive interactions with students, directly influence the students' persistence to graduation and influences an individual's decision to attend and persist in post-secondary education (Leonard, 2011; Orrock \& Clark, 2018). Leonard (2011) postulates that using the ecological theory is beneficial as it evaluates the experiences of the individual.

Additionally, ecological systems theory has been useful in higher education settings to examine student engagement and persistence. To understand undergraduate persistence of Hispanic students through graduation, Castaneda-Sound, Blanchard, and Aguilar (2011) used the phenomenological methodologies of interviews and focus groups. The authors conducted interviews of 16 enrolled students during a focus group, held 11 face to-face, in-person and 
phone interviews with prior students who did not persist, and 6 students who had graduated. Castaneda-Sound, et al., (2011) found factors of persistence for persisters (currently enrolled or graduates) and non-persisters (those who did not persist) occurred on micro- and meso- levels. On the micro-level, students struggled with intrinsic lack of motivation, which contributed to non-persistence. On the meso-level, some students contributed family ties and lowsocioeconomic status as motivation to persist. The study indicates individual students and their interactions with these systems were either motivating factors or hindrances to persistence.

As exhibited in literature, the independent use of ecological systems theory effectively analyzes one's interactions at the micro and meso levels. To add to the critical reflection of one's interactions across all three systems, incorporating intersectionality theory is ideal. The use of ecological systems theory (Bronfenbrenner, 1979) and intersectionality (Crenshaw, 1991) in tandem is justified in the literature. Ozaki and Renn's (2015) study on multiracial student engagement and Byrd's (2016) research on African American female undergraduate persistence uses both theories. In both studies, the authors discovered that familial supports are a vital indicator of one's ability to persist through college. Through a supportive family system, students gained a sense of positive development and self-concept from interactions with their parents that directly contributed to the ability to navigate challenges to their academic success on campus (Byrd, 2016; Ozaki \& Renn, 2015; Renn, 2003). Also, synonymous with the findings of these studies was that of mesosystem interactions (i.e., community, church, school). For instance, Byrd (2016) discovered that participants used spiritual motivation from church leaders as a means to stay the course and persist. Participants also used the interactions with faculty on campus as a source of support to stay encouraged through persistence (Ozaki \& Renn, 2015). 
Exo-and Macro-system interactions. While a number of interactions occur directly with individuals on the micro- and meso-system levels, interactions occur at the exo- and macrosystem levels. Both of these systems can directly or indirectly influence an individual. Interactions at the exosystem might include the indirect impact and effects of mass media, religious organizations, human service agencies, their portrayal of a population and its impact on an individual (Bronfenbrenner, 1979; Byrd, 2016). The macrosystem is where ideologies about culture, race, government policies, and discrimination is housed. It is through the macrosystem that individuals receive messages from society which may affect ones' experiences. These messages are often communicated through the media, and federal, state, and local governmental structures (Orrock \& Clark, 2015). Exploring issues from the macrosystem level and the impact of these exchanges and interactions — whether directly or indirectly — yields understanding of one's behavior in an environment.

In the macrosystem, interactions may occur in the context of a student's indirect interaction with the educational institution. For example, Archer-Banks and Behar-Horenstein (2012) and Harrison (2017) found that Black females express experiences of unjust school policies that support the success of White students, leaving them to feel as though their cultural deficits were to blame instead of the institutional policies that are perpetuating the disparity of Black and White students in educational settings (Harrison, 2017). Specifically, Archer-Banks and Behar-Horenstein's (2012) studied the experiences of the eight African American high school students from a predominately Black high school in a southeastern school district in the United States. Archer-Banks and Behar-Horenstein (2012) found that school policies and practices impacted their performance and motivation as the participants believed that school 
personnel and teachers held negative biases and stereotypes consistent with that of society and the media—being loud, aggressive, hypersexualized.

Byrd (2016) found similar macrosystem interactions in a study focused on Black females' perception of experiences of college readiness. Using qualitative interviews and focus groups of 10 Black female freshman students, Byrd also found that Black females experience inequitable educational practices. It is also important to note that both Byrd (2016) and Archer-Banks and Behar-Horenstein (2012) found that African American students also described connecting with some teachers who were sensitive and demonstrated concern for their needs, well-being and persistence. Both studies also found that even though Black female students experience barriers on many systemic levels, they also experience triumph.

\section{Theoretical Amalgamation}

Applying intersectionality (Crenshaw 1991) and ecological systems theory

(Bronfenbrenner, 1979) was the most appropriate way to conduct this study, as Bronfenbrenner (1979) declares:

The understanding of human development demands more than the direct observation of behavior on the part of one or two persons in the same place; it requires examination of multi-person systems of interaction not limited to a single setting and must take into account aspects of the environment beyond the immediate situation containing the subject. (p. 21, italics in original)

Utilizing both frameworks challenged me to look beyond the direct educational environment to investigate the persistence of African American females. Theory amalgamation occurs at the exo and macro levels (as indicated with the asterisks in Figure 2) to offer an exceptional means to explore the interactions and responses of the individual with social systems in their environment. 
These frameworks, used in tandem, work to acknowledge the pre-college and college experiences that contribute to the persistence phenomenon. Additionally, the use of both intersectionality and ecological systems theories are compatible as they provide a framework for understanding racial identities and experiences.

Both theories elicit a multi-perspective look into micro, mezzo, and macro systems as a way to understand the experiences and interpret one's behavior and interactions with their environment. To further this point, Ozaki and Renn (2015) posit both of these frameworks take into account the racial and other marginalized identities that vary from individual to individual within the context of their social environments and throughout the lifespan. Not only does the use of both theories offer an exceptional means to explore the interactions and responses of the individual with systems in their environment, but the utility of both also underscore the interactions between systems that marginalize or support the African American female. Lastly, coalescing of the two theories build upon empowerment, acknowledges the experiences, strengths, and uniqueness of African American females who attend PWIs (see Figure 2). 


\section{Figure 2}

Intersectionality and Ecological Systems Conceptual Model

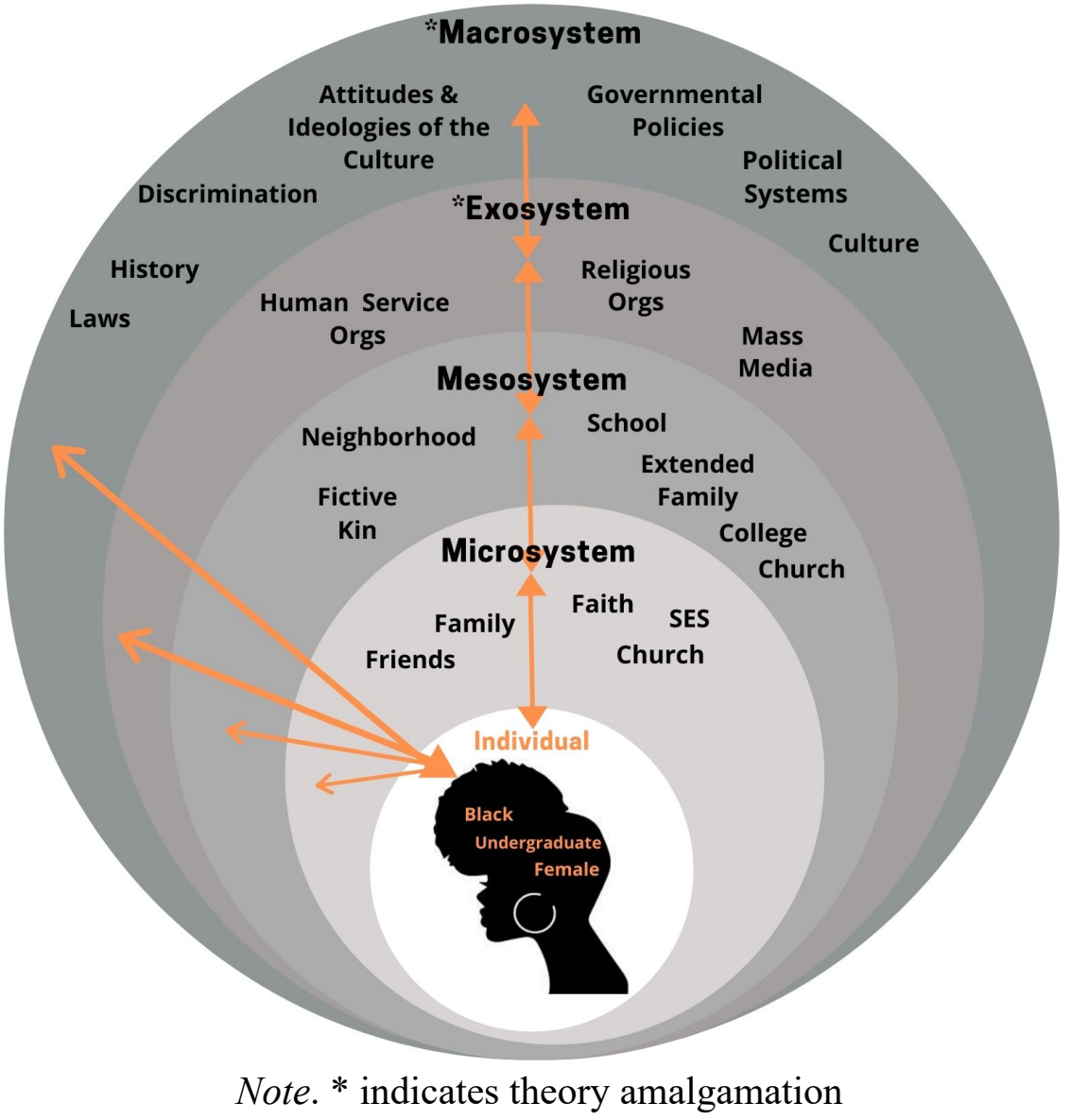

\section{Summary}

This literature review aids in understanding the lived experiences of Black female undergraduates at PWIs. It also offers insight into how Black females experience discrimination and oppression on campus as they matriculate with multiple, interconnecting identities of race, gender, class, and sexuality. Additionally, literature suggests in order to explore one identity, all of them are interconnected, and one identity cannot be assessed without addressing the other. Educational research on these multiple identities is increasing. However, discourses today center on the statistics of enrollment and persistence of Black female undergraduates. And as Patton 
and Croom (2017) explain, these discourses "fail to account for an analysis (and definition) of success beyond numbers, one that considers a larger context in which intersections of identities and systems of oppression that create uniquely raced, gendered, and classed experiences for Black women" (p. 2). The literature further implies the need for stories of persistence to be explored and explained beyond the statistical data, because African American females are persisting at higher rates, but are doing so as they pay the price emotionally, psychologically, and academically, out of experiences of marginalization and oppression.

Most of the articles reviewed indicate an essential limitation in that researchers had small sample sizes, and the findings cannot be generalized to the experiences of all Black female undergraduates. A few researchers offered findings that were specific to gender or race and failed to acknowledge the impact of both gender and race as indicators of persistence. Intersectionality and ecological systems theory are frameworks that will allow this researcher to add to the body of literature that acknowledges the holistic, interconnected identities of Black female undergraduate students. Additionally, these two frameworks will allow me to analyze these experiences, the challenges, and triumphs, as transactions with the social environment.

Narratives of challenges and triumphs to the persistence of African American female undergraduates "are not new; they are old issues that have not been fully acknowledged, explored, and resolved" (Henry et al., p. 140), which is a weakness in the research. The literature reviewed in this section revealed the challenges of persistence faced by African American female undergraduates but did so without always mentioning the strength and resiliency it takes to persist. The study focused not only on the challenges experienced by Black female undergraduates but also on the strength and resiliency to overcome these challenges. Understanding the journeys of these African American female undergraduates may lead to 
change in educational system policies and programming that directly encourage and support persistence of Black girls and women as they matriculate through educational environments (Hannon et al., 2018; Harrison, 2017). Critical to the support of Black female undergraduates is not just acknowledging that they are persisting through graduation at high numbers; but it is also acknowledging that some bring experiences of marginalization and stand to face additional marginalization during their collegiate journey, all of which should be addressed and supported by the institution (Lett \& Wright, 2003). 
SECTION FOUR:

CONTRIBUTION TO PRACTICE 


\section{WINNING WHEN THE ODDS ARE AGAINST YOU:}

\section{A NARRATIVE INQUIRY OF BLACK FEMALE PERSISTENCE AT A PREDOMINANTLY WHITE INSTITUTION}




\section{2}

\section{PROBLEM STATEMENT}

Enrollment of Black female

undergraduate students is rising, outpacing their male counterparts, but their voices of persistence are limited in scholarly literature.

\section{PURPOSE OF THE STUDY}

The purpose of this study is to examine the persistence of undergraduate Black females enrolled at PWIs, as their voices are largely neglected in the literature. The study aims to understand the experiences, including pre-college and college experiences that contribute to Black female undergraduate persistence through graduation. While stories of race and gender are the tip of the iceberg for the study of persistence at a PWI, it is otherwise vital to study additional factors that impede or contribute to persistence.

\section{CONCEPTUAL FRAMEWORK}

\section{Intersectionality and Ecological Systems Theory}

- Intersectionality is a phenomenological means to examine the interconnected marginalized identities of Black women including race, gender, class, and sexual orientation.

- Ecological systems theory is used to explore and organize how an individual experiences social systems and how these interactions or transactions shape one's life from infancy to adulthood, allowing for storytelling to and through a PWI.

- The amalgamation of both theories illuminates the interactions between systems that either marginalize or support African American females. In turn, both theories explore the interactions and responses of the individual with systems in their environment. 


\section{3}

\section{RESEARCH QUESTION}

How da Blackfemale undergraduates

describe their experiences to and thraugh a

Predaminantly Thite Institutian?

\section{DESIGN OF THE STUDY}

\section{Qualitative Study}

- Narrative inquiry

- The methodology employed in this qualitative research study is narrative inquiry. Narrative inquiry is a qualitative method useful in capturing the individual experiences of a single person or a group of people who experience some phenomenon.

- Narrative inquiry allowed the researcher to use a participant's first-person account and analyze it as data and shed light on their experiences.

\section{DATA COLLECTION \& ANALYSIS}

The study took place at the University of Missouri-Columbia

- Interviews included 10 Black female undergraduate students with sophomore-senior classification.

- Participants completed two 45-minute semi-structured interviews via Zoom.

- Interviews were audio and video recorded.

- Each interview was read and viewed in its entirety, coded, and transcribed. 


\section{4}

\section{KEY FINDINGS}

\section{Three themes emerged from participant narratives:}

\section{THEME 1:}

Fueled by Faith, Family, and

Finances

Participants situated family context, faith, and socioeconomic status as influences in their childhood that lead to their intrinsic motivation for higher education.

\section{THEME 2:}

Managing Memories, Messages, and Microaggressions

Participants explained the hardships of vacillating between "two-selves"--being Black and Female in adolescence. Participants shared their experiences of memories, messages, and microaggressions they experience in their journey to a PWI.

\section{THEME 3:}

Balancing Being Black and Bold

Participants described the emotional stresses and impact of gender and race as they journey through the institution.

\section{IMPLICATIONS FOR RESEARCH}

The study highlights the experiences, personalities, character, and journeys of Black female undergraduate students as they journey to and through a PWI.

- Scholars should examine the nuanced stories of mental health and its psychological impact on persistence.

- Further research could explore how Black female undergraduates employ faith as a factor for resilience during their journeys to and through a PWI.

- Exploration of the journeys of Black female undergraduates who identify as a sexual minority (LGBTO) and their experiences of persistence at a PWI is warranted as they were not represented in this study. 


\section{5}

\section{RECOMMENDATIONS}

1. Advisors should be trained in basic foundational skills for interviewing to understand the contextual backgrounds Black women experience before college and how these factors contribute to their academic persistence.

2. Accessible mental health advocates or counselors of color are recommended to be placed in spaces frequented by this population, such as the Black Culture Center or the Center for Academic Success and Excellence (CASE). It is also recommended that noncompetitive campus-wide therapy groups or circles for Black women exist regardless of their belonging in other organizations.

3. An explicit call to action-a call to direct intentional funding toward programming that will promote inclusivity of all Black females on campus. This could include system or campus funding directed toward programming that is not specific to Black females who are categorized by GPA or socioeconomic status.

They give people breadcrumbs and expect them to make banana bread out of it. And we do. We really do.

\section{CONCLUSION}

This research is a clarion call for action by PWI administrators, faculty, and staff to intentionally build, support, and sustain educational environments that address the multiplicative oppressed identities of Black women.

This study can be utilized as a tool for administrators and practitioners to interrupt the cycle of oppression of Black female undergraduates on campus.

The study provides an avenue whereby consideration can be given to individual stories of persistence to target services, spaces, and programming to further enhance Black female experiences on campus. 


\section{6}

\section{REFERENCES}

Booker, K. (2016). Connection and commitment:

How sense of belonging and classroom

community influence degree persistence for

African American women. International

Journal of Teaching and Learning in Higher

Education, 28(2), 218-229.

Bronfenbrenner, U. (1979). The ecology of

human development: Experiments by design

and nature. Cambridge, MA: Harvard

University Press.

Crenshaw, K. (1991). Mapping the margins:

Intersectionality, identity politics, and

violence against women of color. Stanford

Law Review, 43(6), 1241-1299.

Patton, L. D., \& Croom, N. N. (2017). Critical perspectives on undergraduate Black women. In L. D. Patton \& N. N. Croom (Eds.), Critical perspectives on Black women and college success (pp. 1-13). New York, NY:

Routledge. 
SECTION FIVE:

CONTRIBUTION TO SCHOLARSHIP 
Christine Woods, EdD, MSW, LCSW

University of Missouri School of Social Work

711 Clark Hall

Columbia, MO 65202

May 31, 2021

Kimberly A. Griffin

University of Maryland, College Park

Journal of Diversity in Higher Education

Dear Dr. Griffin,

I am pleased to submit the enclosed manuscript entitled, Winning When the Odds are Against You: A Narrative Inquiry of Black Female Persistence at a Predominantly White Institution for consideration in the Journal of Diversity in Higher Education. This narrative analysis offers a glimpse of the lived journeys of Black female undergraduates at a predominantly White institution - institutions that have startling disparities in racial diversity and graduation rates by race. Further, this paper provides insight into the factors that influence Black female undergraduate persistence, which directly impacts the engagement of administrators, faculty, and practitioners. The findings of this research acknowledges the nuanced stories of mental health, trauma, and its psychological impact on Black female persistence. Further, it sheds light on the necessity of culturally responsive access to mental health services for Black females on campus. Through their faith and use of innate resiliency, Black females are persisting through graduation

This manuscript urges a call to action for administrators of PWIs to foster inclusion, diversity, sustained programming, and support for marginalized students. As such, this article should be of interest, as its premise is to encourage change in diverse learning environments. Please consider this manuscript submission as it aligns and seeks to guide the efforts of institutions of higher education in the pursuit of inclusive excellence. 
Regards,

Christine Woods, Ed.D., MSW, LCSW

Assistant Teaching Professor

University of Missouri School of Social Work 
Winning When the Odds are Against You: A Narrative Inquiry of Black Female Persistence at a Predominantly White Institution

Christine Woods, EdD

University of Missouri-Columbia

\begin{abstract}
African American females are enrolling and graduating college at increasing rates and outpacing their male counterparts to graduation. While their graduation rates increase, narratives of their journeys to and through college are sparse in the literature. This qualitative study examines the narratives of persistence of 10 Black female undergraduates enrolled at a Mid-Western Predominantly White Institution (PWI). Through the lenses of Crenshaw's intersectionality and Bronfenbrenner's ecological systems theory, this study explores factors that impede or promote persistence through the socio-environmental contexts of Black female undergraduates' journeys to and through a PWI. Using a semi-structured interview protocol, participants share stories of persistence beginning from childhood. Interview data underscore family context, faith, and issues of race, gender, and class as influential factors of persistence toward graduation at a PWI. Implications for practice and research are presented, and recommendations for administrators and practitioners are offered.
\end{abstract}

Keywords: persistence, Black, African American female, systems theory, intersectionality 
The focus of this research was to identify factors that contribute to or impede persistence of Black female undergraduate students who are enrolled at Predominately White Institutions (PWI). The study addresses the lived experiences of Black undergraduate female students persisting at the University of Missouri-Columbia, a mid-Western, land-grant, Research I institution. While we know that Black females are persisting, their voices are neglected in the literature.

There has been a significant increase in enrollment and degree completion of Black females in higher education (Booker, 2016; Thomas \& Jackson, 2007; Winker-Wagner, 2009). According to the National Center for Educational Statistics (2019), from 2007-2017, enrollment of Black female students rose from 34\% to $40 \%$. However, persistence to graduation for Black students overall remains low. In a longitudinal study conducted by the National Center for Educational Statistics (2019), from 2011-2017, 39\% of first-time Black college students who were enrolled at a public 4-year institution graduated with a bachelor's degree, compared to the overall completion rate of $59 \%$. The degree attainment rate for African American students is also low relative to $65 \%$ of White students who graduated with their bachelor's degree during the same time. Enrollment of African American students is projected to rise twenty percent by the year 2026 (NCES, 2019).

\section{Literature Review}

Most remarkably recorded in the literature on Black female persistence has been scholarly research that focuses on the rate in which Black female undergraduates are matriculating through graduation (Commodore, Baker, \& Arroyo, 2018; Patton \& Croom, 2017). However, little is known about how race, gender, class and sexual orientation influence or impede the persistence of Black female undergraduate college students. For example, what we 
know is that Black females are outpacing their male counterparts in degree attainment, and yet scholarly narratives focus on the persistence of African American males (Patton \& Croom, 2017; Winkle-Wagner, 2009). The intersections of gender, race, class, and sexual orientation are seen as challenges to persistence. However, they influence the decision of African American women to attend college and are ironically the tools they use for persistence (Patton \& Croom, 2017). For many Black college women, issues of race, class, gender, and sexual orientation are factors of persistence that present themselves before college and factors that contribute to persistence through their college journeys (Smith; 2008; Zamani, 2003).

\section{Factors that Influence Persistence}

The intersections of race and gender for African Americans have historically created a barrier for African Americans in the educational system, even in their adolescent developmental years (Harrison, 2017). One begins to become aware of his/her racial and gender identity as early as grammar school . It is in adolescence that race and gendered issues become more complicated as African American children cope with negative perceptions and stereotypes from others (Archer-Banks \& Behar- Horenstein 2012; Harrison, 2017). The adverse effects of race and gender can have lasting emotional ramifications for Black females and can impact persistence in secondary and post-secondary education (Miles, hone, Clemons, \& Golary, 2011). Winkler-Wagner (2015) suggests that racialized experiences in grammar and secondary school directly influence college success.

In addition to race and gender as factors of persistence, the intersection of class influences Black female persistence. Implications brought on by the intersection of class or socio-economic status are also common in the discourse of the persistence of African American female undergraduates. Black students from working-class families or low-income 
neighborhoods experience a myriad of issues related to persistence long before college (Perna, 2000). In fact, Harrison (2017) and Donavan \& Guillroy (2017) propose that Black girls often are victims of microaggressions in the classroom and are often discriminated against because of social class. Although class is not a reliable predictor of persistence, the additional stressors that social class bring do place Black female at higher risk for underperforming in educational settings.

Another influential factor of persistence faced by African American females is their sexual orientation. Sexual orientation adds another dimension of the self or one's identity to have to navigate in any context, including at a PWI. Guyton and McGasky (2012) and Patton and Simmons (2008) suggest Black lesbians who attend PWIs are subject to triple minority status by occupying identities of being female, Black, and lesbian and have to contend with additional issues that exist when the intersections of race, gender, class, and sexual orientation collide. Black lesbians students are likely to experience more discrimination than Black heterosexual females because of negative attitudes and judgments about the lesbian, gay, bisexual, and queer/questioning (LGBQ) community (Guyton \& McGasky, 2012; Henry, Richards, \& Fuerth, 2011). Homophobic attitudes, biases, and acts of discrimination toward Black lesbian females present discrimination presents barriers present challenges to persistence through graduation.

With the increased projection of Black student enrollment and knowing the majority of Black students who enroll in college matriculate at PWIs (Stewart, 2017), it is critical to hear and understand the voices of African American female undergraduate who matriculate at a PWI. The current study examines the persistence of undergraduate Black females enrolled at PWIs, as their voices are largely neglected in the literature. For this study, persistence is defined as the continuation of educational pursuits in the attainment of a bachelor's degree (Booker, 2016). The 
study aims to understand the experiences, including pre-college and college experiences that contribute to Black female undergraduate persistence through graduation. While stories of race and gender are the tip of the iceberg for the study of persistence at a PWI, it is otherwise vital to study additional factors that impede or promote persistence.

\section{Conceptual Framework}

The theories used to undergird the present study are intersectionality (Crenshaw 1991) and ecological systems theory (Bronfenbrenner, 1979). Using both of these allowed the researcher to answer the research question: How do Black female undergraduate students describe their journeys to and through a predominantly White institution?

These two theories were used to understand the dynamic pre-college and college lived experiences of African American females enrolled at a PWI. Further, the conceptualization of both theories (see Figure 1) shed light on how Black female undergraduates navigate higher education within the context of their social environment and the intersection of multiple identities such as race, gender, class, and sexual orientation.

\section{Intersectionality}

Intersectionality is a phenomenological means to critically examine the multiple and interconnecting identities of Black women (Crenshaw, 1991). Coined by Crenshaw (1991), intersectionality asserts that the lives of Black women or women of color is best understood when one considers the multiple intersecting identities and the interlocking systems of power, oppression, and marginalization of race and gender. Crenshaw (1991) and Carastathis (2014) both share that failure to acknowledge the experiences of both race and gender of Black women fragments their experiences and lives. Unfolding half-truths about their stories further marginalize Black women, keeping their voices silent (Crenshaw, 1991; Strayhorn, 2017). 
Intersectionality grew in response to oppressive gender and race relations and sexual violence and dominance of women of color. Crenshaw (1991) describes intersectionality using three categories: a) structural intersectionality, b) political intersectionality, and c) representational intersectionality. Structural intersectionality illustrates the experiences of Black women concerning discrimination and domination according to their gender, race, and class in particular settings. Political intersectionality refers to political entities and how their competing agendas work to marginalize the issues that Black women face. Lastly, representational intersectionality offers a frame of reference for how Black women are marginalized and objectified by society and the media, resulting in disempowerment (Crenshaw, 1991).

\section{Ecological Systems Theory}

In addition to using intersectionality to explore the multiple identities and lived experiences of African American female undergraduate students studying at a PWI, the researcher considered the importance of exploring the interactions of participants with their social environment through the use of ecological systems theory (Bronfenbrenner, 1979).

Ecological systems theory is a framework developed by Bronfenbrenner (1979) to understand an individual within the context of where he or she resides (Ashford \& Winston, 2013). Widely used in the social sciences (e.g., social work, psychology, counseling), the theory investigates and organizes the interactions of an individual's experiences with social systems and how these interactions influence one's development and behavior from infancy to adulthood (Bronfenbrenner, 1979; Peirson, Boydell, Ferguson, \& Ferris, 2011). Further, ecological systems theory offers an anti-deficit focus of environmental factors related to the persistence of African American female students (Orrock \& Clark, 2018), and focuses on a holistic perspective of one's weaknesses, strengths, failures, and successes. 
To categorize an individual's interactions with the environment, Bronfenbrenner (1979) uses four levels of inquiry: microsystem, mesosystem, exosystem and macrosystem. The microsystem is the smallest system and consists of face-to-face interactions an individual has with a system (Bronfenbrenner, 1979; Orrock \& Clark, 2018), such as interpersonal relationships individuals directly engage. Bronfenbrenner describes the mesosystem as experiences an individual has with systems outside of the home, such as the community, school, group settings, or church (Bronfenbrenner, 1979). The exosystem identifies and individual's indirect interactions with social structures that may influence one's development and behavior. Those social structures may include the mass media, social service organizations, friends of family, or neighbors. Finally, the macrosystem is defined as an individual's interaction with society and governmental entities. This system involves experiences or messages received from religious, ethnic, political, and economic structures (Bronfenbrenner, 1979). The macrosystem also includes "...one or more setting that does not involve the developing person as an active participant but in which events occur that affect, or are affected by, what happens in that setting" (p. 237). For instance, an individual may be impacted by policy changes at the government level, although he or she is not an active participant in legislative hearings. Peirson et al. (2011) assert that it is through the ecological systems perspective that individual experiences with the social environment influence one another and advance or impede the development of the individual.

\section{Theoretical Amalgamation}

The use of both intersectionality and ecological systems theories are compatible as they provide a conceptual framework for understanding racial identities and experiences in a couple of ways. First, both theories can elicit a multi-perspective look into micro, meso, exo, and macro systems as a way to understand the experiences and interpret one's behavior and interactions 
with their environment. To further this point, Ozaki and Renn (2015) posit both of these frameworks take into account the racial and other marginalized identities that vary from individual to individual within the context of their social environments and throughout the lifespan. Lastly, the two theories build upon empowerment and acknowledge systems of oppression that affect an individual, especially in education.

The amalgamation of both theories intersect at the exo-and macro-level (see Figure 1) to offer an exceptional means to explore the interactions and responses of the individual with systems in their environment. The utility of both theories also illuminated the interactions between systems that marginalize or support the African American female. Lastly, coalescing of the two acknowledged the experiences, strengths, and uniqueness of African American females who attend PWIs. 


\section{Figure 1}

Intersectionality and Ecological Systems Conceptual Model

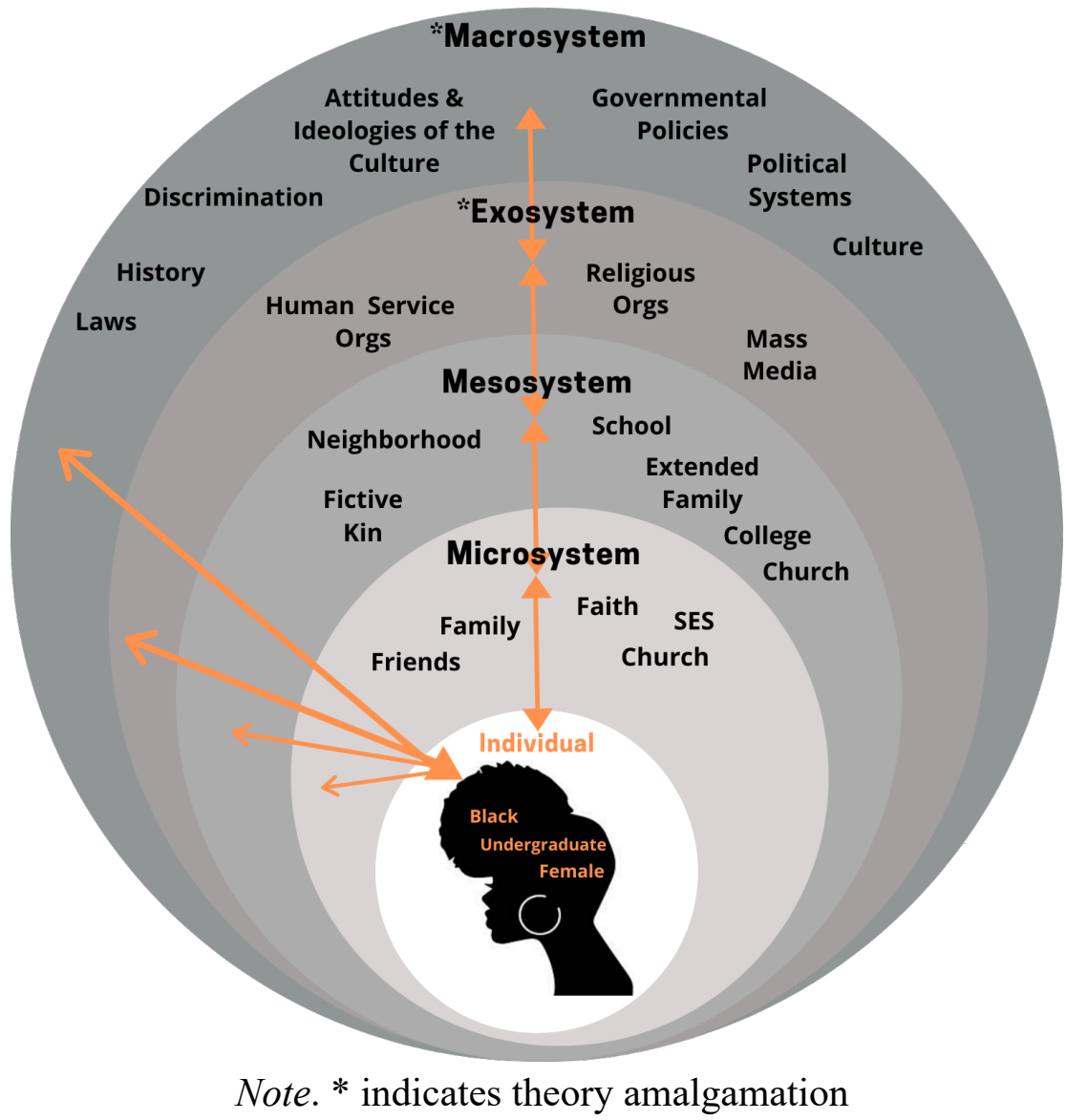

\section{Methodology}

The methodology employed in this qualitative research study is narrative inquiry.

Narrative inquiry is a qualitative method useful in capturing the individual experiences of a single person or a group of people and is a "way of characterizing the phenomena of human experience" (Connelly \& Clandinin, 1990). The use of narrative inquiry was most appropriate to answer the research question: How do African American female graduates describe their experience to and through a Predominately White Institution? Further, narrative inquiry allows 
for sense-making, interpretation, and meaning of ones' thoughts and actions (Merriam \& Tisdell, 2016). It best explores how one shares their stories.

Merriam and Tisdale (2016) further posit narrative inquiry allow the researcher to use a participant's first-person account and analyze it as data and shed light on the participant's life experiences. This methodology makes use of biographical, psychological, and linguistic analysis, which allows for in-depth constructions of the meaning of lived experiences. As Haynes (2013) explains it, narrative inquiry is "invisible to standard objective methodologies" (p. 108) as it emphasizes subjective accounts of one's experiences and allows participants to ascribe meaning and interpretation of their frustrations, setbacks, comebacks, and triumphs through their personal stories with their voices.

\section{Participants}

The research question guided the researcher's decision to use purposeful and snowball sampling for participant recruitment (Creswell, 2014; Merriam \& Tisdell, 2016; Ryan, Coughlan,

\& Cronin, 2007), as it was important to target the population lived experiences of persistence at a PWI. Purposive and snowball sampling provide the researcher with the opportunity to elicit indepth information from participants who are experiencing the subject matter (Merriam \& Tisdell, 2016). Miriam and Tisdell (2016) further share that, "Purposeful sampling is based on the assumption that the investigator wants to discover, understand, and gain insight and therefore must select a sample from which the most can be learned" (p. 96). Therefore, to gain more insight and more in-depth understanding of Black female persistence at a PWI, African Americans who identified as Black or African American and cisgender female were the primary participants of the study. 
In qualitative research, the number of participants or sample size is ambiguous and depend primarily on qualitative data saturation (Merriam \& Tisdell, 2016). The researcher interviewed 10 participants who met the following criteria: a) identified as African American or Black, b) identified as a cisgender female (gender identity corresponds with female sex assigned at birth), c) currently enrolled at MU as an undergraduate student, and d) have completed one year (at least 24 hours) of academic coursework (see Table 1). Recruitment began once IRB approval was received. Students who agreed to participate in the study were asked to recommend any other students who might be interested in the study.

\section{Table 1}

Description of Participants and Demographics

\begin{tabular}{llll}
\hline Participants & Class Level & Age & Degree Program \\
\hline Crystal & Senior & 21 & $\begin{array}{l}\text { Information } \\
\text { Technology }\end{array}$ \\
Amber & Sophomore & 19 & Journalism \\
Kendra & Junior & 21 & Health Sciences \\
Alonna & Senior & 22 & Health Sciences \\
Iris & Sophomore & 20 & Journalism \\
Kim & Junior & 23 & Social Work \\
Jasmine & Senior & 22 & Psychology \\
Nicole & Sophomore & 20 & Physics and Math \\
Tammy & Senior & 21 & Black Studies \\
Erica & Sophomore & 18 & Psychology \\
\hline
\end{tabular}

After solidifying the 10 participants for the study, each participant completed a survey that confirmed they met the criteria to participate, explained informed consent, the criteria to be eligible for the $\$ 50$ cash incentive and structure for each interview. After confirmation that each participant met the participation criteria, participants provided demographic information. 


\section{Data Collection}

The study took place at the University of Missouri-Columbia (MU). MU, established in 1839 , is a public predominantly White land grant university in the Midwest, located in a town with a population of 121,000 (U.S. Census Bureau, 2019). MU is centrally located between two urban cities, Kansas City, Mo and St. Louis, MO. Because of its location, MU now draws a large number of its Black student populations from these large urban areas. The total enrollment in fall of 2018 was 29,866 (University of Missouri, Student Body Profile, 2018). According to the MU student profile (2018), African American students constitute 7\% of the total student population, while $75 \%$ of enrolled students are White. Concerning enrollment by gender, women represent $54 \%$ of the demographic; and men account for $46 \%$ of the total enrolled population.

To collect data, the researcher interviewed 10 participants. Prior to the start of each interview, the researcher discussed informed consent and advised participants of the risks of participating in the study (Creswell, 2014; NASW, 2017; AERA, 2011). Further, the researcher used an interview protocol to conduct semi-structured, in-depth interviews as interviews allow participants to share the personal and objective meaning of their lived experiences (Creswell, 2013; Creswell, 2014; Merriam \& Tisdale, 2016). After interviewing the first participant, the researcher revised the interview protocol ensure participants' stories captured their ideas about programming needed to support their persistence. In qualitative research, evaluating and revising the protocol is not uncommon and is a mechanism to enhance validity of the tool and substantiate data. that supports the study. Under the duress of the COVID-19 pandemic, instead of face-toface interviews, each participant completed two 45-minute interviews using Zoom technology. Each interview was audio and video recorded, yielding approximately 720 hours of qualitative data, which add to the rigor and trustworthiness (Creswell, 2014; Hatch 2002) of this study. 


\section{Data Analysis}

According to Rapley (2004), qualitative data analysis is "always an ongoing process" (p. 26) that should follow each interview. After each interview the researcher transcribed the interviews. Transcribing interviews is essential to establish rigor (Merriam \& Tisdell, 2016; Starks \& Trinidad, 2007). Once transcribed, interviews were read twice. After reading the interview transcriptions the researcher was able to inductively process the meaning participants described during their interviews by utilizing axial and chunk coding (Creswell, 2014; Braun \& Clark, 2008; Merriam \& Tisdell, 2016). The researcher used Dedoose software to electronically code the transcriptions. After coding the interviews, the researcher identified three themes and created 10 subthemes according to each participant's narrative.

\section{Researcher Positionality and Ethical Considerations}

During this research, it was important to consider my own positionality and experiences, as my biases may have the potential to influence the analysis. As implored by Vagle (2018) it is critical for the researcher to bridle one's biases when interpreting the data as researcher bias can influence data analysis. Bridling is an ongoing process of observing, naming, and examining one's own judgements (Vagle, 2018). The use of bridling, as suggested by Vagel (2018) is to “become more familiar with one's judgements so they do not compromise one's openness to the phenomenon" (p. 14).

As a Black female and two-time graduate of MU, the researcher recognized the potential for bias and its impact on data analysis. Additionally, the researcher's experiences and journey to and through college had distinct similarities. However, knowing that projecting biases on to participants meaning of their journey yields great ethicality issues. The researcher remained cognizant of experiences as a Black female student who has navigated and persisted at this 
university. The researcher considered the data and bridled biases to render objective analysis of the narratives shared by participants of this study.

Another consideration of ethical concerns during data analysis was ensuring the validity of the study. To ensure internal validity and to establish trustworthiness, the researcher engaged in member-checking by soliciting feedback from participants about the accuracy of their interpretations in their individual transcripts (Creswell, 2014; Merriam \& Tisdell, 2016). Additionally, member-checking ensures that the researcher is limited to his own interpretations, lessening the chance for researcher subjectivity in data analysis.

\section{Findings from Participant Narratives}

Through their narratives, participants answered the research question: How do African American female undergraduates describe their journeys to and through a Predominately White Institution? The participants journeys were captured using three emerging themes: a) Fueled by Faith, Family, and Finances, b) Making Meaning of Memories, Messages, and Microaggressions, and c) Balancing Being Black and Bold. Each of the themes capture the essence of the participants stories. There were elements evident of each theme throughout all participant interviews. However, the researcher assigned themes that were prominent in the each of the individual's narrative about their journeys to and through a PWI. Although challenging to construct the themes, the researcher recognized through the interviews and analysis that quotes shared by participants were relevant to more than one theme. Within the themes it is also important to note that subthemes emerged as participants shared their childhood journey, their journey to college, and their journey through college (see Table 2). 


\section{Table 2}

Themes and Subthemes Table

\begin{tabular}{ll}
\hline Theme & Sub Themes \\
\hline $\begin{array}{l}\text { Theme One: Fueled by Family, Faith, } \\
\text { and Finances }\end{array}$ & $\begin{array}{l}\text { Family context, faith, and class as } \\
\text { influence }\end{array}$ \\
$\begin{array}{l}\text { Theme Two: Making Meaning of Memories, Mixed- } \\
\text { Messages, and Microaggressions }\end{array}$ & Vacillating between "two-selves" \\
Theme Three: Balancing Being Black and Bold & The impact of race and gender
\end{tabular}

\section{Theme One:}

\section{Fueled by Family, Faith, and Finances:}

The theme of childhood challenges was captured as these young women began describing their childhood. This theme puts into perspective the challenges they overcame in their childhood that eventually led them to the road of their academic journey toward attending a PWI. This theme ultimately captures the resilience and persistence of Black girls on their journeys toward college through their faith and family tragedies.

The journeys of four participants aligned with theme one (Family, Faith, and Finances) are directly related to the literature that family can either be a determinant or non-determinant of college attendance for a student (Stewart, et. al., 2017). The participants described the closeness of their families and their situational factors as motivation to attend and persist in college (Arana, Castaneda-Sound, Blanchard, \& Aguilar, 2011; Guiffrida \& Douthit, 2010). In their own stories, each participant explained the impact of family, family loss, and financial issues in their childhood as a basis for attending college. Two narratives indicate the loss of a parent. At young ages, Alonna and Kim experienced the loss a parent. After their losses, both participants found 
themselves intrinsically motivated for higher education. Alonna clearly described the loss of her father and the way in which her family context fueled her passion for college:

And so that was a big time period for me because once that happened [the death of her father] my stepdad became very mentally abusive toward me, my younger brother, and my mom. It was bad because my dad wasn't there anymore [he was killed]. And he knew if my dad was around, none of that would have been happening. So that occurred and it was getting really, really bad...the pure disrespect. I got everything out [of the house] and ended up taking antidepressants and started counting down my days until it was time for me to go to college.

Family context would also be proven to be a factor toward persistence as Kim shared a similar story of her childhood trauma and push toward higher education. She shared:

We lived in the city, which some of the city is kind of like impoverished...We moved around a lot. My mom had a lot of financial issues...And then when I was about 13 my mom passed away because she struggled with drug addiction.

Kim went on to share her experiences of living with other family members which made life emotionally and academically difficult. Not only was her socio-economic status a factor in her upbringing, but the traumatic experience of losing her mother to substance abuse was and is still emotionally difficult to understand. Academically she recalled being taunted in elementary and high school for not having the latest 'this and that." At that time, Kim didn't realize the impact poverty had on her academics. As she reflected during her interview, she was able to make meaning of her loss and the impact of poverty. She explained, "and you know, but now that I'm older, my experiences impact me in a positive way because it keeps me, it keeps me going, even now." She let her environmental circumstances fuel her passion for reading, which became her motivation through secondary school to become admitted to college.

Other narratives in this study also included references to how family relationships and family ties are what intrinsically motivated participants during childhood to attend college. Noting the difference in family interactions of other participants, Erica and Amber both came 
from middle-class families, which for them, were not determinants for college. In fact, Amber described her family as "bougie" and that her grandfather was a prominent principal and financial contributor to the education system in their town. She described her grandfather's status and relationship with him as the primary influence in her love for education, recalling, "I had no other choice but to go to college." Erica also explained her motivation for doing well in school during her childhood journey. Both of her parents had master's degrees, so her sentiments about persistence in childhood was that "it was not an option." Although socioeconomic status was not what lead her to seek higher education, she remembered her parents telling her she would have other challenges. Erica recalled her parents' words:

You know, like, you're going to have to work like a little harder than your White counterparts because they are not going to always see you. And so that was always going through my head, like having to work harder.

In other words, Erica was constantly be reminded in middle school and high school years that even though she identified with her White peers, she was still different—she was Black—she still had to prove herself.

Not only did these women mention family and finances as influences in their educational journey, Alonna and Erica also acknowledged their faith as being an intricate part of childhood. Sharing their connections to faith, both women conceptualized that it was faith that gave them strength to get through childhood and is what they use for coping as they continue to persist through college. Erica explained her faith in this manner:

That [faith] is really important to me because I don't want to lose that connection I have with my faith...I'm just like praying and asking God to make sure I have a sound mind and take all the anxieties away. So, it's [faith] helped me throughout college.

Erica's leverage of faith, family, and financial security during her college journey is an example of how Black females have experienced their journeys to and through college. 


\section{Theme Two}

\section{Making Meaning of Memories, Mixed-Messages, and Microaggressions}

This theme underscores the life journey of the participants and their journeys to college. The participants recalled their memories, mixed-messages, and microaggressions they received in relation to race and gender before entering college. Archer-Banks and Behar-Horenstein (2012) suggest one begins to become aware of his/her identity as early as grammar school and that it becomes more complicated during these times as African Americans cope with negative perceptions and stereotypes. Participants who described encounters of mixed-messages, memories, and microaggressions painted a vivid picture on how these factors influenced their persistence toward higher education.

Iris who attended Catholic institutions throughout grammar and secondary schools offered her memories of race and gendered experiences in high school.

I had a lot of troubles dealing with that [attending predominately White schools], especially because like some, unfortunately, like some White people don't understand some stuff that Black people go through. Sometimes it's like stereotyping is very difficult, especially at that age that we are still developing and growing up and maturing as a child. So that [attending predominantly White schools] was a little bit difficult.

Being the "outsider" was a sentiment contended with during this time. She recalled having to change "my whole persona" and code switch her language to "fit it." Although she felt grounded in the presence of her family, Iris struggled with her Blackness at school.

Like Iris, Jasmine and Kendra also faced microaggressions that challenged their identities. Both participants described being told they "talk White" and had to contend with this in and outside of the classroom. Participants explained the mixed messages and microaggressions that misrepresent who they are as Black and female. Jasmine recalled being in high school: 
Honestly, I felt like I didn't fit in with either [Black students or White students] side. Like, I was like, okay, so I'm not White, but I'm as smart as the White kids.

Not only did she encounter these circumstances in high school, but she also soon found out college was no different. Jasmine learned for the first time what it meant to code switch upon attending MU. As she reflected on her freshman year of college she stated, "I have to do that all the time. I feel like I kind of have to if I want to, I guess, be presented in a way to them [White people]." Kendra also recounted the emotional turmoil of vacillating between identities. Being "tired" is how she explained what it was like attending social events with White and Black peers, but, with time, "I learned how to like I guess be around different types of people, but be myself, instead of like flopping back and forth." For both participants, Jasmine was accepting that code switching and vacillating between being Black and White was exhausting while navigating predominantly White secondary schools. In addition to these mixed messages, participants encountered stereotypes of being loud, rude, and insensitive, which are stereotypes and perceptions of Black women that have been portrayed in the media and in a White patriarchal society (Wagner-Winkler, 2009)

\section{Theme Three: Balancing Being Black and Bold}

One cannot mention Black female persistence at a PWI without explicating what it means to be Black and female on campus. As previous themes outlined participant journeys to a PWI, the third theme highlights how participants detail their journeys through a PWI. Being a Black female undergraduate persisting at a PWI warrants retelling the stories of these women in a way that illuminates the impact of race and gender during their experience at a PWI.

The participants in this theme discussed several factors as it relates to the mental and psycho/emotional grit it takes to navigate the institution through the lens of race and gender. Nicole, a stem major, recalled being the only Black in her major and explained that White 
students did not acknowledged her. She supposed it was because she is "Black and female." Afterall, she was "just as smart as her White counterparts in STEM." Other participants shared their experiences of being invisible in the classroom and on campus in general.

Crystal shared her sentiments of being Black and female in her Information and Technology classes. She noted:

I've noticed being the only female because it was only like one other female. And it is frustrating because I'm mainly the only Black woman in all my classes, if not the only Black person. And like they kind of don't acknowledge me. I might be on a row [sitting in class] with all White boys and they would just kind of ignore me. And I felt like I had to prove myself for them to talk to me. But when they needed help, they heard me all of a sudden.

Crystal was not only aware of the invisibility encountered, but also that her voice was silenced and the lack of emotional support she sought on campus was limited. As she was sharing her sentiments of being supported on campus she stated, “there aren't many spaces for Black women. I feel like us as a Black community like we've gotten better at just creating spaces for ourselves." Even when trying to create spaces of their own, Nicole often felt isolated from other Black women and men on campus. She remembers:

I don't know how to like to explain it in like a very direct way. But I do feel like the Black student body, if you're not in, you're out. But I don't know what makes you in. But they definitely know what makes you out. So, I don't know what I've done to be excluded. Excluding me, it's just, it's very clear. You know, like, okay, you're not like this group at all.

As perplexing as this might have been for Nicole, for Tammy issues of race and gender was not uncommon. As she navigated campus she noticed that spaces she thought would be inclusive were not. When asked about spaces she feels less comfortable in, she despondently disclosed she feels a sense of disconnection with the Women's Center. In a place where the title suggests a space for all women she shared: 
...it's the environment and like the mood. And also, like it's just like a bunch of White women. And you would think like okay, like oh we [we are] women, like we're all women right? Some of them [staff or students] in there are like stereotypical White feminists who really don't care about women. Like they just care about White women. Like a lot of them occupy that space. And a lot of them don't like to talk about any other intersecting identities between your womanhood.

Bothered by the constant acts of racism and discrimination as a Black female she recognized the marginalization that Black women encountered on campus, especially the stereotype of the "angry Black woman." Tammy spoke of reasons Black women should be angry. She expressed, "I believe this stereotype to be true in a sense because Black women should be angry. Like we have to be angry. . . like we need to be angry because if we're not, we're overlooked." Tammy shared her frustration when she has had opportunities to convey the needs of Black students in groups, organizations, and administration settings:

Like, here are my grievances laid out. This is the plan of action. This is what you need to do. This is what the administration needs to do. These are the policies that need to change. And I'm angry about it because this is not my job to do this. This is your [administration] job.

Throughout the study all participants shared their needs and frustrations as they navigate the institution. All of the women throughout their time at this institution voiced the impact race and gender had on their mental health and sought counseling at some point in their college journey. Counseling proved to be ineffective as participants expressed there were no counselor of color to connect with and they felt uncomfortable talking about race and gendered related experiences on campus, thus leaving them vulnerable. Participants collectively shared that Black women work hard to prove they are smart, encounter the negative effect of discrimination and continue to persist in the face of these barriers. Tammy stated, “...we don't have a choice but to keep going. Like dropping out, not graduating, that is not an option.” The women in the study all 
mentioned that persistence, being successful, and graduating is not about them personally. But it is about being an example for future Black women who will attend a PWI.

\section{Discussion}

This study sought to answer the research question: How do Black female undergraduates describe their journey to and through a Predominantly White Institution? In this section, the researcher will review the major themes and their connections to the research question, the theoretical concepts that undergird this study, and the implications for practice. Lastly, the researcher will end with concluding thoughts and implications for future research.

Although some connections in the findings were made to literature this discussion will center the frameworks, Crenshaw's intersectionality and Bronfenbrenner's ecological system, within the context of the participants' narratives to inform administrators and practitioners of the experiences and needs of Black female undergraduates.

\section{Intersectionality}

Crenshaw's (1991) intersectionality theory critically explores the identities of women of color and posits one must view their intersecting marginalized identities of race, gender, class and sexual orientation to have a holistic view of Black female experiences in relation to systems of power and oppression, while simultaneously highlighting the resilience of Black women in light of systematic tensions. The participants in the present study occupy at least three of these marginalized statuses_-being Black, female, and low-income. Although the criteria for the present study included a call for cisgender females, all participants identified as heterosexual. Therefore, an analysis of being a sexual minority could not be made within the context of the theories. Crenshaw (1991) further postulates, “ Through an awareness of intersectionality, we can better acknowledge and ground the differences among us and negotiate a means by which 
these differences will find expressions" (p. 378). Failure to acknowledge the experiences of both race and gender of Black women fragments their experiences and lives. The experiences of the ten participants in the present study cannot merely be described within just a racial context. One cannot deny the oppressive gendered experiences these women endured during their journeys to and through a PWI.

Participants shared their perspectives of race and gendered microaggressions and discrimination beginning in grammar school. This relates to Harrison's study (2017) on the barriers of race and gender and gender identity in early adolescence. Beginning in early childhood Black females contend with stereotypes and microaggression of both Black and White counterparts, as they began to navigate the psychological challenge of "double-consciousness"looking at oneself through the eyes of White society and adjusting ones behavior toward "acting White" or Black in either environment to assimilate or be accepted (Du Bois, 1994). Of all participants, nine shared stories of having to code switch or change the way they "talked" to fit in with White peers.

Stereotypes such as being loud, rude, and insensitive are rooted in the perceptions others have of Black women as they are portrayed in the media and in society which directly aligns with Crenshaw's (1991) representational intersectionality—women are discriminated against based on media and societal views. Participants' experiences also aligned with political and structural intersectionality. Tammy's experiences of being involved in meetings with administrators and vocalizing her disdain about policy and that administrators "give people breadcrumbs and expect them to make banana bread out of it" is an example of political intersectionality (Crenshaw, 1991) and Bronfenbrenner's (1979) macrosystem level interactions, in that some political entities may work to marginalize issues that Black women face. Two 
participants recognized the impact of structural intersectionality as they articulated their thoughts about the Women's Center. Tammy explained the center as only targeting "White stereotypical women" and not caring about the intersectionality of Black women, thus creating an unwelcoming environment. Furthermore, the targeted acts (directly or indirectly) of others towards these women presented additional emotional and academic barriers. Some participants acknowledged being a direct target of racial and gendered discrimination, which caused academic and emotional distress during matriculation in college.

The intersection between race and gender is, as Crenshaw (1991) shares, a culprit of harm that can inhibit or complicate Black women's persistence. If one identifies race and gender as salient factors of discrimination, it is expedient to pontificate the importance of discrimination and oppression toward Black women from low-socioeconomic backgrounds. Black undergraduate females who choose to attend college are more likely than White students to come from lower socioeconomic (SES) backgrounds (Guiffrida, 2006; Perna, 2000; Smith, 2008). Unfortunately, low SES status is a precollege factor that impacts persistence for Black students. Three participants in the present study self-identified with a low-income background. While explaining their needs, participants recalled blatant discrimination and microaggressions attacking their intelligence and belonging at the institution. While being raised in a low-income home is not a sole predictor of Black females' college going behavior or persistence, low SES status contributes to the complexity of experiences as they persist a disadvantage for psychological and emotional distress at PWIs.

Intersectionality (Crenshaw, 1991) sheds light and is helpful for administrators, faculty, and practitioners to understand not only the trauma Black female undergraduates bring from their 
childhood, but the multiplicative harm done to Black female undergraduates at their institutions because of their marginalized identities.

It is fair, in my opinion to not only offer the utility of intersectionality because intersectionality does have its limitations. Intersectionality offers a broad perspective of oppression. And, while the purpose of this study was to acknowledge multiple oppressive identities of Black undergraduate females, intersectionality does not definitively identify which one of the identities causes the most harm (Byrd, 2016).

\section{Ecological Systems}

As mentioned earlier, ecological systems theory is widely used in the social sciences (e.g., social work, psychology, counseling) field to investigate and organize the interactions of an individual's experiences with social systems and how these interactions influence one's development and behavior from infancy to adulthood (Bronfenbrenner, 1979; Peirson, Boydell, Ferguson, \& Ferris, 2011). Further, ecological systems theory offers an anti-deficit focus of environmental factors related to the persistence of African American female students (Orrock \& Clark, 2018), and focuses on a holistic perspective of one's experiences, challenges, and triumphs. The ecological systems model captures the experiences and transactions that participants of the study encountered as they shared their journeys to and through a PWI.

Where Crenshaw's (1991) intersectionality theory offers a broader scope of societal acts of oppression, Bronfenbrenner's (1979) ecological systems model categorizes the individual's transactions, experiences, and relationships within the contexts of their environment. To categorize an individual's interactions with the environment, Bronfenbrenner (1979) uses four levels of inquiry. First, the microsystem is the smallest system and consists of face-to-face interactions an individual has with a system such as friends, family, and other interpersonal 
relationships individuals directly engage. All the participants expressed they were in some way directly impacted by family, classmates, and colleagues as they described their journeys to and through college. Because ecological systems is a model that studies the transactions of the individual, it is important to note that participants shared their individual reactions and contributions to those within their microsystems. All ten participants shared that their motivations for success meant being an example and giving back to other Black and Brown girls to ensure their persistence to graduation.

Secondly the mesosystem involves the experiences an individual has with systems outside of the home, such as the community, work, school, group settings, or church (Bronfenbrenner, 1979). Three of the participants were from low-income homes which present financial barriers toward persistence. These participants were not directly involved nor caused financial implication of their persistence. Nonetheless these participants experienced financial barriers. Participants also shared the influence of church as contributing factor toward persistence. Next, the exosystem identifies an individual's indirect interactions with social structures that may influence one's development and behavior. Those social structures may include the mass media, social service organizations, friends of family, or neighborhood. Participants transactions at the exosystem varied. Kim experienced living in "the hood" with lack of educational resources and the need to attend obtain higher education to defy the odds of her living her adult life in the same manner. While Erica lived in a suburban neighborhood with access to unlimited educational resources, Erica's intrinsic motivation was not same. Her motivation was to continue the educational legacy of her parents. Although both participants differed in their exosystem transactions, they were motivated to attend and persist in college. 
The fourth and final system, the macrosystem, involves experiences or messages received from religious, laws, political, and economic structures (Bronfenbrenner, 1979). It is at the macrosystem in which Crenshaw's (1991) intersectionality theory intersect, further illuminating the experiences of racial, gendered, class discrimination during childhood and beyond. All of the participants discussed microaggressions in the classroom in elementary, secondary, and postsecondary institutions, especially discrimination while attending college. Participants highlighted the absence of targeted programs and services specifically for Black females, leaving them continually vulnerable on campus and society.

Understanding the utility of ecological and intersectionality theories in tandem will aid administrators, faculty and practitioners in understanding the overall journeys of Black females who are enrolled at PWIs. Understanding the barriers Black females experience at the margins of race, gender, and class before they enter the institution and during matriculation could assist in the development of targeted services and programming that support Black female persistence.

To support the persistence of Black females on campus, educators, administrators, and practitioners have to be willing to hear their narratives to employ the three A's: Acknowledge their experiences, address their needs, and assist in their journeys.

\section{Limitations}

Like any qualitative study, this research presented some limitations. The first limitation relates to recruitment of the study. The study encouraged participation of Black cisgender females who also identified as LGBTQ. All participants in the present study identified as heterosexual. Therefore, narratives are void of the voices of sexual minorities-another factor of persistence for Black females which needs to be studied in future research. Recruitment was also affected due to the onset of the COVID-19. The pandemic's arrival occurred at the beginning of 
the recruitment process. Although recruitment emails went out to the intended targets and organizations, I was limited in who participated in the study. At the onset of the pandemic, not all students had adequate internet or internet access for participating in the interviews via Zoom, which limited participant responses and participation.

Additionally, zoom presented limitations in that some students appeared guarded in their responses. For instance, as one participant described the relationship with her mother, she was interrupted by her mother's presence in the room she chose to conduct the interview. As the interview moved forward, there were times when the participant whispered because her mother was in a room nearby. Holding interviews in person and in a private location could have strengthened the participant's narrative and the connection between me and the participant. Connelly \& Clandinin (1991) suggest interviews should be a collaborative process between the researcher and the participant over time. In this case, Zoom, coupled with the pandemic limited my face-to-face time with participants. I also would like to note that during the time of the interviews, some participants were experiencing "zoom fatigue," as campus classes had transitioned to remote learning and participants spent their entire days attending class via zoom. Zoom fatigue may have limited the response of the participants, thus, eliminating some portions of their stories as they might have become weary during the interview.

Finally, interview transcripts were sent to each participant with instructions to review their transcript for inaccuracies in interpretation. Of the ten transcripts sent to participants, only one participant responded with corrections in interpretation. More feedback from participants would have helped address any misinterpretation in their narratives. Otherwise, it is the assumption of the researcher that all accounts of participant narratives are accurate. 


\section{Implications for Practice in Higher Education}

Participants' voices irradiate the contextual environmental experiences that contribute to African American females' journey to and through a PWI. The poignant words of the participants provide plausibility and support to Crenshaw's intersectionality theory and Bronfenbrenner's ecological systems model to be the most appropriate model by which to study their persistence. Further, their words illuminate the programming, support, and services needed for a in inclusive campus to foster success and at a PWI. Essential to this research was the ongoing “mesearch” (Douglas, 2016) I personally conducted. Douglas' (2016) work on Bermudian Male experience explains "mesearch" as the constant research of ones' personal identity, experiences, and world view before, during, and after research of phenomenon. As a licensed clinical social worker, administrator, and practitioner at the institution, I understand the nature of assessment and how critical it is to inform planning interventions. As a Black female who grew up in a low-income neighborhood, experiencing family trauma, attending inadequately supported public schools, and little to no college support on campus while struggling successfully, I know that without a holistic perspective and assessment of a person and their environment, administration cannot adequately plan for their success. Experiences of Black female undergraduates must be validated when making intentional plans to support them.

Keeping assessment of Black females' experiences in the forefront, there were several implications for practice. Administrators, faculty, and staff should be educated on the needs of Black females through the vehicle of their voices. The Black female participants in this study indicate the need for targeted services exclusively for their well-being. Data in this study affirm the resilience and grit Black females inhabit. Their experiences range from being trauma survivors, homelessness, poverty, and discrimination to being on the path to graduation from a 
Research-I institution. Black women are persisting in White institutions with limited financial, social, and emotional support of the university system. The sentiments of participants should be considered in how they would like to be supported. Issues of racial and gendered discrimination are stark and constant reminders of the work to be done to create a welcoming and supportive campus environment that support these women's presence and persistence.

Classrooms are especially harsh toward the presence of Black women. The blatant disrespect, microaggressions, and invisibility felt by Black females on campus are hardly bearable. These narratives offer valuable lessons that may well elicit inclusive practices and pedagogical changes for faculty in the classroom. In addition to feeling marginalized in classroom spaces, participants shared similar experiences when accessing campus recognized organizations and centers. Tammy in particular described a center on campus that is designed to support all women. But she contends the organization does not honor the intersectional identities of Black women. Consequently, she and one other participate have an aversion for that space and create their own counter-spaces and organizations to meet their social needs without financial contribution from the university, leaving them feeling alienated and detached. With limited directed services and financial support, Black female undergraduates are struggling successfully. Crenshaw (1991) asserts, “...women of color occupy positions both physically and culturally marginalized within dominant society, and so information must be targeted directly to them in order to reach them. (p. 1250).

The present study serves as a starting point to identify the needs and pre-college contexts of Black females persisting at a PWI. The insights of the participants explicate the urgent need for intervention of stakeholders on campus. Administrators, faculty, and staff are urged to take a more culturally responsive and trauma-informed approach to supporting and meeting the diverse 
needs of these students. To become a culturally responsive and trauma informed institution, the institution must recognize the socio-environmental context of Black females and the way in which this population has experienced trauma. Upon understanding the context of their experiences, the institution, through a trauma-informed lens, can move from an attitude of "What's wrong with this individual?" to "What happened to this person?" When the question changes, administrators and practitioners gain more awareness of the academic, social, and mental health needs for these women. The institution can then respond with policies that support and sustain Black female persistence, faculty and staff trauma trainings, and targeted financial commitment to programming and mental health services. In this way, the institution moves from understanding to action to create systemic change to support Black female resilience and persistence.

\section{Implications for Research}

This study presents several implications for future research in supporting the myriad needs for African American female undergraduates. The study highlights the experiences, personalities, character, and journeys of Black female undergraduate students as they journey to and through a PWI. As they near graduation and seem to outwardly display resilience, their environmental experiences vastly differ than what is seen with the naked eye. The lived internal struggles of Black women should remain a focus of study. The utilization of intersectionality and ecological systems theory (Bronfenbrenner, 1979; Crenshaw, 1991) are appropriate frameworks by which to understand the multiple marginalized, interlocking identities, and systemic experiences Black women are afforded long before college and while existing on a patriarchal dominated campuses. 
Scholars should examine the nuanced stories of mental health and its psychological impact on persistence. Leadership should be aware of the level of trauma and mental health needs students bring with them and accumulate while on campus. Additional research would contribute to the Black female persistence phenomenon and affirm the need for access to mental health services which would lessen the harm and distress Black undergraduate females experience across campus.

In addition, further research could explore how Black female undergraduates employ faith as a factor of resilience and add to the body of literature that situates their coping and resilience to and through a PWI, despite barriers. Finally, as a result of the present study, future research could explore the journeys of Black female undergraduates who identify as a sexual minority (LGBTQ) and their experiences of persistence at a PWI. Despite the rise of the LGBTQ population in educational institutions, their voices are largely neglected in the literature as is in the case of the present study. Examining these additional factors may further explain the journeys of African American females and their needs while matriculating at a PWI.

\section{Conclusion}

This research focused on the factors that impede or promote persistence for ten African American women who are enrolled at a PWI. Through their narratives, the participants provided insight to the lived, contextual, and environmental factors of their lives, beginning from childhood. Participants described their homes, neighborhoods, schools, discrimination, and faith journey, in voices of resilience as they narrated the realities of their lives for others to understand. The findings suggest the myriad of needs each of them bring to the intuition and acquire along their college journey. This research is a clarion call for action by PWI administrators, faculty, and staff to intentionally build, support, and sustain educational 
environments that address the multiplicative oppressed identities of Black women. Moreover, consideration must be given to each individual story of persistence to target services, spaces, and programming that further enhance Black female experiences on campus. The women in this study embody its title: Winning When the Odds are Against You. To decrease the odds of Black female persistence at PWIs, administrators have to acknowledge their experiences, address their needs, and assist in their journeys. 


\section{Journal References}

AERA. (2011). Code of ethics: American Educational Research Association. Educational Research, 40(3), 145-156. doi:10.3102/0013189X11410403

Arana, R., Castaneda-Sound, C., Blanchard, S., \& Aguilar, T. (2011). Indicators of persistence for Hispanic undergraduate achievement: Toward an ecological approach. Journal of Hispanic Higher Education, 10(3), 237-251.

Archer-Banks, D. A. M., \& Behar-Horenstein, L. S. (2012). Ogbu revisited: Unpacking highachieving African American girls' high school experiences. Urban Education, 47(1), 198-233. doi: 101.1177/0042085911427739

Bronfenbrenner, U. (1979). The ecology of human development: Experiments by design and nature. Cambridge, MA: Harvard University Press.

Braun, V., \& Clarke, V. (2008). Using thematic analysis in psychology. Qualitative Research in Psychology, 3(2), 77-101.

Byrd, J. A. (2016). Low-income high-ability Black female students' perceptions of experiences that have influenced their college readiness: A qualitative analysis (Doctoral dissertation). Retrieved from https://ir.uiowa.edu/etd/2188

Caldwell, L. D., \& Stewart B. J. (2001). Rethinking w. e. b. dubois' “double consciousness”: Implications for retention and self-preservation in the academy. In L. Jones (Ed.), Retaining African Americans in higher education: Challenging paradigms for retaining students, faculty \& administrators (pp. 225-234). Sterling, VA: Stylus.

Casey, K. (1993). I answer with my life. New York: Routledge.

Casey, K. (1995). The new narrative research in education. Review of Research in Education, 21, 211-253. Retrieved from www.jstor.org/stable/1167282 
Cook, D. A, \& Williams, T. (2015). Expanding Intersectionality: Fictive kinship networks as support for the educational aspirations of Black women. The Western Journal of Black Studies, 39(2), 157-166.

Commodore, F., Baker, D. J., \& Arroyo, A. T. (2018). Black women college students: A guide to student success in higher education. New York, NY: Routledge.

Connelly, F. M., \& Clandinin, D. J. (1990). Stories of experience and narrative inquiry. Educational Research, 19(5), 2-14.

Crenshaw, K. (1991). Mapping the margins: Intersectionality, identity politics, and violence against women of color. Stanford Law Review, 43(6), 1241-1299.

Creswell, C. W. (2013). Qualitative inquiry and research design: Choosing among five approaches. (3rd ed.). Thousand Oaks, CA: SAGE.

Diemer, M. A., \& Li, C.-H. (2012). Longitudinal roles of precollege contexts in low-income youths' postsecondary persistence. Developmental Psychology, 48(6), 1686-1693. doi: $10.1037 / \mathrm{a} 0025347$

Douglas, T.M. O. (2016). Border crossing brothas: Black males navigating race, place, and complex space. New York, NY: Peter Lang Publishing.

Du Bois, W. E. B. (1994). The souls of Black folk. Avenel, NJ: Grammercy.

Guiffrida, D. A. (2006). Preparing and supporting African American college students. In G. R. Walz, J. C. Bleuer \& R. K. Yep (Eds.), VISTAS Online, 21, 29-102. Retrieved from https://www.counseling.org/docs/default-source/vistas/preparing-and-supporting-africanamerican-college-students.pdf?sfvrsn $=4 d d d 7 e 2 c \_10$ 
Guiffrida, D. A., \& Douthit, K. Z. (2010). The Black student experiences at predominantly White colleges: Implications for school and college counselors. Journal of Counseling \& Development, 88, 311-318.

Harper, Shaun. (2009). Niggers no more: A critical race counter-narrative on Black male student achievement at predominantly White universities and colleges. International Journal of Qualitative Studies in Education, 2(6), 697-712.

Harrison, L. (2017). Redefining intersectionality theory through the lens of African American young adolescent girls' racialized experiences. Youth and Society, 49(8), 1023-1039. doi:10.1177/0044118X15569216

Hatch, J. A. (2002). Doing qualitative research in education settings. Albany: SUNY Press.

Henry, W. J., Richards, E. M., \& Fuerth, K. M. (2011). Black and gay in college. College Student Affairs Journal, 30(1), 63-74.

Hones, D. F. (1997). Known in part: Transforming the story, the teller, and the narrative researcher. Qualitative Inquiry, 4, 225-248.

Janak, E. (2018). Bracketing and bridling: Using narrative reflexivity to confront research bias and the impact of social identity in a historical study. Philanthropy \& Education, 1(2), 82-93.

Johnson, M. J., \& Reynolds, A. L. (2018). Factors influencing academic success among African American college women: The impact of African American acculturation and religiosity. Journal of Black Psychology, 44(5), 403-421). doi: 10.1177/0095798418777400.

Merriam, S., \& Tisdell, W. (2016). Qualitative research: A guide to design and implementation. San Francisco, CA: Jossey-Bass. 
Miles, S. Jones, T. B. Clemons, K. M., \& Golay, P. (2011). 'Bein' alive \& Bein' a woman \& Bein' colored is a metaphysical dilemma": Black female social integrations at a predominantly White institution. In C. R. Chambers (Ed.), Support systems and services for diverse populations: Considering the intersection of race, gender, and the needs of Black female undergraduates, (pp. 107-129). Bingley, UK: Emerald.

Mitchall, A. M., \& Jaegar A. J. (2018). Parental influences on low-income, first-generation students' motivation on the path to college. Journal of Higher Education, 89(4), 582609. doi: 10.1080/00221546.2018.1437664

National Association of Social Workers. (2017). NASW Code of Ethics. Retrieved from https://www.socialworkers.org/About/Ethics/Code-of-Ethics/Code-of-Ethics-English

Orrock, J., \& Clark, M. A. (2018). Using systems theory to promote academic success for African American males. Urban Education, 53(8), 1013-1042.

Patton, L. D., \& Croom, N. N. (2017). Critical perspectives on undergraduate Black women. In L. D. Patton \& N. N. Croom (Eds.), Critical perspectives on Black women and college success (pp. 1-13). New York, NY: Routledge.

Peirson, L. J., Boydell, K. M., Ferguson, H. B., \& Ferris, L. E. (2011). An ecological process model of systems change. American Journal of Community Psychology, 47, 307-321. doi: $10.1007 / \mathrm{s} 10464-010-9405-\mathrm{y}$

Perna, L. W. (2000). Differences in the decision to attend college among African Americans, Hispanics, and Whites. Journal of Higher Education, 71(2), 117-141.

Smith, M. J. (2008). College choice process of first generation Black female students: Encouraged to what end? Negro Educational Review, 59(3-4), 147-161. 
Stewart, E. B., Stewart, E. A., \& Simons, R. L. (2007). The effect of neighborhood context on the college aspirations of African American adolescents. American Education Research Journal, 44(4), 896-919. doi: 10.3102/0002831207308637.

Stutey, D, M., Givens, J., Cureton, J. L., \& Henderson, A. J. (2020). The practice of bridling: Maintaining openness in phenomenological research. Journal of Humanistic Counseling, 59(2), 144-156. Doi: 10.1002/johc. 12135

University of Missouri. (2018). Student body profile 2018. Retrieved from: https://enrollment.missouri.edu

U.S. Census Bureau. (2019). Quick facts columbia city, mo, united states. Retrieved from https://www.census.gov/quickfacts/fact/table/columbiacitymissouri/PST045218

U.S. Department of Education (2019). Degrees conferred by race and sex. Retrieved from: https://nces.ed.gov/fastfacts/

Vagle, M. D., Hughes, H. E., \& Durbin, D. J. (2009). Remaining skeptical: Bridling for and with one another. Field Methods, 21, 347-367.

Vagle, M. D. (2009). Validity as intended: 'Bursting forth toward' bridling in phenomenological research. International Journal of Qualitative Studies in Education, 22, 585-605.

Vagle, M. D. (2018). Crafting phenomenological research, second edition. Taylor and Francis. doi.org/10.4324/9781315173474

Watt, S. K. (2003). Come to the river: Using spirituality to cope, resist, and develop identity. New Directions for Student Services, 104, 29-40.

Winkle-Wagner, R. (2009). The unchosen me: Race, gender, and identity among Black women in college. Baltimore, MD: John Hopkins University Press. 
SECTION SIX:

SCHOLARLY PRACTITIONER REFLECTION 
As I reflect on this journey, I am reminded of the words of a friend, "Keep going faithfully in the right direction and you will build traction." Traction is movement toward progress. Traction has landed me here to write reflections of my dissertation process. The dissertation journey has challenged me in many ways. And it has been transformational for me personally, academically, and professionally.

Personally, I have developed a keen sense of awareness of my abilities. The psychological distress and presence of imposter syndrome manifested during phases of the dissertation process. Self-reflection has been the most valuable part of this process. Reflection of my successes and accomplishments invalidate the fallacy of imposter syndrome that surfaced during this process. Reflecting on my life and the strength of its circumstances is what lead me to my dissertation topic. Further, acknowledging my skills and strengths inventories during the program served as reassurance of my suitability to not only be in the program, but also to persist. As an academic, I was pushed to learn and expel knowledge - to apply wisdom in my research and in the dissemination of research (Macgregor \& Fellabaum, 2016). Finally, as a professional, my leadership capacity has been expanded. This growth spurt increased my capability to lead with theory to affect organizational change.

\section{Influence of Dissertation on my Practice as an Educational Leader}

Leadership, as defined by Northouse (2013), is a process whereby an individual influences a group of individuals to achieve a common goal" (p. 5). During this process, I have developed my leadership in several ways. I now explore and use caution when analyzing data to drive decision making, especially in the areas of recruitment and retention in my current position. I understand the importance of considering qualitative and quantitative data to draw inferences and make decisions that lead to best practices. 
Beginning this study at the onset of the novel Coronavirus (COVID-19) challenged my patience. I doubted my ability to finish, asking myself, "will this research come to fruition at such an unprecedented time?" The weariness of the pandemic coupled with the surmounting pressure to complete my dissertation was a times overwhelming. As my mother taught me as a child, patience is a virtue. Not only did I learn this as a child, but I have also learned that patience is a leadership trait, either innate or one that emerges over time (Northouse, 2013). Patience with myself, with the dissertation process, and the will to complete what I started was apparent as I navigated uncharted territory with research, the uncertainty of COVID-19, and its impact on the country. Patience, process, and persistence are vital in leading and affecting change in organizations (Bolman \& Gallos, 2011). I have come to realize that patience is key in affecting change in how the institution supports Black female undergraduates. However, patience with inaction (persistence) is ineffective. It is my hope that this research study is used as a tool to interrupt the cycle of oppression Black female undergraduates experience on campus—-for process is an active response that "balances advocacy with inquiry" (Coghlan \& Brydon-Miller, 2014, p. 4).

I have grown in leadership knowing that advocating for change will present challenges for which I am equipped to endure until change ensues (Bolman \& Gallos, 2011). As an advocate for change, I continue my commitment to solving problems of practice within the organization and the community in which I serve.

\section{Influence of Dissertation on my Practice as a Scholar}

There were many things I discovered about myself as a scholar during this process. As I interviewed partitipants in this study, I realized, I too experienced the same barriers that would pose themselves as imposter syndrome. There were points in this process where I questioned my 
scholarly abilities — am I good enough, am I scholarly enough. I find significance in this finding because I am cognizant that no matter what stage of educational attainment or status, Black women are predisposed to adversity. And, overtime through determination and tenacity, we are able to transcend barriers and persevere in what we are called to do.

In reflection of my work in this process I have developed and accomplished several things — defying my own expectations:

1. I have amalgamated two valid theories and fostered a conceptual model that has not been utilized to evaluate persistence of Black undergraduate women.

2. I have utilized my ethical consciousness for systematic inquiry to investigate Black female persistence.

3. I have experienced using qualitative software to analyze and interpret data and make institutional recommendations for practice.

Surpassing my doubts and pushing back fear, this process has sharpended my competence as a scholarly practitioner. Furthermore, I have learned to be confident as a steward of practice - to engage in research to create change, using practical wisdom, and incorporating theory (MacGregor \& Fellabaum, 2016; Perry, 2016). Engaging and completing this dissertation is just the beginning of my work as a scholarly practitioner. I am looking forward to my scholarly practice for years to come.

\section{Conclusion}

As a scholar I believe it is my duty to continue to address the inequities that arise in the educational system. Walking the path of least resistance is not an option. It is not an option for me to observe social injustice at this institution and stand idle waiting for change to happen. I have an obligation to change the culture. The ELPA program has helped me to understand that 
organizational leadership and my role as a scholarly practitioner is not merely about having a degree. Rather, it is taking discrepancies of injustice within the institution and using my agency and understanding of systematic inquiry to solve such problems and affect organizational change. 


\section{References}

Adkisson, T. (2015, November 9). Concerned student 1950 lays out goals for post tim wolfemizzou. KBIA. Retrieved from https://www.kbia.org/post/concerned-student-1950-laysout-goals-post-wolfe-mizzou\#stream/0

AERA. (2011). Code of ethics: American Educational Research Association. Educational Research, 40(3), 145-156. doi:10.3102/0013189X11410403

Anderson, J. D. (1988). The education of Blacks in the south, 1860-1935. Chapel Hill, NC: The University of North Carolina Press.

Arana, R., Castaneda-Sound, C., Blanchard, S., \& Aguilar, T. (2011). Indicators of persistence for Hispanic undergraduate achievement: Toward an ecological approach. Journal of Hispanic Higher Education, 10(3), 237-251.

Archer-Banks, D. A. M., \& Behar-Horenstein, L. S. (2012). Ogbu revisited: Unpacking highachieving African American girls' high school experiences. Urban Education, 47(1), 198-233. doi: 101.1177/0042085911427739

Baber, L. L. (2012). A qualitative inquiry on the multidimensional racial development among first-year African American college students attending a predominately White institution. Journal of Negro Education, 81(1), 67-81.

Bluford, L. H. (1939, October 6). [Letter of Appeal to University of Missouri Officials]. University of Missouri Graduate School Records, 1911-1967, The State Historical Society of Missouri, Manuscript Collection-Columbia (C3354). Retrieve from https://historicmissourians.shsmo.org/historicmissourians/name/b/bluford/\#section3

Bolman, L. G., \& Deal, L. G. (2010). Reframing the path to school leadership: A guide for teachers and principals. (2nd ed). Thousand Oaks, CA: Corwin. 
Bolman, L. G., \& Deal T. E. (2013). Reframing organizations: artistry, choice, and leadership (5th ed.). San Francisco, CA: Jossey-Bass.

Bolman, L. G. and Gallos, J. V. (2011). Reframing academic leadership. San Francisco, CA: Jossey-Bass.

Booker, K. (2016). Connection and commitment: How sense of belonging and classroom community influence degree persistence for African American women. International Journal of Teaching and Learning in Higher Education, 28(2), 218-229.

Braun, V., \& Clarke, V. (2008). Using thematic analysis in psychology. Qualitative Research in Psychology, 3(2), 77-101.

Bridges, S. K., Selvidge, M. M. D., \& Matthews, C. R. (2003). Lesbian women of color: Therapeutic issues and challenges. Multicultural Counseling and Development, 31, 113130.

Bright, L. K., Malinsky, D., \& Thompson, M. (2016). Causally interpreting intersectionality theory. Philosophy of Science, 83(1), 60-81.

Bronfenbrenner, U. (1979). The ecology of human development: Experiments by design and nature. Cambridge, MA: Harvard University Press.

Brown-Collins, A., \& Sussewell, D. (1986). The Afro American woman's emerging selves. Journal of Black Psychology, 13, 1-11.

Bruce, D. D. (1992). W.e.b dubois and the idea of double consciousness. American Literature 64(2), 299-309.

Byrd, J. A. (2016). Low-income high-ability Black female students' perceptions of experiences that have influenced their college readiness: A qualitative analysis (Doctoral dissertation). Retrieved from https://ir.uiowa.edu/etd/2188 
Caldwell, L. D., \& Stewart B. J. (2001). Rethinking w. e. b. dubois' “double consciousness”: Implications for retention and self-preservation in the academy. In L. Jones (Ed.), Retaining African Americans in higher education: Challenging paradigms for retaining students, faculty \& administrators (pp. 225-234). Sterling, VA: Stylus.

Carter, R. T. (1995). The influence of race and racial identity in psychotherapy: Toward a racially inclusive model. New York, NY: Wiley.

Carastathis, A. (2014). The concept of intersectionality in feminist theory. Philosophy Compass, $9(5), 303-314$.

Cary, R. L. (2018). "What am I going to be losing?”: School culture and the family-based college-going dilemmas of Black and Latino adolescent boys. Education and Urban Society, 50(3), 246-273. doi:10.1177/0013124517713112

Casey, K. (1993). I answer with my life. New York: Routledge.

Casey, K. (1995). The new narrative research in education. Review of Research in Education, 21, 211-253. Retrieved from www.jstor.org/stable/1167282

Coghlan, D., \& Brydon-Miller, M. (2014). The SAGE encyclopedia of action research (Vols. 12). London: SAGE. doi: 10.4135/9781446294406

Commodore, F., Baker, D. J., \& Arroyo, A. T. (2018). Black women college students: A guide to student success in higher education. New York, NY: Routledge.

Connelly, F. M., \& Clandinin, D. J. (1990). Stories of experience and narrative inquiry. Educational Research, 19(5), 2-14.

Cooper, J. N., Porter, C. J., \& Davis, T. J. (2017). Success through community cultural wealth: Reflections from Black female college athletes at a historically Black college/university 
(HBCU) and a historically White institution (HWI). Journal of Intercollegiate Sport, 10(2), 129-156.

Crenshaw, K. (1991). Mapping the margins: Intersectionality, identity politics, and violence against women of color. Stanford Law Review, 43(6), 1241-1299.

Crenshaw, K. W. (1991). Demarginalizing the intersection of race and sex: A Black feminist critique of antidiscrimination doctrine, feminist theory and antiracist politics. Stanford Law Review, 43(6), 1241-1300.

Creswell, C. W. (2013). Qualitative inquiry and research design: Choosing among five approaches. (3rd ed.). Thousand Oaks, CA: SAGE.

Creswell, J. W. (2014). Research design: Qualitative, quantitative, and mixed methods approaches. Thousand Oaks, CA: SAGE.

Dache, A., Quaye, S. J., Linder, C., \& McGuire, K. M. (2019). Rise up!: Activism as education. East Lansing, MI: Michigan State University Press.

Diemer, M. A., \& Li, C.-H. (2012). Longitudinal roles of precollege contexts in low-income youths' postsecondary persistence. Developmental Psychology, 48(6), 1686-1693. doi: $10.1037 / \mathrm{a} 0025347$

Donavan, R. A., \& Guillory, N. A. (2017). Black women's college experience: Influence of sociostructural stressors. In L. D. Patton \& N. N. Croom (Eds.), Critical perspectives on Black women and college success (pp. 188-199). New York, NY: Routledge.

Douglas, T. M. O. (2012). Border crossing brothas: A study of Black bermudian masculinity, success, and the role of community-based pedagogical Spaces. (Doctoral Dissertation). Retrieved from https://libres.uncg.edu/ir/uncg/f/Douglas_uncg_0154D_10918.pdf 
Douglas, T.M. O. (2016). Border crossing brothas : Black males navigating race, place, and complex space. New York, NY: Peter Lang Publishing.

Douglas, T. M. O., \& Peck, C. M. (2013). Education by any means necessary: An historical exploration of community-based pedagogical spaces for peoples of African descent. Educational Studies, 49(1), 67-91.

Douglas, T. M. O., \& Shockley, K. G. (2017). Truths, triumphs, and testaments of hope when campus and community voices rise. Journal of Negro Education, 86(3), 199-203.

Douglas, T. M. O. \& Witherspoon-Arnold, N. (2016). Exposure in and out of school: A Black Bermudian male's successful educational journey. Teachers College Record. 118(6): 136.

Du Bois, W. E. B. (1994). The souls of Black folk. Avenel, NJ: Grammercy.

Evans, S. Y. (2016). Black women in the ivory tower: 1850-1954 An intellectual history. University Press of Florida. https://ebookcentral.proquest.com/lib/umcolumbiaebooks/detail.action?docID $=4747754$.

Garvey, J. C., Squire, D. D., Stachler, B., \& Rankin, S. (2018). The impact of campus climate on queer-spectrum student academic success, Journal of LGBT Youth, 12(2), 1-17. http://doi.org/10.1080/19361653.2018.1429978

Gildford, T. T., \& Reynolds, A. (2011). "My mother's keeper”: The effects of parentification on black female college students. Journal of Black Psychology, 37(1), 55-77. doi: $10.1177 / 0095798410372624$

Gill, S. J. (2010). Developing a learning culture in nonprofit organizations. Los Angeles, CA: Sage. 
Glover, S. T. (2017). “Black Lesbians—-Who will fight for our lives but us?”: Navigating power, belonging, labor, resistance, and graduate student survival in the ivory tower. Feminist Teacher, 27(2-3), 157-175.

Goldin, C., Katz, L. F., \& Kuziemko, I. (2006). The homecoming of American college women: The reversal of the college gender gap. Journal of Economic Perspectives, 20(4), 133156.

Guiffrida, D. A. (2006). Preparing and supporting African American college students. In G. R. Walz, J. C. Bleuer \& R. K. Yep (Eds.), VISTAS Online, 21, 29-102. Retrieved from https://www.counseling.org/docs/default-source/vistas/preparing-and-supporting-africanamerican-college-students.pdf? sfvrsn $=4 \mathrm{ddd} 7 \mathrm{e} 2 \mathrm{c} \_10$

Guiffrida, D. A., \& Douthit, K. Z. (2010). The Black student experiences at predominantly White colleges: Implications for school and college counselors. Journal of Counseling \& Development, 88, 311-318.

Guyton, C. W., \& McGasky, F. (2012). Sending an sos: How social support networks contribute to the success of Black lesbians at predominantly White institutions. In C. R. Chambers \& R. V. Sharpe (Eds.), Black female undergraduates on campus: Successes and challenges in diversity in higher education, (Vol. 12, pp. 135-157). Bingley, UK: Emerald. Retrieved from http://ebookcentral.proquest.com

Hannon, C. R., Woodside, M., Pollard, B. L., \& Roman, J. (2016). The meaning of African American college women's experiences attending a predominantly White institution: A phenomenological study. Journal of College Student Development, 57(6), 652-666. 
Harper, Shaun. (2009). Niggers no more: A critical race counter-narrative on Black male student achievement at predominantly White universities and colleges. International Journal of Qualitative Studies in Education, 2(6), 697-712.

Harrison, L. (2017). Redefining intersectionality theory through the lens of African American young adolescent girls' racialized experiences. Youth and Society, 49(8), 1023-1039. doi:10.1177/0044118X15569216

Hatch, J. A. (2002). Doing qualitative research in education settings. Albany: SUNY Press.

Haynes, C. S. (2013). Tightrope walkers: Narratives of academically successful AfricanAmerican women attending predominantly White institutions. (Doctoral dissertation). Retrieved from http:// ttp://rave.ohiolink.edu/etdc/view?acc_num=osu1366996649

Henry, W. J., Richards, E. M., \& Fuerth, K. M. (2011). Black and gay in college. College Student Affairs Journal, 30(1), 63-74.

Henry, W. J., West, N. M., \& Jackson, A. (2010). Hip-hop's influence on the identity development of Black female college students: A literature review. Journal of College Student Development, 51, 237-251. doi:10.1353/csd.0.0135

Hollis, A. (2019). University activism and the central role of Black womyn. In A. Dache, S. J. Quaye, C. Linder, \& K. M. McGuire (Eds.), Rise up!: Activism as education (pp. 147155). East Lansing, MI: Michigan State University Press.

Hones, D. F. (1997). Known in part: Transforming the story, the teller, and the narrative researcher. Qualitative Inquiry, 4, 225-248.

Hooper, L. M., Wallace, S. A., Doehler, K., \& Dantzler, J. (2012). Parentification, ethnic identity, and psychological health in Black and White American college students: 
Implications of family-of-origin and cultural factors. Journal of Comparative Family Studies, 43(6), 811-835.

Howard-Hamilton, M. F. (2003). Theoretical frameworks for African American women. Meeting the Needs of African American Women, 104, 19-27. doi.org/10.1002/ss.104

Hughes, R. L., \& Howard-Hamilton, M. F. (2003). Insights: Emphasizing issues that affect African American women. New Directions for Student Services, 104, 95-103.

Janak, E. (2018). Bracketing and bridling: Using narrative reflexivity to confront research bias and the impact of social identity in a historical study. Philanthropy \& Education, 1(2), 82-93.

Johnson, A.G. (2018). Privilege, power and difference ( $6^{\text {th }}$ ed). New York, NY: McGraw-Hill Education.

Johnson, J. M. (2017). Choosing elites: Experiences of working-class Black undergraduate women at an ivy league university. In L. D. Patton \& N. N. Croom (Eds.), Critical perspectives on Black women and college success (pp. 158-169). New York, NY: Routledge.

Jones, C., \& Shorter-Gooden, K. (2003). Shifting: The double lives of Black women in America. New York, NY: HarperCollins.

Kotter, J. P. (2011). What leaders really do. In HBR's 10 must reads on leadership (pp. 36-55). Boston, MA: Harvard Business Review Press.

Kezar, A., Fries-Britt, S., Kurban, E., McGuire, D., \& Wheaton, M. M. (2018). Speaking truth and acting with integrity: Confronting challenges of campus racial climate. Washington, DC: American Council on Education. Retrieved from https://www.acenet.edu/Documents/Speaking-Truth-and-Acting-with-Integrity.pdf 
Leonard, J. (2011). Using Bronfenbrenner's ecological model theory to understand community partnerships: A historical case study of one urban high school. Urban Education, 46(5), 987-1010. doi: $10.1177 / 0042085911400337$

Lett, D. F., \& Wright, J. V. (2003). Psychological barriers associated with matriculation of African American students in predominantly White institutions. Journal of Instructional Psychology, 30(3), 189-196.

Lewis, C. W., \& Moore, J. L., III. (2008). Urban public schools for African American students: Critical issues for educational stakeholders. Educational Foundations, 22(1/2), 3-9.

Levi, D. (2017). Group dynamics for teams (5th ed.). Los Angeles, CA: Sage.

Lige, Q. M., Peteet, B. J., \& Brown, C. M. (2017). Racial identity, self-esteem, and the impostor phenomenon among African American college students. Journal of Black Psychology, 43(4), 345.

MacGregor, C. J. \& Fellabaum, J. (2016). Dissertation redesign for scholarly practitioners in educational leadership: Increasing impact through dissemination-ready sections. In V. Storey \& K. Hesbol (Eds.), Contemporary approaches to dissertation development and research methods, (pp. 53-69). Hershey, PA: Information Science Reference.

Manning, K. (2013). Organizational theory in higher education. New York, NY: Routledge.

Mattis, J., Grayman, N., Cowie, S., Winston, C., Watson, C., \& Jackson, D. (2008). Intersectional identities and the politics of altruistic care in a low-income, urban community. Sex Roles, 59(5-6), 418-428. doi:10.1007/s11199-008-9426-2

Martin, B. L. (1991). From Negro to Black to African American: The power of names and naming. Political Science Quarterly, 106(1), 83-84. 
Merriam, S., \& Tisdell, W. (2016). Qualitative research: A guide to design and implementation. San Francisco, CA: Jossey-Bass.

Middlebush, F. A. (1950, September 12). University of Missouri, Admission of Blacks, Papers, 1950-1953. [Letter to All Members of the University Staff: Columbia and Rolla] African American Experience in Missouri (http://digital.shsmo.org/cdm/compoundobject/collection/aaem/id/219/rec/44) The State Historical Society of Missouri.

Mihelic, K., Lipicnik, B., \& Tekavcic, M. (2010). Ethical leadership. International Journal of Management \& Information Systems, 14(5), 31-41.

Miles, S. Jones, T. B. Clemons, K. M., \& Golay, P. (2011). 'Bein' alive \& Bein' a woman \& Bein' colored is a metaphysical dilemma": Black female social integrations at a predominantly White institution. In C. R. Chambers (Ed.), Support systems and services for diverse populations: Considering the intersection of race, gender, and the needs of Black female undergraduates, (pp. 107-129). Bingley, UK: Emerald.

Minztberg, H. (2005). The five basic parts of the organization. In Y.S. Jang, J. S. Ott, \& J. M. Shafritz (Eds.), Classics of organizational theory (6th ed.), (pp. 219-230). Belmont, CA: Wadsworth. (Reprinted from The structure of organizations: A synthesis of research, pp. 18-34, 1979, Upper Saddle River, NJ: Prentice Hall)

Mitchall, A. M., \& Jaegar A. J. (2018). Parental influences on low-income, first-generation students' motivation on the path to college. Journal of Higher Education, 89(4), 582609. doi: $10.1080 / 00221546.2018 .1437664$

Moen, T. (2006). Reflections on narrative research. International Journal of Qualitative Methods, 5(4), 56-69. 
Morris, E. W. (2007). “Ladies or "loudies"? Perceptions and experiences of Black girls in classrooms. Youth \& Society, 38(4), 490-515.

Munoz-Plaza, C., Quinn, S. C., \& Rounds, K. A. (2002). Lesbian, gay, bisexual, and transgender students: Perceive social support in the high school environment. The High School Journal, 85(4), 52-63.

National Association of Social Workers. (2017). NASW Code of Ethics. Retrieved from https://www.socialworkers.org/About/Ethics/Code-of-Ethics/Code-of-Ethics-English

National Association of Student Personnel Administrators. (2019). Submission guidelines. Retrieved from https://www.naspa.org/journals/journal-of-student-affairs-research-andpractice

Orrock, J., \& Clark, M. A. (2018). Using systems theory to promote academic success for African American males. Urban Education, 53(8), 1013-1042.

Ozaki, C. C. \& Renn, K. A. (2015). Engaging multiracial college students. In S. Quaye \& S. Harper (Eds.), Student Engagement in Higher Education: Theoretical Perspectives and Approaches for Diverse Populations (2nd ed, pp. 92-104). New York, NY: Routledge.

Patton, L. D., Crenshaw, K., Haynes, C., \& Watson, T.N. (2016). Why we can’t wait: (Re)Examining the opportunities and challenges for Black women and girls in education. The Journal of Negro Education, 85(3), 194-198.

Patton, L. D., \& Croom, N. N. (2017). Critical perspectives on undergraduate Black women. In L. D. Patton \& N. N. Croom (Eds.), Critical perspectives on Black women and college success (pp. 1-13). New York, NY: Routledge.

Patton, L. D., \& Simmons, S. L. (2008). Exploring complexities of multiple identities of lesbians in a Black college environment. Negro Educational Review, 59(3-4), 197-215. 
Peirson, L. J., Boydell, K. M., Ferguson, H. B., \& Ferris, L. E. (2011). An ecological process model of systems change. American Journal of Community Psychology, 47, 307-321. doi: $10.1007 /$ s10464-010-9405-y

Perna, L. W. (2000). Differences in the decision to attend college among African Americans, Hispanics, and Whites. Journal of Higher Education, 71(2), 117-141.

Perry, J. A. (2016). The scholarly practitioner as a steward of the practice. In V. Storey \& K. Hesbol (Eds.), Contemporary approaches to dissertation development and research methods, (pp. 300-312). Hershey, PA: Information Science Reference.

Phelps-Ward, R. R., Allen, C., \& Howard, J. L. (2017). A rhetorical analysis of Beyoncé's "freedom": An examination of Black college women's experiences at predominately White institutions. Taboo: The Journal of Culture \& Education, 16(2), 50-64.

Porter, C. J. (2017). Articulation of identity in Back undergraduate women: Influences, interactions, and intersections. In L. D. Patton \& N. N. Croom (Eds.), Critical perspectives on Black women and college success (pp. 88-100. New York, NY: Routledge.

Rapley, T. (2004). Interviews. In C. Seale, G. Gobo, J. F. Gubrium, \& D. Silverman (Eds.), Qualitative research practice. London, United Kingdom: Sage.

Reid, J. M., \& Moore, J. L. III (2008). College readiness and academic preparation for postsecondary education: Oral histories of first-generation urban college students. Urban Education, 43(2), 240-261.

Renn, K. (2003). Understanding the identities of mixed-race college students development through a developmental ecology lens. Journal of College Student Development, 44(3), 383-403. 
Ricks, S. A. (2014). Falling through the cracks: Black girls and education. Interdisciplinary Journal of Teaching and Learning, 4(1), 10-21.

Robertson, R. V., Mitri, A, \& Delinder, J V. (2005). The social adjustment of African American females at a predominantly White mid-western university. Journal of African American Studies, 8(4), 31-45.

Robertson, R. V., \& Mason, D. (2008). What works? A qualitative examination of the factors related to the academic success of African American males at a predominantly White college in the south. Challenge, 14(2), 67-89.

Robinson, S., \& Franklin, V. (2011). Working against the odds: The undergraduate support needs of African American women. In C. R. Chambers (Ed.), Support systems and services for diverse populations: Considering the intersection of race, gender, and the needs of Black female undergraduate (pp. 21-41). Bingley, UK: Emerald.

Rosales, A. M., \& Person, D. R. (2003). Programming needs and student services for African American women. New Directions for Student Services, 104, 53-65.

Ryan, F., Coughlan, M., \& Cronin, P. (2007). Step-by-step guide to critiquing research. Part 2: Qualitative research. British Journal of Nursing, 16(12), 738-744.

Shaw, M. D. (2017). Supporting students who struggle successfully. In C. R. Chambers (Ed.), Support systems and services for diverse populations: Considering the intersection of race, gender, and the needs of Black female undergraduate (pp.200-212). Bingley, UK: Emerald.

Shorter-Gooden, K., \& Washington, N. C. (1996). Young, Black, and female: The challenge of weaving an identity. Journal of Adolescence, 19, 465-475. doi:10.1006/jado.1996 
Shujaa, M. J. (1994). Education and schooling: You can have one without the other. In M.J. Shujaa (Ed.), Too much schooling, too little education: A paradox of Black life in White societies (pp. 13-36). Trenton, NJ: African World Press, Inc.

Schultz, J. R. (2010). The scholar-practitioner: A philosophy of leadership. Scholar-Practitioner Quarterly, 4(1), 52-64.

Simmons, L. D. (2013). Factors of persistence for African American men in a student support organization. The Journal of Negro Education, 82(1), 62-74.

Sims, G. A. (2008). Irrelation as a social construct for African American college women on a predominantly White campus. College Student Journal, 42(2), 691-702.

Smith, L. C., Shin, R. Q., \& Officer, L. M. (2012). Moving counseling forward on lgb and transgender issues: Speaking queerly on discourses and microaggressions. The Counseling Psychologist, 40(3), 385-408. doi: 10/1177/0011000011403165

Smith, M. J. (2008). College choice process of first generation Black female students: Encouraged to what end? Negro Educational Review, 59(3-4), 147-161.

Starks, H., \& Trinidad, S. B. (2007). Choose your method: A comparison of phenomenology, discourse analysis, and grounded theory. Qualitative Health Research, 17(10), 13721380.

Stewart, D. L. (2017). A counternarrative of Black women in predominantly White liberal arts colleges, 1945-1965. In L. D. Patton \& N. N. Croom (Eds.), Critical perspectives on Black women and college success (pp. 31-43). New York, NY: Routledge.

Stewart, D. L. (2008). Being all of me: Black students negotiating multiple identities. Journal of Higher Education, 79, 185-207. doi: 10.1353/jhe.2008.007 
Stewart, E. B., Stewart, E. A., \& Simons, R. L. (2007). The effect of neighborhood context on the college aspirations of African American adolescents. American Education Research Journal, 44(4), 896-919. doi: 10.3102/0002831207308637.

Strayhorn, T. L. (2017). Using intersectionality in student affairs research. New Directions for Student Services, 157, 57-67. doi.org/10.1002/ss.20209

Stutey, D, M., Givens, J., Cureton, J. L., \& Henderson, A. J. (2020). The practice of bridling: Maintaining openness in phenomenological research. Journal of Humanistic Counseling, 59(2), 144-156. Doi: 10.1002/johc. 12135

Thomas, J. C.; Wolters, C. Horn, C., \& Kennedy, H. (2014). Examining relevant influences on the persistence of African-American college students at a diverse urban university. Journal of College Student Retention, 15(4), 551-573.

Thompson, V. G., \& Jackson, J. A. (2007). The education of African American girls and women. The Journal of Negro Education, 76(3), 357-372.

Toldson, I. A. (2020). The author's reflections on no b.s. (bad stats): Black people need people who believe in Black people enough not to believe every bad thing they hear about Black people. Numeracy 13(1), 1-6. doi: https://doi.org/10.5038/1936-4660.13.1.6

Tracy, S. J. (2010). Qualitative quality: Eight "big-tent" criteria for excellent qualitative research. Qualitative Inquiry, 16(10), 837-851. doi:10.1177/107780041083121

Tuitt, F. (2010). Enhancing visibility in graduate education: Black women's perceptions of inclusive pedagogical practices. International Journal of Teaching and Learning in Higher Education, 22(3), 246-257.

Trachtenberg, B. L. (2018). The 2015 university of Missouri protests and their lessons for higher education policy and administration. Kentucky Law Journal, (107), 61-121. 
United States Census Bureau. (2017). QuickFacts. Retrieved from

https://www.census.gov/quickfacts/fact/table/columbiacitymissouri/PST045217\#PST045 217

University of Missouri (2019). Registrar: Important facts. Retrieved from http://catalog.missouri.edu/aboutmu/importantfacts/

University of Missouri (2019). Inclusion, Diversity, and Equity: 2016 Campus climate survey. Retrieved from https://diversity.missouri.edu/our-work/campus-climate-survey/2016campus-climate-survey/

University of Missouri. (2018). Enrollment management \& strategic development. Retrieved from

https://musis2.missouri.edu/enrollment_sum_report/enrollment_summary_fs2018.cfm University of Missouri. (2018). Student body profile 2018. Retrieved from: https://enrollment.missouri.edu

University of Missouri. (2018). Institutional research \& quality improvement. Retrieved from: https://irqi.missouri.edu/enrollment-data/

U.S. Census Bureau. (2019). Quick facts columbia city, mo, united states. Retrieved from https://www.census.gov/quickfacts/fact/table/columbiacitymissouri/PST045218

U.S. Department of Education (2019). Degrees conferred by race and sex. Retrieved from: https://nces.ed.gov/fastfacts/

Vagle, M. D. (2018). Crafting phenomenological research, second edition. Taylor and Francis. doi.org/10.4324/9781315173474 
Vega, D., Moore, J. L. III, \& Miranda, A. H. (2015). In their own words: Perceived barriers to achievement by African American and Latino high school students. American Secondary Education, 43(3), 36-59.

Warde, B. (2008). Staying the course: Narratives of African-American males who have completed a baccalaureate degree. Journal of African American Studies, 12, 59-72. doi: $10.1007 / \mathrm{s} 12111-007-9031-4$

The White House. (2015). My brother's keeper. Retrieved from https://obamawhitehouse.archives.gov/my-brothers-keeper

Williams, J. L., \& Nichols, T. M. (2012). Black women's experiences with racial microaggressions in college: Making meaning at the crossroads of race and gender. In $\mathrm{C}$. R. Chambers \& R. V. Sharpe (Eds.), Black female undergraduates on campus: Successes and challenges in diversity in higher education, (Vol. 12, pp. 75-95). Bingley, UK:

Emerald. Retrieved from https://doi.org/10.1108/S1479-3644(2012)0000012007

Winkle-Wagner, R. (2015). Having their lives narrowed down? The state of Black women's college success. Review of Educational Research, 85(2), 171-204.

Winkle-Wagner, R. (2009). The unchosen me: Race, gender, and identity among Black women in college. Baltimore, MD: John Hopkins University Press.

Winkle-Wagner, R., Kelly, B. T., Luedke, C. L., \& Reavis, T. B. (2019). Authentically me: Examining expectations that are placed upon Black women in college. American Educational Research Journal, 56(2), 407-443.

Zamani, E. (2003). African American women in higher education. New Directions for Student Services, 104, 5-18.

Vagle, M. D., Hughes, H. E., \& Durbin, D. J. (2009). Remaining skeptical: Bridling for and 
with one another. Field Methods, 21, 347-367.

Vagle, M. D. (2009). Validity as intended: 'Bursting forth toward' bridling in phenomenological research. International Journal of Qualitative Studies in Education, 22, 585-605.

Vagle, M. D. (2018). Crafting phenomenological research, second edition. Taylor and Francis. doi.org/10.4324/9781315173474 
APPENDICES 


\section{Appendix A}

Participant Recruitment Letter

Hello!

My name is Christine Woods and I am a doctoral student in the Educational Leadership and Policy Analysis program at the University of Missouri-Columbia. I am conducting a research study on the persistence of African American female undergraduate students who are enrolled at a Predominantly White Institution (PWI). The study will investigate how African American female students describe their journeys to and through college. The intent of this study is to allow faculty, administrators, and practitioners to hear and understand the stories of persistence of Black undergraduate females to enhance policy and programming to meet their needs.

I am seeking participants for this study. I would like to interview participants who meet the following criteria:

- Identify as African American or Black,

- Identify as a cisgender female (gender corresponds to female sex assigned at birth),

- Currently enrolled at MU as an undergraduate student, and

- Have completed one year (at least 24 hours) of academic coursework.

Your participation will include the completion of a brief demographic survey and 2 (two) 45minute individual interviews via Zoom. Interviews will be scheduled at a date and time convenient for you.

Your participation in this study is completely voluntary. Information that you share is confidential. In return for your time and effort, you will receive a $\$ 50$ incentive upon completion of both interviews.

If you are interested in this study and meet the criteria for participation, please contact me, Christine Woods, at woodscm@missouri.edu and we will schedule a time to meet.

\section{IRB \#2021503}

Sincerely,

Christine Woods

Doctoral Candidate

University of Missouri-Columbia 
Appendix B

Initial Response Email

\section{Hello $[\mathrm{XXXXX]}$,}

My name is Christine Woods and I am a doctoral student here on MU's campus. Thank you for your interest in participating in my research study, "African American Female Undergraduate Persistence at a Predominantly White University." This study is in partial fulfillment of my Doctor of Education degree in Educational Leadership and Policy Analysis at the University of Missouri-Columbia.

To be eligible to participate in the study you must: a) identify as African American or Black, b) identify as a cisgender female (gender identity corresponds to female sex assigned at birth), c) be currently enrolled at MU as an undergraduate student, and d) have completed one year (at least 24 hours) of academic coursework.

If you meet the stated criteria, I would like to schedule a time to proceed with an approximate 45-minute interview with you. Please complete the doodle poll at

https://doodle.com/poll/fkxr3ps2w6srvgku_to select a day and time that you are available over the next two weeks to participate in the interview.

Upon hearing from you, I will send a letter of confirmation with the date, time, and Zoom link we will use for the interview. The confirmation will also include a link to review the informed consent and a brief demographic survey to complete before the date of the initial interview. In return for your time and effort, you will receive a $\$ 50$ incentive upon completion of both interviews.

Your participation is greatly appreciated!

Please let me know if you have any questions or concerns. I look forward to hearing from you. I may be contacted at 573-777-9311 or via email at woodscm@missouri.edu.

Thank you,

Christine Woods

Doctoral Candidate

University of Missouri-Columbia 


\author{
Appendix C \\ Interview Confirmation Email
}

\title{
Hello $[\mathrm{XXXXXX]}$
}

Thank you for following up! The details of the interview can be found below. Please review the informed consent and brief demographic survey before our interview. The survey will take approximately 4 minutes to complete.

The informed consent and survey can be accessed by clicking: XXXXXXXXXX.

Interview Details:

Dates:

Time:

Zoom Link: $\quad$ (calendar invites to follow)

I will send a reminder email the day before the interview. If you have any questions or concerns before then, please do not hesitate to contact me. I would like to remind you that your participation is completely voluntary and that you may withdraw at any time. Information you share is confidential and will not be shared with anyone.

In return for your time and effort, you will receive a $\$ 50$ cash incentive upon completion of both interviews. Compensation will be distributed through an electronic payment platform such as Cashapp, Apple Pay, or Paypal.

Your participation is greatly appreciated!

Sincerely,

Christine Woods

Doctoral Candidate

University of Missouri-Columbia 


\section{Appendix D}

\section{Informed Consent and Demographic Survey}

The research study will investigate African American Female Persistence at a Predominantly White Institution (PWI) and how African American female undergraduates describe their journeys to and through a PWI. The intent of this study is to allow faculty, administrators, and practitioners to hear and understand the stories of persistence of Black female undergraduates to enhance policy and programming to meet their needs.

For this research study, you will complete one demographic survey and two interviews. In return for your time and effort, you will receive a $\$ 50$ cash incentive upon completion of both interviews. Compensation will be distributed through an electronic payment platform such as Cashapp, Apple Pay, or Paypal.

Below, you will be presented with a list of demographic questions in which you will answer. Please be assured that you responses will be kept completely confidential and only known to the researcher. To ensure minimal risk to you, your individual responses nor identity will be revealed as a pseudonym will be assigned to you.

The survey should take around 4 minutes to complete. Your participation is voluntary. You have the right to withdraw at any point during the study, for any reason, and without prejudice. If you choose to terminate your participation, any information or documentation you have disclosed will be destroyed. Should you have any questions about this survey, please contact the principal investigator, Christine Woods, at woodscm@missouri.edu.

By clicking below, you acknowledge:

- Your participation in this survey is voluntary.

- You are aware that you may choose to terminate your participation at any time and for any reason.

By clicking below, you also acknowledge that you meet the following criteria to participate:

a) I identify as African American or Black,

b) I identify as a cisgender female (gender identity corresponds to female sex at birth),

c) I am currently enrolled at the (MU) as an undergraduate student, and

d) I have completed one year (at least 24 hours) of academic coursework.

I consent, begin the survey

I do not consent, I do not wish to complete the survey

1. Please provide your contact information below. 

a. First and Last Name
b. Email address
c. Contact number

2. Please select the payment platform you prefer to receive your compensation and provide either your CashApp handle, Apple Pay cell number, or PayPal email or phone number.
a. CashApp
b. Apple Pay
c. PayPal

3. I am currently enrolled at MU as an undergraduate student.
a. Yes
b. No

4. Year in college: (Please check the option that applies to you.)

Freshman Sophomore Junior Senior

5. Tell me your age:

6. What is your major:

7. Gender Identity: (Cisgender refers to one who identifies with the sex assigned at birth.)

Cisgender Female or woman

Cisgender Male or man

Transgender female or woman

Transgender male or man

Gender non-conforming or genderqueer

Prefer not to answer

Choose to self-describe:

8. Sexual orientation (Please check all that apply to you) 
Heterosexual

Lesbian

Gay

Bisexual ___ (Choose to self-describe)

9. How do you describe your racial identity? (Please check all that apply)

African American or Black

White or Caucasian or European American

American Indian or Alaska Native

Asian or Asian American

Hispanic or Latina or Latino

Multiracial or Biracial

Prefer not to answer

Choose to self-identify:

10. City and State where you grew up:

11. Racial composition of your high school: (Please check all that apply to you)

Predominantly Black

Predominantly White

Racially Mixed

Other (Please describe)

12. Racial composition of your high school: (Please check all that apply to you)

Predominantly Black

Predominantly White

Racially Mixed

Other (Please describe)

13. Mother's educational background: (Please check all that applies to your mother)

Unknown

Did not complete high school

High School Diploma

Bachelor's Degree

Master's Degree

Doctorate Degree 
14. Father's educational level: (Please put a check all that applies to your father.)

Unknown

Did not complete high school

High School Diploma

Bachelor's Degree

Master's Degree

Doctorate Degree

15. Please describe your family's socioeconomic status:

Low-income

_ Middle class

Upper class

Unknown (explain)

16. What I your current employment status: (Please check all that apply to you)

Unemployed ___ Work Study ___ Part-time ___ Full-time 
Appendix E

Interview Protocol

Interview Date:

Interview Time:

Location of Interview:

Interviewee:

Pseudonym:

Thank you for agreeing to participate in this study. The purpose of this study is to hear and understand the journeys of Black female undergraduate students enrolled at a Predominantly White Institution.

As you are aware from the recruitment letter, this research study is completely voluntary and you may decide to withdraw from the study at any time, without any personal consequences to you. If you choose to terminate your participation, any information or documentation you have disclosed will be destroyed.

To ensure confidentiality, your individual responses and identity will only be known to the researcher. To ensure minimal risk to you, no individual names or identities will be revealed. Pseudonyms will be used instead.

In return for your time and effort, you will receive a $\$ 50$ cash incentive upon completion of both interviews. Compensation will be distributed through an electronic payment platform such as Cashapp, Apple Pay, or Paypal.

Do you have any questions before we begin the interview? Are you comfortable with me recording our interview?

Let's begin.

I would like to start the interview by talking a little about your journey before college and then move into your college experiences.

\section{Demographic Info:}

Can you tell me your background: Name, race and gender you identify as, and where you grew up? 


\section{Journey from Childhood}

1. Tell me the story of your life.

2. Tell me about the environment you grew up in.

3. How would you describe yourself?

4. What does being Black and female mean to you?

5. What messages did you receive from your family about college?

6. How did your family, schools, and community help prepare you for you journey to college?

a. Were they any other services your family received? (church, state services).

\section{Journey to and through College}

7. Tell me about your journey to this institution?

8. What factors lead you to select this institution?

9. What does being Black and female at this institution mean to you?

10. Have there been times when you have experienced an unwelcoming climate or discrimination while attending this institution? Can you describe this experience?

11. Can you describe a positive experience that you ascribe to being Black and female?

12. As a Black female, what stereotypes are you aware of and do they exist on campus? Do these represent who you are? Why or why not?

\section{Institutional Support Through College}

13. Would you agree that Black females have unique challenges while attending a PWI? Please explain.

14. Tell me about a challenge you have had on campus as a Black female in the classroom. How did you handle it?

15. What spaces on campus are most comfortable to you? Why?

16. What spaces on campus are least comfortable to you? Why?

17. When things get hard or when you experience challenges, what motivates or inspires you to keep going?

a. What makes you resilient? 
18. Would you agree that experiences of Black female students can be emotionally distressful? If yes, how have you emotionally dealt with that?

19. What support do you believe the institution provides for American female experiences in college?

20. What type of support would you like to see the institution offer to African American females?

a. Do you feel as though having more Black professors would have helped with your journey?

21. How has your college experience shaped your perceptions being Black and female at a predominantly White institution?

22. The title of this study suggests that Black women are winning against barriers in college. What does winning or being successful in college mean to you?

23. Is there anything you would like to share that I did not ask about your journey?

Closing: Thank you for your time and participation in this interview. If at any time, you would like to change anything about the way you have answered these questions, please feel free to contact me. 
Appendix F

Thank you and Interview Transcript

\section{Dear XXXXX}

Thank you for participating in my study "African American Female Persistence at a Predominantly White University." It was a pleasure speaking with you and hearing your incredible journey to and through college.

I have attached a copy of your interview transcription. Please review for the purposes of accuracy. If there are any inaccuracies or anything else you would to add, please do not hesitate to contact me if. If I do not hear from you within the next week, I will assume that the transcript is accurate and that there are no changes to be made.

Again, thank you for taking the time to share your journey with me. I wish you all the best!

Sincerely,

Christine Woods

Doctoral Candidate

University of Missouri-Columbia 


\section{Appendix G}

\section{IRB Approval Letter}

Institutional Review Board

University of Missouri-Columbia

FWA Number: 00002876

IRB Registration Numbers: 00000731, 00009014
482 McReynolds Hall

Columbia, MO 65211

573-882-3181

irb@missouri.edu

March 25, 2020

Principal Investigator: Christine Michelle Woods

Department: Social Work

Your IRB Application to project entitled Winning When the Odds are Against You: A Narrative Inquiry of African American Female Persistence at a Predominantly White Institution was reviewed and approved by the MU Institutional Review Board according to the terms and conditions described below:

$\begin{array}{ll}\text { IRB Project Number } & 2021503 \\ \text { IRB Review Number } & 262304 \\ \text { Initial Application Approval Date } & \text { March 25, 2020 } \\ \text { IRB Expiration Date } & \text { March 25, 2021 } \\ \text { Level of Review } & \text { Exempt } \\ \text { Project Status } & \text { Active - Exempt } \\ \text { Exempt Categories (Revised Common Rule) } & \text { 45 CFR 46.104d(2)(ii) } \\ \text { Risk Level } & \text { Minimal Risk }\end{array}$

The principal investigator (PI) is responsible for all aspects and conduct of this study. The PI must comply with the following conditions of the approval:

1. Enrollment and study related procedures must remain in compliance with the University of Missouri regulations related to interaction with human participants following guidance at https://research.missouri.edu/about/covid-19-info.php.

2. No subjects may be involved in any study procedure prior to the IRB approval date or after the expiration date.

3. All changes must be IRB approved prior to implementation utilizing the Exempt Amendment Form.

4. The Annual Exempt Form must be submitted to the IRB for review and approval at least 30 days prior to the project expiration date to keep the study active or to close it.

5. Maintain all research records for a period of seven years from the project completion date.

If you are offering subject payments and would like more information about research participant payments, please click here to view the MU Business Policy and Procedure: http:// bppm.missouri.edu/chapter2/2_250.html

If you have any questions or concerns, please contact the MU IRB Office at 573-882-3181 or email to muresearchirb@missouri.edu. 


\title{
Appendix $\mathrm{H}$
}

\section{IRB Exempt Compensation Approval Letter}

\author{
Institutional Review Board \\ University of Missouri-Columbia \\ FWA Number: 00002876 \\ IRB Registration Numbers: 00000731, 00009014
}

482 McReynolds Hall

Columbia, MO 65211

573-882-3181

irb@missouri.edu

April 14, 2020

Principal Investigator: Christine Michelle Woods

Department: Social Work

Your Exempt Amendment Form v.2 to project entitled Winning When the Odds are Against You: A Narrative Inquiry of African American Female Persistence at a Predominantly White Institution was reviewed and approved by the MU Institutional Review Board according to the terms and conditions described below:

$\begin{array}{ll}\text { IRB Project Number } & 2021503 \\ \text { IRB Review Number } & 263442 \\ \text { Funding Source } & \text { MU College of Human Environmental Sciences } \\ \text { Initial Application Approval Date } & \text { March 25, 2020 } \\ \text { Approval Date of this Review } & \text { April 14, 2020 } \\ \text { IRB Expiration Date } & \text { March 25, 2021 } \\ \text { Level of Review } & \text { Exempt } \\ \text { Project Status } & \text { Active - Exempt } \\ \text { Risk Level } & \text { Minimal Risk } \\ \text { Internal Funding } & \text { Departmental Funding }\end{array}$

The principal investigator (PI) is responsible for all aspects and conduct of this study. The PI must comply with the following conditions of the approval:

1. Enrollment and study related procedures must remain in compliance with the University of Missouri regulations related to interaction with human participants following guidance at https://research.missouri.edu/about/covid-19-info.php.

2. No subjects may be involved in any study procedure prior to the IRB approval date or after the expiration date.

3. All changes must be IRB approved prior to implementation utilizing the Exempt Amendment Form.

4. The Annual Exempt Form must be submitted to the IRB for review and approval at least 30 days prior to the project expiration date to keep the study active or to close it.

5. Maintain all research records for a period of seven years from the project completion date.

If you are offering subject payments and would like more information about research participant payments, please click here to view the MU Business Policy and Procedure: http:// bppm.missouri.edu/chapter2/2_250.html

If you have any questions or concerns, please contact the MU IRB Office at 573-882-3181 or email to muresearchirb@missouri.edu. 


\section{VITA}

Christine Woods was born in Kansas City, Missouri to John and Verdis Vincent. She graduated in 1993 from Southeast High School in Kansas City, Missouri. Christine is three-time graduate of the University of Missouri-Columbia. She received her Bachelor of Science in Human Development and Family Studies in 1997, a Master of Social Work in 2002, and Doctorate in Educational Leadership and Policy Analysis in 2021.

Christine's experience and influence has a reach that is far and diverse. For over 24 years, she has done meaningful work in the private sector, public sector, academic setting, and in non-profit organizations. As a leader by profession and in the community, she has contributed a significant amount of time to public service, advocacy, and continuing education. Christine provides guidance to families as a Facilitator of the Parent Café as well as encouragement to children through her own founded programs Kids Empowering Kids and Cupcakes and Conversation. Additionally, she provides consultations and trainings to local agencies on best social work practices.

As the owner and lead therapist of CROWNED Counseling, Christine offers therapy and mental health services for individuals, couples, and families where she guarantees relatable conversations with relevant context to create real change. Aside from being a respected professional in the community, Christine is the Co-Founder of Urban Empowerment Ministries and a proud member of Alpha Kappa Alpha Sorority, Incorporated. 